Published in final edited form as:

J Pediatr Gastroenterol Nutr. 2018 March ; 66(3): 516-554. doi:10.1097/MPG.0000000000001889.

\title{
Pediatric Gastroesophageal Reflux Clinical Practice Guidelines: Joint Recommendations of the North American Society for Pediatric Gastroenterology, Hepatology, and Nutrition (NASPGHAN) and the European Society for Pediatric Gastroenterology, Hepatology, and Nutrition (ESPGHAN)
}

\author{
Rachel Rosen, MD, MPH ${ }^{1, \#}$, Yvan Vandenplas, MD ${ }^{1,{ }^{*}}$, Maartje Singendonk, MD $^{\dagger}$, Michael \\ Cabana, MD§, Carlo Di Lorenzo, MD ${ }^{\ddagger}$, Frederic Gottrand, MD", Sandeep Gupta, MDף, \\ Miranda Langendam, $\mathrm{PhD}^{\dagger}$, Annamaria Staiano, $\mathrm{MD}^{\star *}$, Nikhil Thapar, $\mathrm{MD}^{\dagger \dagger}$, Neelesh Tipnis, \\ MD $\ddagger$, and Merit Tabbers, MD ${ }^{\dagger}$
}

\#Center for Motility and Functional Gastrointestinal Disorders, Division of Gastroenterology, Children's Hospital Boston, Boston, MA, USA *UZ Brussel Kinderen, Brussels, Belgium †'Emma Children's Hospital/AMC, Amsterdam, The Netherlands §Division of General Pediatrics, University of California, San Francisco, CA, USA ‡Division of Pediatric Gastroenterology, Nationwide Children's Hospital, The Ohio State University, Columbus, OH, USA "CHU Lille, Division of Pediatric Gastroenterology, Hepatology and Nutrition, Lille, France IDivision of Pediatric Gastroenterology, Hepatology and Nutrition, University of Illinois, Peoria, IL USA ** Department of Translational Medical Science, Section of Pediatrics, "Federico II" University of Naples, Italy ${ }^{\dagger+}$ Great Ormond Street Hospital for Children, London, UK $¥ \ddagger$ Department of Pediatrics, University of Mississippi Medical Center, Jackson, Mississippi, USA

Correspondence to: Address correspondence and reprint requests to Merit M. Tabbers, MD, PhD, Emma Children's Hospital/ Academic Medical Centre, H7-250, PO Box 22700, 1100 DD Amsterdam, The Netherlands (m.m.tabbers@amc.nl).

${ }^{1}$ Shared first authorship

Potential conflict of interest statement:

C.D.L. is a consultant for Allergan, QOL, IBHealth, Nestlé and Merck. Y.V. has participated as a clinical investigator, and/or advisory board member, and/or consultant, and/or speaker for Abbott Nutrition, Aspen, Biogaia, Biocodex, Danone, Hero, Hypocrata, Mead Johnson Nutrition, Merck, Nestle Nutrition Institute, Nutricia, Olygose, Orafti, Phacobel, Rontis, Sari Husada, United Pharmaceuticals, Wyeth and Yakult. M.C. is a consultant for Abbott Nutrition, Biogaia, Nestec, Mead Johnson Nutrition, Merck Wyeth and Yakult. S.G. is a consultant for Recepots and QOL. F.G. is a consultant for Nestlé, Nutricia and Halyard. A.S. has participated as a clinical investigator, and/or advisory board member, and/or consultant, and/or speaker for Aboca, Angelini, Danone, D.M.G. Italy, Menarini, Miltè, Nestlé, Sucampo, Valeas. N.Th. is a consultant for Danone, Nutricia, Shire Movetis and Sucampo.

N.Ti. is a consultant for Rock West Medical and Sucampo. The other authors report no conflicts of interest.

Rachel Rosen MD, MPH: RR is an expert in gastroesophageal reflux disease and aerodigestive disorders.

Yvan Vandenplas MD, PhD: YV is an expert in gastroesophageal reflux disease.

Maartje Singendonk MD: MS is an expert in esophageal physiology.

Michael Cabana MD: MC is a pediatrician with expertise in consensus guideline

Carlo Di Lorenzo MD: CD is an expert in pediatric motility disorders and gastroesophageal reflux disease

Frederic Gottrand MD: FG is an expert in esophagitis and gastroesophageal reflux disease

Sandeep Gupta MD: SG is an expert in esophageal diseases.

Miranda Langendam PhD: ML is aguideline methodologist

Annamaria Staiano MD: AS is an expert in pediatric motility disorders and gastroesophageal reflux disease.

Nikhil Thapar MD: NT is an expert in pediatric motility disorders.

Neelesh Tipnis MD: NT is an expert in pediatric motility disorders.

Merit Tabbers MD, PhD: MT is an expert in gastroesophageal reflux disease. 


\section{Abstract}

This document serves as an update of the North American Society for Pediatric Gastroenterology, Hepatology, and Nutrition (NASPGHAN) and the European Society for Pediatric Gastroenterology, Hepatology, and Nutrition (ESPGHAN) 2009 clinical guidelines for the diagnosis and management of gastroesophageal reflux disease (GERD) in infants and children and is intended to be applied in daily practice and as a basis for clinical trials. Eight clinical questions addressing diagnostic, therapeutic and prognostic topics were formulated. A systematic literature search was performed from October 1, 2008 (if the question was addressed by 2009 guidelines) or from inception to June 1, 2015 using Embase, MEDLINE, the Cochrane Database of Systematic Reviews and the Cochrane Central Register of Controlled Clinical Trials. The approach of the Grading of Recommendations Assessment, Development and Evaluation (GRADE) was applied to define and prioritize outcomes. For therapeutic questions, the quality of evidence was also assessed using GRADE. Grading the quality of evidence for other questions was performed according to the Quality Assessment of Studies of Diagnostic Accuracy (QUADAS) and Quality in Prognostic Studies (QUIPS) tools. During a three-day consensus meeting, all recommendations were discussed and finalized. In cases where no randomized controlled trials (RCT; therapeutic questions) or diagnostic accuracy studies were available to support the recommendations, expert opinion was used. The group members voted on each recommendation, using the nominal voting technique.

With this approach, recommendations regarding evaluation and management of infants and children with GERD to standardize and improve quality of care were formulated. Additionally, two algorithms were developed, one for infants $<12$ months of age and the other for older infants and children.

\section{Introduction}

In 2009, the joint committee of the North American Society for Pediatric Gastroenterology, Hepatology, and Nutrition (NASPGHAN) and the European Society for Pediatric Gastroenterology, Hepatology, and Nutrition (ESPGHAN) published a medical position paper on gastro-esophageal reflux (GER) and GER disease (GERD) in infants and children (search until 2008), using the 2001 NASPGHAN guidelines as an outline.(1)

Recommendations were based on an integration of comprehensive and systematic review of the medical literature combined with expert opinion.

Since 2009, additional publications on the existing benefits and harms of interventions in the outcomes considered important and resources available for health care justify the development of new a guideline.(2) This current guideline aimed to identify studies that address the diagnostic and therapeutic approach to infants and children with GERD, where GERD is defined as bothersome symptoms related to GER. This definition is not based on the amount of measured reflux or on symptoms not clearly attributable to reflux, and therefore the literature review and discussion is focused on studies fulfilling this definition. The aim of these guidelines is to offer guidance to both pediatric gastroenterologists and primary care physicians with and without easy access to pediatric gastroenterologists. Referral to a pediatric gastroenterologist for the diagnosis and management of complicated 
pediatric clinical situations is ideal; however, in situations where a pediatric subspecialist in not easily available, this guideline considers potential alternative options. The present document provides recommendations for the diagnosis and management of GER and GERD in infants and children. The intent is to serve as a general guideline and should not be considered a substitute for clinical judgement or as a protocol applicable to all patients.

This set of guidelines differs from the 2009 guidelines in several ways: (1) it focuses on reducing acid suppression whenever possible with short empiric trials of 4-8 weeks recommended for GERD symptoms; (2) it shifts away from attributing respiratory and laryngeal symptoms to GER; (3) it adds an algorithm for typical symptoms to incorporate reflux testing to further characterize patients to differentiate patients with reflux based diagnoses versus functional diagnoses; and (4) it adds a recommendation for change of formula to a protein hydrolysate or amino acid based formula before acid suppression in infants.

\section{Methods}

This project started in March 2015 with a literature search for international guidelines concerning pediatric GERD. This search identified two guidelines; i.e. the 2009 guidelines of the NASPGHAN/ESPGHAN and the more recent 2015 National Institute for Health and Care Excellence (NICE) guideline. $(1,3)$ Two reviewers (M.T. and M.S.) independently appraised guideline quality using the 23-item AGREE-II instrument, which rates reporting of the guidance development across six domains: scope and purpose, stakeholder involvement, rigour of development, clarity of presentation, applicability and editorial independence (available online through: http://www.agreetrust.org/wp-content/uploads/ 2013/10/AGREE-II-Users-Manual-and-23-item-Instrument_2009_UPDATE_2013.pdf. (4)Total scores were calculated as standardized averages by domain. In conclusion, the NASPGHAN/ESPGHAN 2009 guidelines were considered of poor overall quality, lacking of appropriate guideline development methodology (i.e. due to no clear description of aims and purpose of guideline, target population(s) and outcome measures; lack of reproducibility and complexity of data representation). The 2015 NICE guidelines were considered to overall be of high quality.

The working group agreed that many statements and recommendations of the 2009 guidelines are largely still applicable, despite its limitations in methodology. It was therefore decided to use relevant and applicable information from the 2009 guidelines in the development of this present document. The updating process was then performed by using the approach of the Grading of Recommendations, Assessment, Development, and Evaluation (GRADE) from October 1, 2008 onwards (the end of the 2009 guideline's literature search).(5)

Using this approach, the project started by formulating eight clinical questions. Questions were chosen first to update the topics already addressed by the 2009 ESPGHAN/ NASPGHAN GERD guidelines. Second, additional (sub) questions were determined by consensus agreement on current gaps in knowledge on diagnosis and management of pediatric GERD. After the questions were formulated, the guidelines committee was 
subdivided into groups that dealt with each question separately. Questions 1, 2 and 8 were answered based on expert opinions and earlier published guidelines and literature relevant to the research question.(1,3) Questions 3, 4, 5, 6 and 7 were answered using the results of systematic literature searches. Two algorithms, one for infants and one for children, for the diagnostic and therapeutic work-up for GERD were developed (Algorithm 1 and 2 respectively).

\section{Overview of the Clinical Research Questions}

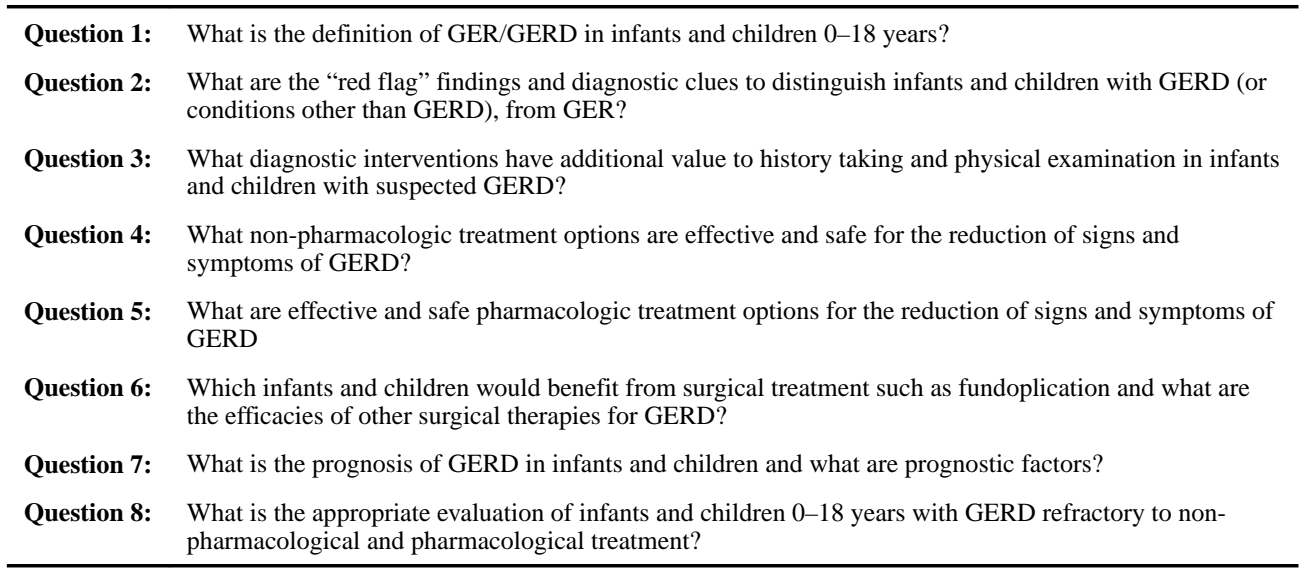

$\mathrm{PPI}=$ proton pump inhibitor; $\mathrm{pH}-\mathrm{MII}=\mathrm{pH}$ multichannel intraluminal impedance; $\mathrm{H} 2=$ histamine receptor $\mathrm{H} 2$

\section{Literature search}

Systematic literature searches were performed by a clinical librarian. The Embase, MEDLINE, PubMed and the Cochrane Database of Systematic Reviews and the Cochrane Central Register of Controlled Clinical Trials databases were searched from October $1^{\text {st }}$ 2008 or from inception for those aspects not addressed in the 2009 guideline, to June $1^{\text {st }}$ 2015. Searches were also conducted from inception in case of large inconsistency in findings in comparison to findings of the 2009 guidelines.

Inclusion criteria were as follows (all inclusion criteria relevant to the research question to be met):

1. Study population consisting of children aged 0-18 years with GER(D). The key words to describe GERD were "Gastroesophageal Reflux" and its abbreviations, "gastric acid reflux" and "esophagitis", taking into account differences in British and American spelling. Additionally, a clear definition of GER(D) had to be provided by the authors.

2. To evaluate the value of tests in diagnosing GERD (question 2), the following inclusion criteria were used: systematic reviews and original studies related to the diagnostic accuracy of the specific tests. The reference standard for GERD had to be defined by the authors in terms of findings at history and physical exam. 
3. In studies evaluating the effect of treatments or interventions for GERD (questions 4, 5,6) the following inclusion criteria were used: systematic reviews of randomized controlled trials (RCT) and/or RCTs containing at least 10 individuals per arm.

4. In studies evaluating the outcome of GERD (question 7), the following inclusion criteria were used: systematic reviews of prospective or retrospective controlled studies, one of the aims of the study was to evaluate the prognosis and clinical course of GERD expressed as duration or recurrence of GERD and determinants that influence prognosis, baseline measurement of at least one of the outcomes of the research population should be provided and a follow-up of at least eight weeks was required.

Additional strategies to identify studies involved searching the reference lists of review articles. No language restriction was applied. In addition, all guideline members were asked to search the literature with respect to their assigned topics in order to possibly uncover further studies that may have been missed by the former search.

\section{Special considerations and limitations}

Because GERD was defined as the presence of bothersome symptoms related to the passage of gastric contents from the stomach into the esophagus and the included studies needed to use symptom resolution as an outcome as part of one of the predefined outcome measures, no extraesophageal studies met the inclusion criteria using the GRADE methodology. However, because extraesophageal symptoms are a primary reason for referral to pediatric gastroenterologists, whenever possible a narrative review of the literature was included on this topic to provide clinical guidance for the diagnosis and management of these patients.

\section{Selection of outcome measures}

The GRADE approach was used to identify outcome measures for the research questions.(5) A draft version was circulated by M.T. and M.S., and every workgroup member was allowed to add outcomes. Group members were asked to rate relative importance of the outcomes on a 9-point scale: limited (1-3), important but not critical (4-6), or critical (7-9) for decision making. The workgroup members were also asked to discuss personal experience and to discuss outcome measures of interest with their patients in daily practice. Finally eight outcome measures were selected: esophagitis (endoscopic/histologic), complications of GERD (Barrett's metaplasia, esophageal stenosis, and others as specified by authors), GERD related signs and symptoms (assessed by the I-GERQ-R instrument (6)), quality of life (both parent and patient reported when applicable), crying and distress (parent reported), visible vomiting and/or regurgitation (both parent and patient reported when applicable), heartburn (both parent and patient reported when applicable) and side-effects of treatment. All outcome measures were considered of critical importance based on the mean scores of the guidelines group members.

\section{Levels and quality of evidence, grade of recommendations}

Levels of evidence and quality of evidence were assessed using the Quality Assessment of Studies of Diagnostic Accuracy (QUADAS; diagnostic questions) and the GRADE system 
(Cochrane Risk of Bias Tool; therapeutic questions) and are summarized in the appendices.

(7) The items in the QUADAS tool include patient spectrum, reference standard, disease progression bias, verification bias, review bias, clinical review bias, incorporation bias, test execution, study withdrawals, and indeterminate results. The QUADAS tool is presented together with recommendations for scoring each of the items included. To assess risk of bias of studies evaluating the outcome of GERD the Quality in Prognostic Studies (QUIPS) tool was used by two reviewers (MT and ML).(7-9) The QUIPS tool assesses risk of bias in six domains: study participation, study attrition, prognostic factor measurement, outcome measurement, study confounding and statistical analysis and presentation. Ratings of the quality of evidence for each statement are based on the grading of the literature. For the diagnostic and prognostic questions, for which the GRADE approach is still in development, conclusions were formulated taking into account overall risk of bias. The results of the risk of bias and quality of the evidence assessment are summarized in Appendices C and D.

\section{Therapeutic questions (Question 4 and 5)}

Using the GRADE system, the quality of evidence for therapeutic interventions was graded as follows:

- High: Further research is unlikely to change our confidence in the estimate of effect.

- Moderate: Further research is likely to have an important impact on our confidence in the estimate of effect and may change the estimate.

- Low: Further research is very likely to have an important impact on our confidence in the estimate of effect and may change the estimate.

- Very low: Any estimate of effect is uncertain.

Strength of recommendations was defined as follows:

Strong: when the desirable effects of an intervention clearly outweigh the undesirable effects, or they clearly do not. Strong recommendations are formulated as 'the working group recommends (...)'.

Weak: when the tradeoffs are less certain (either because of the low quality of evidence or because the evidence suggests that desirable and undesirable effects are closely balanced). Weak recommendations are formulated as 'the working group suggests (...)'

A summary of the definitions and recommendations is provided at the end of this document.

\section{Non-therapeutic questions (Question 3)}

Because of a lack of a validated method for determining the strength of the recommendation for questions other than therapy, we elected to classify recommendations based on the quality of available evidence including the methodology and outcomes assessed. We categorized the evidence as:

Strong: if there were adequately powered, prospective studies supporting the conclusions. 
Moderate: if there were large retrospective studies or small prospective studies supporting the evidence.

Weak: if there were only retrospective studies or expert opinion supporting the results.

\section{Consensus meeting and voting}

A three-day consensus meeting was held in April 2016 (Keflavik, Iceland) in order to achieve consensus on and formulate all recommendations. Each subgroup presented the recommendations during these consensus meetings, wherein these were discussed and modified according to the comments of the attendees. Committee members with conflict of interest with a specific topic excused themselves from the discussion of that topic.

Consensus was formally achieved through nominal group technique, a structured quantitative method. The group anonymously voted on each recommendation. A nine-point scale was used $(1=$ strongly disagree to $9=$ fully agree $)$, and votes are reported for each recommendation. Consensus was reached if $>75 \%$ of the working group members voted $>$ 6 . The consensus was reached for all of the questions. The final draft of the guidelines was sent to all of the committee members for approval in November 2016.

\section{Question 1: What is the definition of pediatric gastroesophageal reflux disease?}

A definition of gastroesophageal reflux (GER) and gastroesophageal reflux disease (GERD) specific to the pediatric population was developed in 2009 as an international consensus document, based on evidence reviewed from pediatric studies.(10) This document was developed in recognition of the special clinical and scientific needs of the pediatric population, not fully addressed by the Montreal consensus document on the adult definition and classification of GERD).(11) Both documents define GER as the passage of gastri contents into the esophagus with or without regurgitation and/or vomiting. GER is considered to be pathologic and referred to as GERD when the reflux leads to troublesome symptoms and/or complications, such as esophagitis or stricturing.

This definition of GERD was adopted in the 2009 published guidelines of NASPGHAN and ESPGHAN and in the 2015 published NICE guideline.(1, 3) However, as a direct consequence of its patient-centered and symptom based nature, this definition is subject to several caveats, which are even more relevant in the pediatric population. In clinical practice, it may be difficult to differentiate GER from GERD in children, and the terms are used interchangeably by health professionals and parents alike. Symptoms of GERD are known to vary widely by age and are non-specific. As a consequence proving that reflux events cause one or multiple symptoms is often difficult. $(1,12)$ This is particularly true in nonverbal infants in whom defining troublesome is problematic. Reported symptoms of infant GERD vary widely and may include excessive crying, back arching, regurgitation and irritability. Many of these symptoms, however, occur in all babies with or without GERD, making a definitive diagnosis challenging. Therefore, the degree of concern of parents is often the factor driving the need for a diagnosis. For older children (particularly those older than the 
age of 8) and adolescents who can communicate more effectively, typical symptoms such as heartburn and regurgitation mimic those seen in adults with GERD.(11, 13-16)

Definitions of GER and GERD are therefore blurred for the pediatric population, making it difficult to identify infants and children who genuinely suffer from GERD and to estimate the true prevalence and burden of the problem. Moreover, to date no gold standard diagnostic tool exists for the diagnosis of GERD in infants and children. Despite these limitations, and given the need for definitions, the working group decided to adapt the definition of pediatric GERD as formulated in the 2009 consensus statements for all age groups. To date, no other definitions for pediatric GERD have been proposed, and validation studies on this definition have not been performed. In the present guideline, every effort was made to use the terms GER and GERD strictly as defined.

GERD is also known to be a prominent phenomenon in children who have other underlying medical conditions such as prematurity, neurologic impairment and pulmonary problems, including cystic fibrosis. The present guideline was not intended to specifically focus on patients with congenital anomalies, including esophageal atresia (EA) among others, since these are addressed in specific guidelines concerning these entities. $(3,17-19)$

\section{Definitions}

\begin{tabular}{ll}
\hline GER: & the passage of gastric contents into the esophagus with or without regurgitation and vomiting. \\
GERD: & When GER leads to troublesome symptoms that affect daily functioning and/or complications. \\
Refractory GERD: & GERD, not responding to optimal treatment after eight weeks. \\
Optimal Therapy: & $\begin{array}{l}\text { Maximum pharmacologic and/or non-pharmacologic therapy based on the available health-care } \\
\text { facilities in the region of practice of the subspecialist }\end{array}$ \\
\hline
\end{tabular}

(See under "Summary of the Definitions" for an overview of other definitions used in this guideline).

\section{Recommendation}

Based on expert opinion, the working group recommends to use the definitions of GER/ GERD as described in this section for all infants and children.

VOTING: 7, 7, 7, 7, 8, 8, 8, 8, 8, 9. (Moderate strength)

\section{Question 2: What are the "red flag" findings and diagnostic clues to distinguish infants and children with GERD (or conditions other than GERD), from GER?}

Clinical history of disease and physical examination in the evaluation of GERD is important to distinguish GER from GERD, to identify possible complications of GERD and also to exclude more worrisome disorders requiring further investigation and management. Infants and children present with a wide range of non-specific symptoms that may be interpreted as GERD symptoms, but the reliability of these clinical manifestations as a consequence of 
GER is not always clear. As this may lead to both over- and under-diagnoses and -treatment, the working group considered it important to provide an overview of common symptoms and signs to identify GERD. Clarifying 'red flags' (alarm features) red flags should warrant further investigation by health-care professionals to rule out complications of GERD and to uncover underlying disorders presenting with signs or symptoms of GER, particularly regurgitation and/or vomiting (Algorithms 1 (infants) and 2 (children), Tables 1, 2 and 3).

For this purpose, the working group critically reviewed evidence from existing guidelines, systematic reviews and consensus documents to establish a comprehensive list of symptoms and signs indicative of GERD (Question 2, Table 1).(1, 3, 20, 21) Additionally, the working group highlighted a number of clinical manifestations and features, including gastrointestinal and systemic manifestations, which they considered to be recognized as 'red flags' suggesting possible other disorders apart from GERD in the infant or child presenting with regurgitation and/or vomiting (Question 2, Table 2).

It should be noted that a general concern is that the reported definitions of GERD and outcome measures used to assess treatment efficacy vary widely among studies with outcomes ranging from symptom resolution to reduction in the number of reflux events or healing of esophagitis. This heterogeneity makes comparisons among studies difficult.

\section{Diagnostic approach of infants (age 0-12 months) with frequent regurgitation and/or vomiting}

In the infant with recurrent regurgitation or 'spitting', a thorough history (Table 1) and physical examination with attention to warning signals suggesting other diagnoses (Table 1, 3 ) is generally sufficient to establish a clinical diagnosis of uncomplicated infant GER (Algorithm 1). The history should include the age of onset of symptoms, a thorough feeding and dietary history (e.g. length of feeding period, volume of each feed, type of formula, quality of milk supply when breast feeding, methods of mixing the formula, size of the feeds, additives to the feeds, restriction of allergens, time interval between feeding), the pattern of regurgitation/spitting/vomiting (e.g. nocturnal, immediately post prandial, long after meals, digested versus undigested), a family medical history, possible environmental triggers (including family psychosocial history and factors such as tobacco use and secondhand tobacco smoke-exposure), the patient's growth trajectory, prior pharmacologic and dietary interventions and the presence of warning signs (Table 2).(22, 23) Physiologic GER seldom starts before the age of one week or after the age of six months.(24)

While most reflux in infants is benign, some infants merit additional testing. While the presence of warning signs obviously merits additional testing, the more difficult subgroup of patients is the group of infants presenting with fussiness, crying and arching with or without spitting but who otherwise are thriving. In this population, there is often intense pressure by families to start anti-reflux therapies or pursue diagnostic testing because of the perceived severity of symptoms. In the absence of warning signs, diagnostic testing and/or therapies including acid suppression are NOT needed if there is no impact of the symptoms on feeding, growth or acquisition of developmental milestones. In the presence of 'red flags' (Table 2), conditions other than GERD may be more likely (differential diagnosis of GERD, 
Table 3). The diagnostic approach of infants with frequent regurgitation or vomiting is presented in Algorithm 2.

\section{Diagnostic approach of children (age 12 months - 18 years) with frequent regurgitation and/or vomiting}

Physiologic regurgitation and episodic vomiting are frequent in infants. Onset of GERD symptoms after the age of 6 months or persistence of symptoms beyond 12 months raises the possibility of alternative diagnoses to infant GER. Because these symptoms are not unique to GERD, referral to a pediatric gastroenterologist for evaluation to diagnose possible GERD and to rule out other diagnoses is recommended based on expert opinion. The goal of additional testing is to rule out mimickers or complications of GERD. Testing may include laboratory tests, contrast imaging, upper GI endoscopy and/or esophageal $\mathrm{pH} / \mathrm{MII}$, depending on presenting symptoms (Table 2 and 3). The diagnostic approach of children with frequent regurgitation or vomiting is presented in Algorithm 2.

\section{Diagnostic and therapeutic approach to infants and children with possible extraesophageal reflux disease}

Because the outcome evaluated for these guidelines is based on the evaluation and treatment of bothersome GERD symptoms, extraesophageal symptoms were not included due to the heterogeneous nature of the symptoms and the lack of a clear way to prove that symptoms are actually related to movement of gastric contents from the stomach into the esophagus. However, because these symptoms are a frequent cause for referral and parental concern, the literature is reviewed and presented narratively, whenever possible.

\section{Recommendation}

Based on expert opinion, the working group recommends to use Tables 1-3 for symptoms and signs that may be associated with gastroesophageal reflux disease (GERD), for alarm symptoms and diagnostic clues to identify an alternative underlying disease which are responsible for the symptoms.

Voting: 7, 7, 8, 8, 8, 8, 8, 8, 9, 9. (Weak Recommendation)

\section{Question 3: What diagnostic interventions have additional value to history taking and physical examination in infants and children with suspected GERD?}

The diagnosis of GERD is based primarily on clinical suspicion, which can be strengthened by additional diagnostic investigations that are aimed to quantify and qualify GERD). Other diagnostic interventions may be utilized to rule out conditions other than GERD in the presence of specific diagnostic clues. In the absence of a single 'gold standard' investigation to diagnose GERD in infants or children, the diagnostic tests discussed in this section should be seen in this light. 
Our search resulted in two original studies and one systematic review that were eligible for inclusion.(25-27) After checking reference lists of this systematic review and the ESPGHAN/NASPGHAN 2009 and NICE 2015 guidelines (See Appendix A for summary of search strategy, results and study selection), seven other original studies could be included, resulting in a total of nine original studies with eight studies reporting on pH-metry (27-34), three on endoscopy $(28,30,33)$, two on GI-scintigraphy $(27,28)$ and one each on biomarkers (26) and upper GI series(28). Characteristics of included studies can be found in Appendix B1. The QUADAS checklist can be found in Appendix C1.(7)

\section{Barium contrast study}

The search identified one study comparing rates of gastroesophageal reflux events seen during barium imaging in symptomatic and asymptomatic infants and children ages 3 month old to 17 years old.(28) In this study, there were no definitions of how a positive test was defined so calculation of specificity or sensitivity was not possible.

\section{Other considerations for the use of barium imaging}

Other studies, while not meeting inclusion criteria, have shown that reflux events can be detected in as many as $50 \%$ of children undergoing radiologic imaging, regardless of symptoms. As such, routine use of upper GI barium contrast study in the evaluation of infants and children with GERD, especially uncomplicated GERD, is not supported by literature or clinical practice.

While the use of upper GI barium contrast to establish or negate a diagnosis of GERD in infants and children is not supported by literature nor clinical practice, the test does carry some utility in the evaluation of infants and children with alarm signs or in patients with symptoms that are particularly intense or not responsive to traditional therapies in order to evaluate for anatomic abnormalities. The test can be used to evaluate for other conditions that might mimic or predispose to GERD such as hiatal hernia, malrotation, pyloric stenosis, duodenal web, duodenal stenosis, antral web, esophageal narrowing, Schatzki's ring, achalasia, esophageal stricture, and esophageal extrinsic compression. One of the most important roles for barium imaging is in the evaluation of children who have had anti-reflux surgery who are symptomatic with persistent typical or atypical reflux symptoms, dysphagia or pain; barium imaging can be helpful to differentiate an obstructing fundoplication with esophageal stasis from a slipped or loose fundoplication. $(35,36)$

\section{Barium imaging in the evaluation of extraesophageal symptoms-For patients} with extraesophageal symptoms, barium imaging can serve several important roles, including evaluation for tracheoesophageal fistulae or of esophageal stasis putting patients at risk for aspiration. Videofluroscopic swallow studies (VFSS), while not assessing for gastroesophageal reflux, do assess for oropharyngeal dysphagia with resultant aspiration, the symptoms of which are mimickers of GERD. $(37,38)$ Pediatric studies have shown that neither the clinical history nor observed feeding sessions can accurately predict which patients have oropharyngeal dysphagia versus gastroesophageal reflux disease.(37, 39) 
In conclusion, there is insufficient evidence to support the use of a barium contrast study for the primary diagnosis of GERD in infants and children.

\section{Recommendations}

3.1 Based on expert opinion, the working group suggests not to use barium contrast studies for the diagnosis of GERD in infants and children.

VOTING: 8, 8, 9, 9, 9, 9, 9, 9, 9, 9. (Weak Recommendation)

3.2 Based on expert opinion, the working group suggests to use barium contrast studies to exclude anatomical abnormalities.

VOTING: 8, 8, 9, 9, 9, 9, 9, 9, 9, 9. (Weak Recommendation)

\section{Ultrasonography}

The search did not identify any studies fulfilling our inclusion criteria.

\section{Other considerations related to ultrasonography in the diagnosis of GERD-}

Compared with the results of 24-hour esophageal $\mathrm{pH}$ testing as a diagnostic test for GERD, the sensitivity of color Doppler ultrasound performed for 15 minutes post-prandially is about $95 \%$ with a specificity of only $11 \%$, and reflux frequency detected by ultrasound does not correlate with reflux index (RI) detected by $\mathrm{pH}$ monitoring. $(40,41)$ At present, ultrasound has no role as a routine diagnostic tool for GERD in children, but this test may be of use to evaluate for other conditions that might mimic GERD including, most importantly in the infant population, pyloric stenosis. Abdominal ultrasound may also pick up other diagnoses which may trigger symptoms of discomfort and vomiting including diagnoses such as hydronephrosis, uretero-pelvic obstruction, gallstones and ovarian torsion. Similar to barium study, ultrasound can detect hiatal hernia, length and position of the LES relative to the diaphragm and magnitude of the gastro-esophageal angle of His. It has also been proposed as a diagnostic test for gastric dysmotility, which may have implications from a reflux perspective.

In conclusion, there is no evidence to support ultrasonography for the diagnosis of GERD in infants and children.

\section{Recommendations}

3.3 Based on expert opinion, the working group suggests not to use ultrasonography for the diagnosis of GERD in infants and children.

VOTING: 8, 8, 8, 9, 9, 9, 9, 9, 9, 9. (Weak Recommendation)

3.4 Based on expert opinion, the working group suggests to use ultrasonography to exclude anatomical abnormalities.

VOTING: 8, 8, 8, 9, 9, 9, 9, 9, 9, 9. (Weak Recommendation) 
Esophago-gastro-duodenoscopy (EGD) with/without biopsy-The search identified three studies meeting our inclusion criteria. $(28,33,42)$ EGD has three roles in the evaluation of symptomatic children: to diagnose erosive esophagitis, to diagnose microscopic esophagitis, and to diagnose other conditions mimicking GERD. Erosive esophagitis is defined as visible breaks in esophageal mucosa. Microscopic esophagitis is defined as the presence of eosinophils, papillary lengthening, and/or basal cell hyperplasia. All three studies included in this analysis reported on the visual presence of erosions, and two studies also reported on histologic esophagitis. In patients with GERD defined as the presence of troublesome symptoms, the likelihood of having erosive esophagitis endoscopically ranges from $15-71 \%$ among studies. Similarly, in patients with troublesome symptoms, the likelihood of finding (i.e. sensitivity) microscopic esophagitis was 83-88\%. In these studies, the negative predictive value (NPV) of a macroscopically and histologically normal endoscopy was relatively low ranging from $62-73 \%$, which suggests that a normal endoscopy does not necessarily rule out the possibility of GERD. $(33,42)$ In the studies by Ravelli et al. and Cucchiara et al., no data on the endoscopic appearance of the mucosa were provided for the control group. $(33,42)$ Arasu et al., reporting on the endoscopic mucosal appearance in control patients, found that the NPV was only 33\% in diagnosing GERD.(28) These findings indicate that biopsy without hallmarks of esophagitis or the absence of macroscopic lesions does not rule out the presence of GERD. In all three studies, if mentioned, histology and macroscopic appearance were normal in the control group, which automatically leads to a reported specificity and NPV of 100\%. Visible, endoscopic erosions seen during EGD in the appropriate clinical context confirm a diagnosis of GERD. However, GERD may be present despite normal endoscopic appearance of the esophageal mucosa as well as in the absence of histological abnormalities.

\section{In conclusion, there is insufficient evidence to support the use of EGD with/without biopsy for the diagnosis of GERD in infants and children.}

\section{Other considerations related to EGD in the diagnosis of GERD-EGD is useful}

to evaluate the mucosa in the presence of alarm symptoms (such as hematemesis), to detect complications of GERD (such as strictures, Barrett esophagus), to diagnose conditions that predispose to GERD (such as hiatal hernia) or to diagnose conditions that might mimic GERD (such as eosinophilic esophagitis, infectious esophagitis). Visible breaks in the esophageal mucosa are the endoscopic sign of greatest inter-observer reliability based on adult studies.(11) However, no studies in adults or in children support that microscopic esophagitis without evidence of erosive esophagitis is adequate to diagnose GERD defined as the presence of troublesome symptoms though microscopic esophagitis may, in some contexts, signify the presence of pathologic acid reflux defined by pH-metry.(43) The primary role for esophageal histology is to rule out other conditions in the differential diagnosis, such as eosinophilic esophagitis, Crohn's disease, Barrett esophagus, infection and others.

When biopsies from endoscopically suspected esophageal metaplasia show columnar epithelium, the term Barrett esophagus should be applied and the presence or absence of intestinal metaplasia specified. 
EGD under general anesthesia can be regarded as a safe procedure in pediatric patients. A study involving 13 pediatric facilities that used the PEDS-CORI (Pediatric Endoscopy Database System Clinical Outcomes Research Initiative) found an overall immediate complication rate of pediatric EGD of $2.3 \%$ over 10,236 procedures performed in 9,234 patients (complication rates of $1.7 \%$ for general anesthesia vs $3.7 \%$ for IV sedation).(44) Based upon a survey in almost 400 children undergoing EGD under general anesthesia, most common complications or adverse events were only minor, including sore throat or hoarseness in approximately one third of patients.(45) Nevertheless, EGD cannot be considered a non-invasive procedure, as it involves pre-procedure assessments, dietary restrictions, patient preparation, and specialized teams of pediatric gastroenterologists, pediatric intensive care physicians and pediatric endoscopy nurses.(46)

\section{The role of endoscopy in the evaluation of extraesophageal symptoms}

The rate of erosive esophagitis in children presenting with solely extraesophageal symptoms is not known and is complicated by the widespread use of PPIs. Up to $32 \%$ of children presenting solely with extraesophageal symptoms have microscopic esophagitis, and up to $8 \%$ of children with these symptoms have eosinophilic esophagitis, only presenting with cough or other respiratory symptoms.(47-49) Therefore, the main reason for endoscopy in this population with extraesophageal symptoms is to uncover reflux masqueraders such as eosinophilic esophagitis. Endoscopy can also be used (1) to relieve esophageal outlet obstruction (from fundoplication, and untreated or partially treated achalasia) causing stasis with resultant cough and aspiration, or (2) to diagnose candida esophagitis in children treated with inhaled steroids.

Performance of endoscopy on or off therapy-One of the most controversial issues currently around the performance of endoscopy is whether it should be performed while the patient is on or off acid suppression. The field has evolved over time with a greater understanding of eosinophilic esophagitis and, more recently, proton-pump-inhibitorresponsive EoE. While originally the diagnosis of EoE was made upon the presence of esophageal eosinophils in patients with either a normal pH-metry study or unresponsiveness to an 8 week course of PPI-therapy, recently a subgroup of EoE has emerged that is responsive to PPIs. Therefore, if patients are treated initially with a course of PPIs, esophageal biopsies may not show inflammation and the patient will thereby be misdiagnosed as having non-erosive reflux disease (NERD), hypersensitive esophagus, or may undergo additional unnecessary testing because the initial diagnosis was missed. In light of these concerns, recent guidelines for adults have suggested that patients undergo endoscopy off of acid suppression therapy. $(50,51)$ The benefit to this approach is that patients will receive a definitive diagnosis at the time of the first endoscopy but the negative side is that patients will need to undergo a second endoscopy to assess for healing after instituting therapy. Prospective studies are clearly needed to determine an algorithm that maximizes diagnostic yield, reduces unnecessary medication and procedure costs, and results in more rapid improvement in outcomes. At this time, there is insufficient prospective data to recommend a single approach, and the pros and cons to both approaches should thus be discussed with patients and their families. 


\section{Recommendations}

3.5 The working group suggests not to use esophago-gastro-duodenoscopy to diagnose GERD in infants and children.

VOTING: 7, 8, 8, 8, 9, 9, 9, 9, 9, 9. (Weak Recommendation)

3.6 Based on expert opinion, the working group suggests to use esophago-gastroduodenoscopy with biopsies to assess complications of GERD, in case an underlying mucosal disease is suspected, or prior to escalation of therapy.

VOTING: 6, 8, 8, 9, 9, 9, 9, 9, 9, 9. (Strong Recommendation)

Extraesophageal Biomarkers-Using the GRADE criteria, the only study eligible for inclusion in this section was one on salivary pepsin in which the authors compared the rate of salivary pepsin positivity in preterm infants with clinical signs and symptoms of GERD. (26) Salivary pepsin was detected in 45/101 (44.5\%) infants. Mouth swabs were positive in 26/36 (72\%) infants with GERD and in only 19/65 (29\%) infants without GERD ( $\mathrm{p}$ 0.001 ). Overall, the sensitivity, specificity, positive predictive value and negative predictive value of pepsin to diagnose GERD were of $72 \%, 71 \%, 58 \%$ and $82 \%$, respectively. Because almost one third of control patients was pepsin positive, the utility of salivary pepsin is still debated, and the technology is limited by a lack of normative values for salivary pepsin in the pediatric population.

\section{Other considerations for the use of extraesophageal biomarkers}

- Pepsin: Other studies, not fulfilling the conclusion criteria of the present guideline, measured the diagnostic value of salivary pepsin by comparing it to results from $\mathrm{pH}-\mathrm{MII}$ testing and found this technique to be of limited sensitivity with results depending on concentration cut-off used.(52, 53) Apart from saliva, pepsin has also been measured in bronchoalveolar lavage (BAL) and middle ear fluid. Findings of these studies also most importantly suggest a lack of sensitivity (ranging from 57-84\%) of the biomarker.(54-60)

- Lipid-laden macrophage index: Studies comparing the lipid-laden macrophage index in BAL fluid to impedance and endoscopy fail to show any relationship. This suggests that the lipid laden macrophage index is not a biomarker of gastroesophageal reflux and should therefore not be used for diagnosis. $(52,54,61)$

- Bilirubin: Continuous monitoring of bilirubin using fiberoptic measurements in the esophagus is limited by the required dietary restriction during testing, thereby limiting its reliability and sensitivity. This test is therefore not recommended for use in clinical practice. $(62,63)$

In conclusion, evidence to support routine use of biomarkers such as salivary pepsin is insufficient to establish a diagnosis of extraesophageal reflux disease. 


\section{Recommendations}

3.7 The working group suggests that salivary pepsin should not be used for the diagnosis of GERD in infants and children.

\section{VOTING: 7, 7, 8, 8, 8, 8, 8, 9, 9, 9. (Strong Recommendation)}

3.8 Based on expert opinion, the working group suggests not to use currently available extraesophageal biomarkers for the diagnosis of GERD in infants and children.

VOTING: 7, 7, 8, 8, 8, 8, 8, 9, 9, 9. (Strong Recommendation)

3.5 Manometry/motility studies: The search did not identify any studies fulfilling our inclusion criteria.

\section{Other considerations related to esophageal manometry in the diagnosis of}

GERD-Manometry and other motility studies are designed to discriminate between normal GI physiology and neuromuscular diseases and can be used to identify the lower esophageal sphincter in order to accurately place $\mathrm{pH}$ - or $\mathrm{pH}$-impedance probes. The current gold standard for the evaluation of esophageal motility is high-resolution manometry, which utilizes a catheter with closely placed pressure sensors $(1-2 \mathrm{~cm}$ apart $)$ to allow a more detailed view of intraluminal pressure activity than conventional manometry. High resolution manometry was the key technique used to identify transient lower esophageal sphincter relaxations (TLESRs) as the predominant mechanism of GER in patients and it is also helpful in identifying other mechanisms of reflux such as hypotensive LES pressure or other risk factors for reflux such as the presence of a hiatal hernia. When combined with impedance, high resolution esophageal manometry (HRM) can also quantify the proportion of TLESRs associated with bolus movement into the esophagus, but is not predictive of GERD. Another possible application for HRM is in the pre- and post-operative evaluation of children undergoing fundoplication for the treatment of GERD. Although previous studies suggested that there was little role for manometry in predicting the outcome of fundoplication (64), newer modalities may confer some practical benefit. Loots et al, for example, used a novel pressure-flow analysis technique to identify esophageal motility parameters that are associated with post-operative complications such as dysphagia. They created a Dysphagia Risk Index that seemed better able to predict post-operative dysphagia in both adults supported by an uncontrolled pilot study of 10 children. $(65,66)$ Additionally, based upon pediatric studies, HRM with or without impedance may be of value to assess for "R waves" and retrograde bolus flow to diagnose rumination, a mimicker of intractable reflux symptoms.(67-71)

\section{HRM in the evaluation of extraesophageal symptoms}

HRM with impedance can rule out esophageal motility disorders whose presenting symptoms are often similar to GERD. HRM with impedance can not only detect abnormalities of peristalsis and esophageal outlet obstruction but also associated abnormalities in bolus transit. Esophageal stasis puts patients at high risk for aspiration, not from reflux but due to the retained fluid secondary to the dysmotility or obstruction, with 
signs and symptoms often being similar to GERD. Manometry can also be paired with $\mathrm{pH}-$ MII in 24-hour reflux studies to improve the cough-reflux correlation; manometrically coughs appear as high pressure, simultaneous pressure spikes on the pH-MII tracing. The accuracy of the device is increased by the fact that every cough-reflux pair can be detected. (72)

In conclusion, there is no evidence to support the use manometry for the diagnosis of GERD in infants and children.

\section{Recommendations}

3.9 Based on expert opinion, the working group suggests not to use manometry for the diagnosis of GERD in infants and children.

VOTING: 8, 8, 8, 8, 8, 8, 8, 9, 9, 9. (Strong Recommendation)

3.10 Based on expert opinion, the working group suggests to consider the use of manometry when a motility disorder is suspected.

VOTING: 6, 8, 8, 8, 8, 8, 9, 9, 9, 9. (Strong Recommendation)

\section{Scintigraphy}

The search identified two studies on scintigraphy. $(27,28)$ Of these, one was carried out in children aged up to 17 years (28) and the other in infants/children up to two years with wheezing symptoms.(27) In one study, there was no clear definition of GERD provided by authors making interpretation of the results difficult.(27, 28) In the study by Arasu et al., where positive scintigraphy (defined as 'any esophageal activity') was identified, sensitivity and specificity were only moderate (69 and $78 \%$ respectively).(28) The other study did not provide cut-off values for test positivity, and no calculations on sensitivity or specificity could be performed. $(27,28)$

Other considerations for the use of scintigraphy in the evaluation of GERDGastric scintigraphy is the standard technique for the assessment of gastric emptying, but protocols also exist for the evaluation of GER in children.(73-75) Although guidelines now exist for its use to diagnose reflux in children, clinical application has been limited by a lack of standardization of the technique.(76) Apart from showing refluxed tracer into the esophagus, gastric scintigraphy may reveal impaired gastric emptying which may be a risk factor for GERD or may reveal tracer in the bronchi suggesting pulmonary aspiration either from direct aspiration of the tracer or from aspiration of refluxed gastric contents.(77) Performance of gastric scintigraphy may be indicated when GERD symptoms are not responding to standard therapies and other diagnoses or triggers such as delays in gastric emptying are being considered.

In conclusion, there is insufficient evidence to support the use of scintigraphy for the diagnosis of GERD in infants and children. 


\section{Recommendation}

3.11 Based on expert opinion, the working group suggests scintigraphy should not be used for the diagnosis of GERD in infants and children.

VOTING: 8, 8, 8, 9, 9, 9, 9, 9, 9, 9. (Strong Recommendation)

\section{Trial of transpyloric or jejunal feeding}

The search did not identify any studies fulfilling our inclusion criteria.

\section{Other considerations for the use of transpyloric feeding to diagnose GERD-}

While transpyloric feeding is often used to treat intractable GERD (Question 6), the use of transpyloric feeding as a diagnostic test for GERD has not been studied. However, because transpyloric feeding reduces the reflux burden to a similar extent as fundoplication, additional studies using transpyloric feeding as a diagnostic test are needed. $(78,79)$

In conclusion, there is no evidence to support the use of transpyloric feeding trials for the diagnosis of GERD in infants and children.

\section{Recommendation}

3.12 Based on expert opinion, the working group suggests that transpyloric/jejunal feeding trials should not be used for the diagnosis of GERD in infants and children.

VOTING: 6, 7, 8, 8, 8, 9, 9, 9, 9, 9. (Moderate Recommendation)

\section{Proton pump inhibitor (PPI) trials}

The search did not identify any studies fulfilling our inclusion criteria.

Other considerations for the use of PPIs as a diagnostic test for GERD-Short 1-2-week trials of proton pump inhibitor trials (PPIs) have been used diagnostically in adults with typical reflux symptoms ("PPI test"). This test is based on the hypothesis that if symptoms respond to PPIs, they are therefore GERD-related and a diagnosis is made. While no pediatric studies have been designed to validate this test, we did evaluate therapeutic trials in infants and children during which early time points for symptom resolution were assessed. The discussion below relates to acid suppression for diagnosis, and not for treatment of GERD. Because no studies meet inclusion criteria, the recommendations are based on assessment of intermediate endpoints of treatment trials.

- Results from studies in infants: Five RCTs of PPIs in preterm and full term infants with treatment periods ranging from $2-4$ weeks have been published. None of the trials show symptom reduction over placebo regardless of the trial length. Based on these results, a short trial of a PPI is not recommended as a diagnostic test for infants.(80)

- Results from studies in children: Several studies, both open-label and therapeutic RCTs, assessing the effect of PPIs on GERD symptom reduction in children with and without 
esophagitis, showed that the greatest symptomatic improvement occurs in the first 2-4 weeks of PPI administration, suggesting that this duration may be sufficient as a diagnostic test for GERD in this population(81-84) Other treatment trials have used longer courses of PPIs for treatment without assessment of symptom resolution at earlier endpoints so the assessment of a shorter "PPI test" for symptom resolution could not be evaluated.(85) Because these studies were not powered to assess symptom resolution at interim time points and because of concern that some patients have persistent symptoms related to inflammation after only 2-4 weeks of therapy, a diagnostic trial window of 4-8 weeks was chosen by the working group. However, shorter courses may be applicable and preferred, particularly when the clinical suspicion for reflux is low or the concern for side effects is high.

- Results from studies in adults: There are data supporting the use of a PPI trial in the diagnosis of GERD in adult patients presenting with typical symptoms. Initial studies suggest that a 1-2 week trial is adequate for the diagnosis with a sensitivity ranging from $78 \%-83 \%$ compared with the reference test used (erosive esophagitis or $\mathrm{pH}$-detected pathologic reflux).(86-88) In another adult study, PPI responsiveness after a seven day trial in adults with non-erosive disease predicted an $85 \%$ probability of complete resolution of heartburn after four weeks; this study is of particular importance as it is the only one that applies symptom resolution as the "gold standard" for diagnosis of GERD, the definition used in these guidelines.(89) Despite the possible value of a PPI trial as a diagnostic test for GERD, in adults with typical symptoms, more than $50 \%$ of patients with typical symptoms may not respond to acid suppression and require additional testing. $(90,91)$

- PPI use as a diagnostic test for extraesophageal symptoms: No data conclusively support the use of PPIs in the diagnosis of extraesophageal symptoms in the pediatric literature. $(92,93)$ Because of the heterogeneous nature of extraesophageal symptoms, patient selection and the assessment of clinical improvement in these symptoms, which may have a multitude of causes, are difficult. In pediatrics, only one randomized, blinded placebo controlled study by Holbrook et al. addresses the use of PPIs in the treatment of asthma.(93) While this was powered as a 24 week treatment trial, interval analyses at earlier time points (1 or 2 months) after starting therapy show no symptomatic improvement suggesting that even short trials (i.e. diagnostic trials) are not beneficial. In the infant population, one 2 week RCT of lansoprazole was powered to assess improvement in GERD symptoms but as secondary outcomes, Orenstein et al assessed changes in the extraesophageal symptoms of coughing, wheezing and hoarseness. The authors found no benefit of lansoprazole compared with placebo for extraesophageal symptoms, but again this study was not powered for these outcomes. Based on these two RCTS, insufficient evidence exists to support a short trial of PPIs as a diagnostic test for extraesophageal reflux symptoms. Finally, a recent Cochrane review failed to show a benefit of PPIs for cough in children.(94)

In conclusion, there is no evidence to support empirical PPI therapy for the diagnosis of GERD in infants. Expert opinion suggests that in an older child or adolescent with typical symptoms suggesting GERD, a diagnostic trial of PPIs can be justified for 4-8 weeks. 


\section{Recommendations}

3.13 Based on expert opinion, the working group suggests that a trial of PPIs should not be used as a diagnostic test for GERD in infants.

\section{VOTING: 5, 6, 7, 7, 7, 8, 8, 9, 9, 9. (Weak Recommendation)}

3.14 Based on expert opinion, the working group suggests a 4-8 week trial of PPIs for typical symptoms (heartburn, retrosternal or epigastric pain) in children as a diagnostic test for GERD.

\section{VOTING: $3,7,7,7,8,8,8,9,9,9$. (Weak Recommendation)}

3.15 Based on expert opinion, the working group suggests that trial of PPIs should not be used as a diagnostic test for GERD in patients presenting with extraesophageal symptoms.

VOTING: 7, 8, 8, 8, 8, 8, 8, 9, 9, 9. (Weak Recommendation)

\section{$\mathrm{pH}-$ metry/wireless $\mathrm{pH}$ recording}

The search identified seven studies assessing the value of $\mathrm{pH}$-metry for the diagnosis of GERD in children.(27-34) In three studies, no p-values or cut-off values for test-positivity were provided, so neither sensitivity nor specificity data could be extracted for these studies. $(29,34,42)$ In the study by Ravelli et al., none of the controls underwent pH-metry, also hampering sensitivity and specificity analysis.(33) Two studies used values of controls as normal values and inherently show a pH-metry specificity of $100 \% .(31,32)$ The last and most recent study used the Reflux Index (RI, defined as the percentage of time that $\mathrm{pH}<4$ ) to determine pathological GERD (where abnormal was defined as $\mathrm{pH}<4$ for $>10 \%$ for infants $<1$ year and 5\% infants $>1$ year). (27) It should however be noted that for this population, although attempts have been made, no 'true' normative values have been established because of the ethics of performing invasive studies in healthy infants and children. $(75,95)$ The authors found the RI measured by pH-metry had a sensitivity and specificity $50 \%$ and $82 \%$, respectively, using history and physical examination as the gold standard method for diagnosing GERD.

\section{Other considerations for the use of pH-metry as a diagnostic test for GERD-}

Limitations to $\mathrm{pH}$-metry technology include:

1. Determination of the value $\mathrm{pH}$-metry as a diagnostic tool for GERD and to differentiate it from GER is difficult because of lack of a gold standard for comparison. Early pH-metry studies used esophageal manometry, endoscopy, scintigraphy, symptom presence and barium imaging as the gold standard methods to diagnose reflux events. $(28,29,31)$ All of these "gold standards" have significant limitations, with high rates of false positivity.

2. Obtaining data in healthy controls is not ethically feasible because of the invasive nature of pH-metry, hindering determination of true "normal" values. 
3. Non-acid reflux particularly in young infants and children is common, and $\mathrm{pH}-$ metry is blind to reflux episodes with $\mathrm{pH}>4$, which comprises $45-89 \%$ of pediatric reflux episodes.(96)

4. $\mathrm{pH}$-metry poorly identifies full column reflux $(97,98)$ and fails to correlate symptoms with esophageal acid events,(97) making it an inadequate tool for the diagnosis of extraesophageal symptoms.

5. While correlation of symptoms with reflux events is one of the main indications for $\mathrm{pH}$-metry, patients/parents often fail to report symptoms, a factor which compromises symptom correlation.(72) In addition, the appropriate time frame in which to consider a symptom correlated with reflux is debated.(99, 100)

Indications for pH-metry: Despite these limitations, the working group considers several indications for performance of $\mathrm{pH}$-metry in the evaluation of GERD when $\mathrm{pH}-\mathrm{MII}$ is not available (See also under $\mathrm{pH}-\mathrm{MII})$ :

1. Diagnosis of acid related disorders:

pH-metry can be helpful in correlating symptoms with acid reflux episodes. This is of particular importance in differentiating non-erosive reflux disease (NERD) from other acid disorders, such as functional heartburn and hypersensitive esophagus or in conditions that are clearly acid related such as dental erosions. $(101,102)$ In addition, pH-metry can be helpful in clarifying the role of acid in patients with esophageal eosinophilia.(103-105)

2. Correlate persistent symptoms with acid GER events (See also under pH-MII)

3. Efficacy of acid suppression

In patients with persistent symptoms or esophagitis in high risk patients (e.g. esophageal atresia, cystic fibrosis, or neurologically compromised patients) despite acid suppression, performance of pH-metry may be helpful in determining the degree of breakthrough acid in patients on therapy as these patients may be inadequately acid suppressed on standard medication doses.(106, 107) (Limitations - see also under pH-MII) In conclusion, there is insufficient evidence to support the routine use of pH-metry for
the diagnosis of GERD in infants and children.

Other $\mathrm{pH}$-based diagnostic testing options-Wireless $\mathrm{pH}$ recording has been proposed as an alternative to $\mathrm{pH}$ probe monitoring. During endoscopy, the wireless recording device is clipped to the esophagus. The advantage of the device is that the patient does not have a catheter in the nose, so for some children (for example, those with developmental delay or autism or in patients with cystic fibrosis and chronic cough) the wireless device is preferable. In addition, for patients with exercise induced GERD symptoms, the wireless recording device is often more comfortable when exercising (including swimming). Finally, the wireless device records $\mathrm{pH}$ changes for a minimum of 48 hours but some studies have reported up to 5 days of recording. Pediatric studies have shown that the wireless $\mathrm{pH}$ recording results are comparable to the $\mathrm{pH}$ probe in patients that 
underwent both simultaneously.(108) Pediatric studies have also shown that 2 days of recording may allow for improved reflux detection due to the additional recording time. (109) Complications of the device occurred in $0-15 \%$ of patients, including esophageal tears, chest pain, and device failure (failure to record or early detachment).(108-110) While concerns have been raised about performing the studies after sedation, pediatric studies have failed to show a significant anesthesia effect beyond $2-6$ hours after placement.(111, 112)

Oropharyngeal $\mathrm{pH}$ monitoring has also been proposed as a less invasive test to measure changes in pharyngeal $\mathrm{pH}$ as an indicator of extraesophageal reflux. A catheter is placed in the nose with the sensor lying immediately above the uvula. In a single pediatric study by Chiou et al, 15 patients underwent simultaneous oropharyngeal $\mathrm{pH}$ monitoring and $\mathrm{pH}-\mathrm{MII}$ testing.(97) The authors failed to show any relationship between changes in the oropharyngeal $\mathrm{pH}$ and esophageal reflux events detected by $\mathrm{pH}-\mathrm{MII}$ suggesting that oropharyngeal monitoring does not represent GER events. Adult studies have since shown similar results. $(113,114)$ Therefore, because of this inadequate sensitivity, oropharyngeal monitoring is not recommended.

$\mathrm{pH}$ of exhaled breath condensate has been proposed as a method for diagnosing extraesophageal reflux, but preliminary data indicate that it lacks the sensitivity needed to discriminate between patients with and without pathologic reflux.(115)

Other testing for extraesophageal symptoms-Airway appearance: While earlier studies in adults and children suggested that there may be a relationship between the appearance of the larynx and evidence of GER, these studies were limited because they were neither prospective nor blinded and the diagnosis of reflux was made using insensitive tools such as oropharyngeal $\mathrm{pH}$ monitoring or barium imaging. In a single prospective pediatric study, in which airway exams were blindly scored by three otolaryngologists in children undergoing $\mathrm{pH}-\mathrm{MII}$ testing for respiratory symptoms, no relationship was found between laryngeal appearance scored by using a validated scoring system, the reflux finding score, and any reflux parameter by pH-MII. These findings suggest that the appearance of the airway does not correlate with pathologic reflux.(116)

\section{Recommendations}

3.16 Based on expert opinion, when pH-MII is not available, the working group suggests to consider to use $\mathrm{pH}$-metry only to

1. Correlate persistent troublesome symptoms with acid gastroesophageal reflux events (See also under pH-MII)

\section{VOTING: 6, 7, 7, 7, 7, 8, 8, 9, 9. (Strong Recommendation)}

2. Clarify the role of acid reflux in the etiology of esophagitis and other signs and symptoms suggestive for GERD.

VOTING: 6, 7, 7, 7, 7, 8, 8, 9, 9. (Strong Recommendation)

3. Determine the efficacy of acid suppression therapy. 


\section{pH-impedance monitoring (pH-MII)}

The search did not identify any studies fulfilling our inclusion criteria.

\section{Other considerations when using $\mathrm{pH}-\mathrm{MII}$ for the diagnosis of GERD}

- pH based testing versus pH-MII: The advantage of pH-MII above the sole monitoring of the esophageal $\mathrm{pH}$ lays its ability to accurately detect (1) refluxate with $\mathrm{pH}<4$ and greater than 4, (2) full column refluxate, (3) liquid and gas reflux, and (4) drops in esophageal $\mathrm{pH}$ due to reflux versus swallow-related drops in $\mathrm{pH}$. Because of these advantages, in validation studies, pH-MII had a high sensitivity compared to $\mathrm{pH}$-metry for the detection of reflux episodes, particularly when non-acid reflux was prevalent (e.g. patients taking acid suppression, infants who are fed frequently).(117-125) With the advent of pH-MII, the importance of refluxate with $\mathrm{pH}>4$ was realized. In the literature, two terms are used interchangeably to describe reflux with $\mathrm{pH}>4$ : non-acid reflux and weakly acidic reflux. For the purposes of this discussion, we will use the term non-acid reflux, which may also include (weakly) acidic reflux.

Despite the advantages of $\mathrm{pH}-\mathrm{MII}$ over $\mathrm{pH}$-metry, there are still some limitations to the technology:

1. $\mathrm{pH}-\mathrm{MII}$ technology is not available in all medical centers.

2. As with pH-metry, defining reference ranges is limited by the lack of true control patients. Nevertheless, some attempts to establish normal values in pediatrics have been made, albeit all in symptomatic children.(126, 127)

3. In patients with motility disorders or significant esophagitis, $\mathrm{pH}-\mathrm{MII}$ (both software and manually analyzed) may underestimate the amount of reflux episodes as a result of low baseline impedance values, compromising the ability for baselines to drop by more than 50\%, the accepted definition of reflux by impedance. While a low impedance baseline may alert the clinician to the presence of esophagitis, it does not avert the need for endoscopy.(128, 129)

4. Despite availability of guidelines (130), considerable diversity exists in performance and interpretation of $\mathrm{pH}-\mathrm{MII}$ recordings among users, with diverging results of inter- and intra-observer reproducibility of studies.(130-133) Additionally, analysis is time-consuming and is best performed by those with considerable expertise.

5. No studies have yet been performed in pediatrics that convincingly show that the results of pH-MII testing influence clinical outcomes. $(134,135)$

6. While correlation of symptoms with reflux events is one of the main indications for $\mathrm{pH}-\mathrm{MII}$, patients/parents fail to report more than 50\% of symptoms (as with all reflux testing) compromising symptom correlation.(72) In addition, the 
appropriate time window by which it can be established that a symptom is correlated with reflux is debated. $(99,100)$

- Clinical considerations to perform pH-MII: Despite the above limitations, the working group endorses several indications for the performance of $\mathrm{pH}-\mathrm{MII}$ in the evaluation of GERD.

\section{Differentiate patients with non-erosive reflux disease (NERD), hypersensitive esophagus and functional heartburn in patients with normal endoscopy: The recently} published Rome IV criteria for esophageal disorders included new classifications for adults with typical GERD symptoms including chest pain and heart burn. In patients with persistent typical symptoms despite acid suppression, pH-MII can clarify the diagnosis of non-erosive reflux disease (NERD; pathologic reflux regardless of symptom correlation), hypersensitive esophagus (positive symptom correlation with either acid or nonacid reflux events but no pathologic reflux), and functional heartburn (negative symptom correlation and no pathologic reflux; see "Summary of the Definitions for full definitions).(136) A single pediatric study examines the incidence of the Rome IV subgroups in pediatrics. Mahoney et al. used these new Rome IV criteria to classify 45 children with typical reflux symptoms with no evidence of endoscopic erosions. Of these 45 patients, $27 \%$ of were categorized with NERD, 29\%, with reflux hypersensitivity and 44\% with functional heartburn.(137) Distinguishing these disease entities may have therapeutic impact. Based upon adult literature, reflux hypersensitivity may be treated with traditional reflux therapies (medications, fundoplication), whereas functional heartburn may be treated with neuromodulators.(138-140)

2. Determine the efficacy of acid suppression therapy: While $\mathrm{pH}$-metry can be used to determine if there is persistent esophageal acid exposure despite therapy, $\mathrm{pH}$-MII catheters can determine this as well as how much non-acid reflux is present in children taking acid suppression. Rosen et al. found that the mean-sensitivity of MII-pH was $76 \pm 13 \%$ compared to $\mathrm{pH}$-metry whose mean-sensitivity was $80 \pm 18 \%$. When patients taking acid suppression were studied, the mean-sensitivity of the $\mathrm{pH}$-metry dropped to $47 \pm 36 \%$, whereas the meansensitivity of MII-pH in treated patients was $80 \pm 21 \%$.(123) Therefore, pH-MII should be considered as a diagnostic test in symptomatic patients taking acid suppression.

\section{Correlate persistent troublesome symptoms with acid and non-acid gastroesophageal} reflux events: Several studies in infants and children using $\mathrm{pH}-\mathrm{MII}$ in the postprandial period highlight the importance of non-acid reflux events in this period, making $\mathrm{pH}-\mathrm{MII}$ the preferred choice for measurement of reflux events in children with predominant postprandial symptoms that would be missed by standard pH-metry alone.(119, 124, 141-143) The 7 impedance sensors distributed throughout the esophagus on the $\mathrm{pH}-\mathrm{MII}$ catheter allow accurate detection of full column reflux events which may be important in patients with extraesophageal symptoms. $(97,118)$

4. Clarify the role of acid and non-acid reflux in the etiology of esophagitis and other signs and symptoms suggestive for GERD: $\mathrm{pH}-\mathrm{MII}$ monitoring plays an important role in the correlation of symptoms with both acid and non-acid reflux events with improved 
symptom correlation compared to $\mathrm{pH}-$ metry alone. The combination of $\mathrm{pH}-\mathrm{MII}$ has proven useful for the evaluation of symptom correlations between reflux episodes and symptoms such as pain/irritability, apnea, cough, other respiratory symptoms, and behavioral symptoms. $(118,144-147) \mathrm{pH}-\mathrm{MII}$, as with $\mathrm{pH}$-metry, may also clarify the role of acid and non-acid reflux in the generation of esophagitis, though data are conflicting on the relationship between esophagitis and acid and non-acid reflux events measured by pH-MII. $(148,149)$

- Study to be done on or off acid suppression?: No pediatric studies have examined if $\mathrm{pH}$ MII testing should be performed on or off acid suppression. If the goal of testing is to determine the efficacy of therapy in persistently symptomatic patients, testing should be performed on acid suppression. If the goal is symptom correlation, several adult studies support the performance of $\mathrm{pH}-\mathrm{MII}$ testing off acid suppression because of an increased yield of acid-related symptoms. $(150,151)$

- Symptom Association: Three main symptom indices are used to correlate reflux episodes with symptoms: the symptom index (SI), symptom sensitivity index (SSI), and symptom association probability (SAP).(152-154) While some conflicting data exist depending on the symptom index chosen, $\mathrm{pH}-\mathrm{MII}$ results in a higher degree of symptom association compared with $\mathrm{pH}$-metry alone. However the theoretical benefits of individual symptom indices is still being debated. Although pediatric studies suggest the SI and the SAP are most frequently positive, no studies prove that one index is superior to another in predicting response to therapies in children. Due to a lack of evidence showing benefit in predicting outcomes, no index is recommended over another at this time.(130)

In conclusion, there is insufficient evidence to support the use of $\mathrm{pH}-\mathrm{MII}$ as a single technique for the diagnosis of GERD in infants and children.

\subsection{Recommendations}

Based on expert opinion, the working group suggests to consider to use pH-MII testing only to:

1. Correlate persistent troublesome symptoms with acid and non-acid gastroesophageal reflux events

\section{VOTING: 6, 7, 7, 7, 8, 8, 8, 9, 9. (Strong Recommendation)}

2. Clarify the role of acid and non-acid reflux in the etiology of esophagitis and other signs and symptoms suggestive for GERD.

\section{VOTING: 6, 7, 7, 7, 8, 8, 8, 9, 9. (Weak Recommendation)}

3. Determine the efficacy of acid suppression therapy.

VOTING: 6, 6, 7, 7, 7, 9, 8, 8, 9. (Weak Recommendation)

4. Differentiate NERD, hypersensitive esophagus and functional heartburn in patients with normal endoscopy. 


\section{Question 4: What non-pharmacologic treatment options are effective and safe for the reduction of signs and symptoms of GERD?}

Three original studies and two systematic reviews were eligible for inclusion. After checking reference lists of these systematic reviews and the ESPGHAN/NASPGHAN 2009 and NICE 2015 guidelines (See Appendix A for summary of search strategy, results and study selection), 16 original studies could be included: one trial on positional therapy, one on massage therapy and 14 on feeding modifications.(1, 3, 155-170) Characteristics of included studies can be found in Appendix B2. GRADE profiles can be found in Appendix D1.

Feeding modifications including formula or food thickeners, reduced feeding volumes or more frequent feedings and extensively hydrolyzed or amino-acid based formula, the latter of which should be reserved for patients with severe symptoms not responsive to a protein hydrolysate formula.

\section{Thickened feeding}

The search identified 14 studies on the use of thickened feedings. No studies on the use of reduced feeding volumes, more frequent feedings, or extensively hydrolyzed or amino-acid based formula met our inclusion criteria. All studies were conducted in infants with signs and symptoms of GER as defined by the authors.(1,156-169) Although no studies meet the inclusion criteria specifically assessing the use of thickened feedings in infants or children in GERD, based on expert opinion, the results found on the occurrence of regurgitation/ vomiting in infants with GER are most likely to be extrapolated to infants with GERD. The overall quality of evidence of included studies was low to very low and methodology and definitions for GER varied widely among studies (Appendix B2, D1). No definitive data showed that one particular thickening agent is more effective than another. In ten studies, visible vomiting and/or regurgitation was used as an outcome measure.(157, 160, 161, 163$167,169,170)$ Three studies showed a reduction in the number of episodes of regurgitation per day (Pooled Mean Difference: $-1.18,95 \%$ CI -1.96--0.66), $(160,161,164)$ and two studies showed a reduction in vomiting per day (Pooled Mean Difference - 0.93 (95\% CI $-1.31--0.55) .(160,166)$ Ostrom et al. compared soy formula with added fiber (as a thickener) to cow's milk in a double blinded randomized controlled trial and found a significant reduction in the percentage of feedings with regurgitation and the number of subjects with any regurgitation at the end of the 4 week trial in those patients that received the soy formula with fiber ( $\mathrm{p}$ < 0.03).(161) In contrast, Ummarino et al. performed an open label randomized controlled trial of thickened feedings versus patient/family reassurance versus magnesium alginate with simethicone. In this study, the authors found that thickening reduced median symptom scores over the course of the eight week study to a greater extent than reassurance alone ( $\mathrm{p}<0.001)$. (170) Grade of severity of regurgitation was reduced in another study, albeit not significantly (MD -1.10, 95\%CI -2.49-0.29).(157) The remaining studies did not report sufficient data to draw group-group comparisons at the end of study period compared with baseline. 
While the previously discussed studies focused on symptom scores and the amount of regurgitation, four studies used crying/distress as an outcome measure, although only two studies presented adequate data upon which it was possible to draw conclusions.(159, 161, $167,168)$ In a randomized trial, regurgitation, vomiting, and other symptoms such as irritability were significantly reduced in the corn starch-thickened formula group compared with enriched formula-fed patients four and eight weeks after initiating the formula changes. (159) Ostrom et al. found, in their four week trial, no significant differences in GERD symptoms in infants receiving soy formula with fiber compared with cow's milk formula without added fiber ( $p>0.05)$.(161)

In summary, across all studies, thickening of feedings improves visible regurgitation but the impact on non-regurgitation symptoms is less clear (i.e. as determined by predefined outcome measures and/or occurrence of side-effects and adverse events)..(158, 159, 162$165,167,168)$

\section{Other considerations with thickeners}

- The efficacy of thickeners as assessed by pH-MII: The search yielded one systematic review published after 2008 on the use of thickened feedings for the treatment of GER in healthy infants.(171) As this study applied different inclusion and exclusion criteria, fourteen studies were included for meta-analysis and the conclusion of the analysis was that the thickening: 1) reduced vomiting and visible regurgitations per day, 2) increased the number of days without regurgitation, and 3) reduced symptoms such as crying and irritability. Horvath et al. also highlighted that thickening does not improve the acid reflux parameters measured by $\mathrm{pH}$-metry including the RI, number of acid gastroesophageal reflux episodes per hour, or number of reflux episodes lasting $>5$ minutes. In this systematic review, there was a reduction in the duration of the longest reflux episode of $\mathrm{pH}<4$ based on the pooled results of two RCTs $(\mathrm{n}=116)$.(171) One argument for a lack of improvement in $\mathrm{pH}$-metry parameters is that thickening would be expected to reduce post-prandial reflux which is typically non-acid and therefore may be missed by $\mathrm{pH}$-metry. However, in two trials of thickening performed using $\mathrm{pH}-\mathrm{MII}$ parameters as outcomes, thickening still did not result in reducing the total reflux burden when comparing feeding periods with and without thickening within individual patients. $(172,173)$

\section{Safety of thickeners}

- Cereal based: Recent reports have raised concerns about the safety of rice cereal as a thickening agent for infants and children. Safety concerns were raised because of elevated levels of inorganic arsenic in all forms of rice including infant cereals. Arsenic exposure has been linked to neurotoxicity and long term cancer risk in areas with environmental arsenic contamination. In April 2016, the United States Food and Drug Administration (FDA) proposed an action level, or limit, of 100 parts per billion for inorganic arsenic in infant rice cereal, which corresponds to a level proposed by the European Commission for rice destined for the production of food for infants and young children. Despite this FDA warning, rice cereal still enjoys advantages as a thickener, including its ability to dissolve more thoroughly than other cereals without clogging nipples, its affordability, and its long track record of use in infants. Whenever possible, using rice cereal with low or no arsenic is recommended. 
- Commercial thickeners: The search did not identify any studies on the efficacy of thickening of breastmilk. In a cross-over study, Corvaglia et al. evaluated the effect of thickening of human milk by precooked starch in reducing GER in five preterm infants and found no significant reduction in the number of $\mathrm{pH}-\mathrm{MII}$ detected reflux episodes with thickened feeds when compared to unthickened feeds.(173) In the vast majority of infants presenting with physiological GER, breastfeeding should be further encouraged. However, for babies with significant reflux such that thickening is being considered, breastmilk can be thickened with xanthum gum or carob bean based thickeners but not with cereal, the latter of which is digested by the amylases in breast milk. While these commercial thickeners are available for use in breast milk, some cautions exist. Carob bean thickeners are approved for use in infants after 42 weeks gestation. Xanthum gum thickeners are approved for infants greater than 1 year old because of concerns of necrotizing enterocolitis.(174, 175)

- Reduction of ingested volume: A reduction of the ingested volume per feeding is a common recommendation that can be found in many reviews, guidelines and recommendations for GERD treatment.(1,3,176) No RCTs have studied reduced feeding volumes. Omari et al. showed that in preterm and term infants with GERD, using more frequent feedings led to a reduced RI in this specific group.(119) Although no data relate ingested volume to frequency and volume of regurgitation, avoiding overfeeding by adjusting feeding frequency and volume for age and weight while maintaining an appropriate total daily amount of formula or breastmilk is recommended (Algorithm 1).

- Elimination of cow's milk protein: No RCTs evaluate extensively hydrolyzed or amino acid based formulas for the treatment of GERD. However, a subset of infants with allergy to cow's milk protein (CMPA) experience regurgitation and vomiting indistinguishable from that associated with physiologic GER or GERD and it is for this reason that, even in acid suppression trials, cow's milk elimination trials are often performed prior to randomization for reflux medications.(177) In these infants, vomiting frequency decreases significantly (usually within 2 weeks) after the elimination of cow's milk protein from the diet, and reintroduction causes recurrence of symptoms. Because regurgitation is sometimes the sole manifestation of CMPA in healthy-appearing infants, non-breast-fed infants with suspected CMPA should receive a formula with an extensively hydrolyzed protein. In breast-fed infants, the mother can achieve similar results by restricting all dairy including casein and whey from her diet. According to the recently published ESPGHAN guidelines on CMPA, amino acids-based formulae should be reserved for the patients with intractable or severe symptoms.(178) While no trials compare the use of protein hydrolysate formulas to milk based formulas in the treatment of symptoms of GERD, children with suspected CMPA who are given an amino acid based formula for 24 hours followed by a cow's milk containing formula for 24 hours have significantly more reflux events measured by $\mathrm{pH}-\mathrm{MII}$ during the cow's milk feeding compared to the amino acid based feeds.(179) Corvaglia et al. studied 18 infants with symptoms of feeding intolerance, constipation or distension that were treated for one week with a hydrolyzed protein formula.(180) After this one week trial, if the infants had GERD symptoms, they underwent pH-MII testing while receiving cow's milk formula alternating with protein hydrolysate formula as part of a randomized cross over design trial. The authors found that RI improves during hydrolysate feeds compared with the cow's milk 
feedings, but they found no other differences in any of the reflux parameters as measured by pH-MII. ESPGHAN guidelines recommend against the use of soy-based infant formula, and in Europe soy based formulas are no longer commercially available.(181, 182) Among $10-$ $15 \%$ of the infants with CMPA will also become allergic to soy.(183) Rice hydrolysates are commercially available, but the data are too limited to be considered in these guidelines.

Any patient placed on a protein hydrolysate formula or an amino acid based formula needs close follow up to determine how and when dairy can be safely introduced. Studies have shown that infants and children on CMP restriction may have increased disordered eating patterns and may even develop anaphylaxis to milk protein. $(184,185)$

In conclusion, the use of thickeners may improve slightly the occurrence of overt regurgitation/vomiting as symptoms of GER in infants. It is uncertain whether the use of food thickeners improves other signs and symptoms of GER and whether their use leads to side-effects in infants. While evidence supporting modification of feeding volumes or intervals is lacking, these modifications are without risk or cost, so feeding modification should be considered before more costly or risky interventions. While there is no evidence to support the use of extensively hydrolyzed formula or amino acid-based formula for the treatment of GERD in infants and children who do not have CMPA, symptoms of GERD and CMPA are identical. Therefore, a trial of extensively hydrolyzed formula or amino acid-based formula is indicated in patients who have not responded to conventional GERD therapies. For each of these nonpharmacologic therapies, a minimum 2 week trial is recommended to assess for symptom improvement before considering other therapeutic alternatives.

\section{Recommendations}

4.1 The working group suggests to use thickened feed for treating visible regurgitation/ vomiting in infants with GERD (Algorithm 1).

VOTING: $6,7,7,8,8,8,9,9,9,9$. (weak recommendation)

4.2 Based on expert opinion, the working group suggests to modify feeding volumes and frequency according to age and weight to avoid overfeeding in infants with GERD (Algorithm 1).

VOTING: $7,7,8,8,8,8,8,9,9,9$. (weak recommendation)

4.3 Based on expert opinion, the working group suggests a $2-4$ week trial of formula with extensively hydrolyzed protein (or amino-acid based formula) in formula fed infants suspected of GERD after optimal non-pharmacological treatment has failed (Algorithm 1, or see ESPGHAN 2012 CMPA guidelines).

VOTING: $4,6,7,8,8,8,8,9,9,9$. (weak recommendation)

Positioning therapy-One study was identified that met the inclusion criteria.(156) Loots et al. conducted a study of infants with a positive symptom correlation on pH-MII testing who were randomized to left side or head elevation positioning in addition to medications (PPI or Mylanta). The primary outcome of the study, measured 14 days after initiation of 
treatment, was change in reflux measured by $\mathrm{pH}-\mathrm{MII}$ testing, but symptom improvement was also assessed. Regardless of the medication given, left lateral positioning (LLP) resulted in reduction in the total number of reflux episodes. Vomiting also declined in infants given Mylanta and placed in LLP.(156)

\section{Other considerations on the effect of positioning on reflux parameters}

- pH-MII and motility parameters-As mentioned above, LLP reduced the total number of reflux episodes measured by pH-MII. In a study by Omari et al., the authors measured by impedance and LES pressures in 10 preterm infants placed in the right and left lateral decubitus positions.(186) In this study, both the number of reflux episodes and the TLESRs significantly decreased in infants in LLP compared to right lateral positioning (RLP). A subsequent study by van Wijk et al. found identical effects of positioning on reflux by impedance, and the effect of positioning was immediate; when babies were switched from RLP to LLP and vice versa, the impact on reflux and TLESRs was immediate.(187) No studies met our inclusion criteria on the impact of positioning on symptom reduction as the primary outcome. An uncontrolled trial by Vandenplas et al showed that a $40^{\circ}$ specially constructed antireflux bed resulted in a significant decrease of objective reflux parameters, reflux symptoms and anti-acid medications in infants that tolerated this position.(188) Corvaglia et al. showed that prone and left side position were associated with a decreased number of reflux episodes measured by impedance in premature infants.(189)

- Safety-Despite possible benefits to positioning in the treatment of reflux, no position other than supine position is recommended for infants because of the risk of sudden infant death syndrome (SIDS). Supine sleeping is universally recommended by the National Health Service and the American Academy of Pediatrics as the safest position to prevent the risk of SIDS. Because elevating the head of an infant's crib while the infant is supine may result in the infant rolling to the foot of the crib into a position that may comprise respiration, elevating the head of the crib is not recommended by the American Academy of Pediatrics. (189)

No studies are published on positioning therapy in older children. However, in adults, headof-the-bed elevation modestly decreases time with supine acid exposure compared with a flat position (from $21 \%$ to $15 \%, p<0.05$ ).(190) In another small study by Loots et al. in 10 adult GERD patients, TLESRs, reflux events, distension of proximal stomach, and gastric emptying were increased in the right lateral position compared to left lateral position, whilst this effect was not found in 10 healthy controls.(191)

In conclusion, it is uncertain whether the use of positioning therapy (left side or head elevation positioning) improves the occurrence of crying/distress as signs and symptoms of GERD in infants.

\section{Recommendations}

4.4 The working group recommends not to use positional therapy (i.e. head elevation, lateral and prone positioning) to treat symptoms of GERD in sleeping infants.

VOTING: 6, 6, 7, 8, 8, 8, 9, 9, 9, 9. (strong recommendation) 
4.5 Based on expert opinion, the working group suggests to consider the use of head elevation or left lateral positioning to treat symptoms of GERD in children.

VOTING: 7, 8, 8, 8, 9, 9, 9, 9, 9, 9. (weak recommendation)

Other non-pharmacological interventions including life-style modifications (alcohol and tobacco use/exposure), massage therapy, complementary therapy (hypnotherapy, homeopathy, acupuncture, herbal medicine), pre- and probiotics.

The search yielded one study on the use of massage therapy in infants with a diagnosis of GERD according to their treating pediatrician, but no studies met our inclusion criteria on any of the other interventions.(155) In this single study by Neu et al., 36 infants with GERD diagnosed by I-GERQ-R were randomized to massage therapy or sham therapy including rocking and holding. Both groups experienced improvement in GERD symptoms, measured by I-GERQ-R scores, and no difference was found between groups after the six week intervention. This study was limited by its small size and short length of intervention.

\section{Other considerations for non-pharmacologic therapies}

- Probiotics-No studies met the criteria for inclusion. However, one placebo-controlled RCT investigated the efficacy of Lactobacillus reuteri DSM 17938 given as drops daily for 90 days in 589 term newborns (age < 1 week) in the prevention of colic, regurgitation, and functional constipation. Since this study was a prevention study conducted in infants $<3$ months of age, regardless of the presence of GERD, this study did not meet inclusion criteria. Nevertheless, regurgitation frequency was addressed as a primary outcome in the study. At the conclusion of the three month trial, the mean number of regurgitations per day in the L. reuteri DSM 17938 and placebo groups were significantly different: 2.9 vs $4.6 ; \mathrm{p}<$ 0.01.(192) Significant improvement was also noted in crying time per day $(\mathrm{p}<0.01)$, but this is a symptom not unique to GERD. No studies have been published on the effect of infant formula with probiotics on GERD symptoms.

- Weight loss in obesity-In children, obesity has been associated with a small increase in risk of GERD symptoms compared to non-obese children.(193, 194) However the impact of obesity on GERD complications such as erosive esophagitis is less clear. $(3,195,196)$ No pediatric intervention studies determine if weight reduction changes GERD symptoms. No pediatric studies show a relationship between obesity and reflux events by $\mathrm{pH}-\mathrm{metry}$ or $\mathrm{pH}-$ MII. A review of lifestyle changes in adults with GERD concluded that only weight loss improved pH-metry profiles and symptoms.(197)

In conclusion, it is uncertain whether the use of massage therapy reduces crying/ distress or other signs and symptoms of GERD in infants based on the I-GERQ-R questionnaire. While there is a lack of evidence supporting non-pharmacologic interventions, some interventions (such as tobacco avoidance) are low to no cost and risk and may merit a trial before considering more costly or risky therapies. Other interventions massage therapy, complementary therapy (hypnotherapy, homeopathy, acupuncture, and herbal medicine), dietary supplementation, pre-and probiotics have 
not been adequately studied and may pose more risk and cost so therefore cannot be recommended for the reduction of symptoms of GERD in infants and children.

\section{Recommendations}

4.6 The working group suggests not to use massage therapy to treat infant GERD.

VOTING: 7, 7, 7, 8, 8, 8, 9, 9, 9, 9. (weak recommendation)

4.7 Based on expert opinion, the working group suggests not to use currently available lifestyle interventions or complementary treatments such as prebiotics, probiotics, or herbal medications to treat GERD.

\section{VOTING: 5, 6, 7, 7, 8, 9, 9, 9,9,9. (weak recommendation)}

4.8 Based on expert opinion, the working group suggests informing caregivers and children that excessive body weight is associated with an increased prevalence of GERD.

VOTING: $6,7,7,7,7,8,8,9,9,9$. (weak recommendation)

\section{Parental guidance, education and support}

The search did not identify any studies fulfilling our inclusion criteria.

- Other considerations on education-Patient and parental education, guidance, and support are always considered to be required as part of the treatment of GERD. It is important to inform caregivers about diagnostic and treatment options, side-effects, complications and prognosis (also see section Prognosis). These measures are usually sufficient to manage healthy, thriving infants with symptoms likely to result from physiologic GER.(1) A RCT on physician counseling of families of patients with chronic conditions, such as asthma, has shown that patient education on specific pathophysiology of the disorder, specific methods to prevent or treat symptoms, and patient empowerment, can help improve parent understanding of the disorder, decrease patient symptoms of the chronic disorder and decrease health care utilization. $(198,199)$ However, no studies specifically in pediatric GERD patients have been performed.

In conclusion, there is no evidence to support parental guidance, education and support for the reduction of signs and symptoms of GERD in infants and children.

\section{Recommendation}

4.9 Based on expert opinion, the working group recommends providing patient/parental education and support as part of the treatment of GERD (Algorithm 1).

VOTING: 8, 8, 9, 9, 9, 9, 9, 9, 9, 9. (strong recommendation) 


\section{Question 5: What are effective and safe pharmacologic treatment options for the reduction of signs and symptoms of GERD?}

Ten original studies and 25 systematic reviews were eligible for inclusion. After checking reference lists of these systematic reviews and the ESPGHAN/NASPGHAN 2009 and NICE 2015 guidelines (See Appendix A for summary of search strategy, results and study selection), 12 additional original studies could be included, resulting in a total of 22 original studies. Characteristics of included studies can be found in Appendix B3. GRADE profiles can be found in Appendix D.

Algorithm 1 and 2 display the therapeutic approach to respectively the infant and child with GERD. For recommended dosages for the different drugs we refer to Table 4.

\section{Anti-acids and alginates}

Alginates and antacids are designed to neutralize acid and contain either sodium/potassium bicarbonate, or aluminium, magnesium or calcium salts and are typically used to treat acid related disorders such as heartburn or dyspepsia. The search yielded two studies assessing the use of alginates (one containing $225 \mathrm{mg}$ sodium alginate and $87.5 \mathrm{mg}$ magnesium alginate (170) and one containing magnesium alginate and simethicone (200) versus placebo one study also assessed the use of alginates versus rice-starch thickened formula.(170) Two additional studies assessed the use of alginates vs H2RAs (see section 5).(201, 202) A recent Cochrane review on the currently available pharmacological interventions used to treat children with GER was also reviewed.(203) No studies meeting our inclusion criteria on the use of anti-acids were identified.

Ummarino, et al., assessed GER symptoms using I-GERQ-R questionnaire scores. While they reported that median I-GERQ-R scores were more significantly reduced in the intervention group compared with no intervention $(\mathrm{p}<0.0001)$ or thickened feedings $(\mathrm{p}<$ 0.002), no comparison between groups at end of study period was made.(170) Ummarino, et al., reported on the number of infants with persisting symptoms at week 4 and 8 , showing a significant decrease in the number of infants regurgitating at week 8 when treated with alginates compared with no intervention $(\mathrm{RR}=0.04,95 \% \mathrm{CI} 0.01-0.25)$ and compared with thickened feedings ( $R R=0.26,95 \%$ CI $0.26-0.88)$. (170) The other study, by Miller et al., found the number of vomiting/regurgitation episodes in 24 hours at two weeks was significantly lower compared with baseline $(\mathrm{p}=0.009)$, however the mean frequency of episodes did not differ statistically.(200) In both studies, no significant differences were found in the number of infants with more than one adverse (AE; RR=1.30, 95\% CI $=0.87$ 1.93 ) or serious adverse event (SAE; RR $=1.10,95 \% \mathrm{CI} 0.16-7.43$ ) or in the number of infants withdrawing from the study due to the occurrence of a(n) (S)AE (RR=0.63, 95\%CI $0.20-1.99) .(170,200)$ The evidence for these findings ranged from low to very low quality.

In conclusion, it is uncertain whether the use of alginates improves signs and symptoms of GER based on the I-GERQ-R questionnaire. The use of alginates may slightly improve visible regurgitation/vomiting as signs and symptoms of GER. It is uncertain 
whether the use of alginates for the reduction of signs and symptoms of GER in infants leads to side-effects.

\section{Other considerations for alginates}

- pH-MII parameters-Del Buono et al. studied sodium and magnesium alginate and mannitol (but not bicarbonate) in infants up to six months of age using pH-MII impedance. The 24 hour-reflux burden or the number of reflux events per hour did not differ in patients receiving alginate compared with those receiving placebo.(204) However, the dosage described in the study was lower than that recommended by the manufacturer which may have influenced results. Furthermore, no data on visible regurgitation/vomiting events were reported, so no conclusions about improvement in GERD symptoms can be determined.

- Safety-Over the last five years, very few studies have assessed the efficacy and safety of alginates in childhood. Nevertheless, alginates on-demand and short-term treatment seem to have no significant side effects. The prolonged use of aluminium-containing antacids may lead to increased aluminium plasma concentrations in infants.(205, 206) Chronic high exposure or high-dose ingestion of calcium carbonate can cause milk-alkali syndrome; a triad of hypercalcemia, alkalosis and renal failure. Therefore, aluminium-containing antacids should not be used in children with renal impairment or in infants.

- Other guidelines-In the recently published NICE guidelines, alginates are recommended as an alternative treatment to feed thickening agents in breastfed infants or as a trial in infants in whom symptoms persist despite conservative measures.(3) Additionally, the NICE working group recommends the use of antacids and antacid/alginates for symptom relief in young people suffering from heartburn who have gone through puberty. This recommendation is extrapolated from another NICE guideline on dyspepsia and GERD in adults.

As there is no evidence comparing alginates to any recommended feed thickening agent or on the use of antacids to treat GERD in children or adolescents, the current working group decided to suggest that antacids/alginates should not be used for chronic treatment of infants and children with GERD.

\section{Recommendation}

5.1 The working group suggests not to use antacids/alginates for chronic treatment of infants and children with GERD.

VOTING: $6,7,8,8,8,8,9,9,9,9$. (weak recommendation)

\section{Acid suppressive therapy including proton pump inhibitors (PPIs) and histamine receptor antagonists (H2RAs)}

Results of acid suppression trials are discussed below. When assessing PPI efficacy in treating symptoms, esophagitis, or other GERD complications, the dose, method and timing of administration, variations in drug metabolism, and patient compliance must be considered. 


\section{PPIs vs placebo}

The search yielded seven studies that compared the use of proton-pump inhibitors (PPIs) versus placebo in the treatment of GERD. Definitions of GERD varied widely among studies and included criteria based on $\mathrm{pH}$-monitoring, endoscopic findings, reported clinical symptoms and/or an I-GERQ-R score > 16.(177) Efficacy of different PPIs were assessed, including lansoprazole (207), esomeprazole $(156,208,209)$, rabeprazole (210), pantoprazole (177) and omeprazole.(211) No study comparing different types of PPIs was found. In one study, GERD symptoms were assessed by using the I-GERQ-R score. Although no data were reported, the authors stated that there were no significant differences in I-GERQ-R score in the infants treated with rabeprazole. Quality of evidence was very low.(210) Six studies (all in infants $<12$ months) reported on the efficacy of PPIs in the treatment of crying and/or irritability. None of the six studies identified significant differences in symptom improvement (including symptoms such as crying, cough, arching) between infants who received PPI and those receiving placebo. The evidence was of low to very low quality.(177, 207-211) Four studies of infants with GERD (confirmed by pH-metry) used regurgitation as a primary outcome, and all four found that PPIs did not reduce the frequency of overt regurgitation compared with infants who received placebo.(177, 207, 208, 210) In PPI treated patients, reported side effects included upper and lower respiratory infections, constipation, diarrhea, eczema and vomiting amongst others, but in all studies but one, their incidence was not more common than placebo.(177, 207-212) In the single study that reported adverse events at a greater rate than placebo, the following side effects were reported: upper and lower respiratory infections, diarrhea, otitis media, epididymal infection, arachnoid cyst, febrile convulsion, Klebsiella infection and dehydration.(207)

\section{In conclusion, it is uncertain whether the use of PPIs reduces crying/distress, visible vomiting/regurgitation or signs and symptoms of GERD based on the I-GERQ-R questionnaire in infants with GERD when compared with placebo. It is uncertain whether the use of PPIs leads to side-effects in infants with GERD compared with placebo.}

\section{H2RAs vs placebo}

The search identified three studies on the use of H2RAs, all assessing a different agent: ranitidine, cimetidine and nizatidine. The studies were conducted in mixed populations of both infants and children.(213-215) In two studies, all patients had evidence of reflux esophagitis based on endoscopy.(213, 215) In the other study, infants with a history of GERD symptoms were included.(214)

One study found that compared with baseline, regurgitation and vomiting were reduced more in infants and children who received cimetidine compared to those receiving placebo after four and eight weeks of therapy. However, there was no evidence that cimetidine improved symptoms of crying or distress or heartburn or colic over placebo. The evidence for these findings was of very low quality.(215) Two studies found that endoscopic and histological features of esophagitis were reduced in infants and children who received H2RAs compared with placebo. The quality of the evidence for this finding was low to very low. $(213,215)$ No serious adverse events were reported in any of the three trials. In one 
other study, the number of infants with more than one (treatment related) adverse event (AE) did not differ between infants and children treated with ranitidine or placebo.(214)

In conclusion, it is uncertain whether the use of H2RAs reduces crying/distress, visible regurgitation/vomiting or heartburn in children with GERD compared with placebo. It is uncertain whether the use of H2RAs improves histology/erosive esophagitis in children with GERD compared with placebo. It is uncertain whether the use of H2RAs leads to side-effects in infants and children with GERD compared with placebo.

\section{PPIs vs H2RAs}

The search yielded two studies that compared omeprazole versus ranitidine in infants and children with GERD based on clinical symptoms and results of pH-metry and/or endoscopy. $(30,216)$ The quality of evidence of both studies was very low. Ummarino, et al, found no significant difference in symptom severity scores of crying/distress or chest pain between the groups treated with omeprazole versus ranitidine based on the mean differences in symptom scores after eight weeks of treatment compared with baseline.(216) In the other eight-week study, Cucchiara, et al, found no statistically significant difference in esophagitis healing between infants and children with refractory GERD who received high dose ranitidine compared with omeprazole. The evidence for this finding was of very low quality.(30)

In conclusion, it is uncertain whether the use of omeprazole reduces crying/distress or chest pain as signs and symptoms of GERD in infants and children with GERD compared with ranitidine. It is uncertain whether the use of omeprazole improves histology/macroscopy in infants and children with GERD compared with ranitidine. It is uncertain whether the use of omeprazole leads to more side-effects in infants and children with GERD compared with ranitidine.

\section{PPIs vs antacid}

The search yielded one study that compared esomeprazole vs. an antacid (aluminum hydroxide, magnesium hydroxide and simethicone) in infants with GERD as defined by authors. All infants also received positioning therapy (left-lateral position) during the study period.(156) Based on results of this study, no significant differences were found between esomeprazole-versus antacid-treated infants regarding the number of crying episodes or total minutes of crying. The quality of evidence was very low.(156)

In conclusion, it is uncertain whether the use of esomeprazole reduces crying/distress as signs and symptoms of GERD in infants with GERD compared with antacids.

\section{H2RAs vs antacid/alginate}

The search identified two studies that compared the use of an H2RA with an antacid/ alginate. Oderda, et al, compared famotidine versus an alginate-antacid mixture ( $0.5 \mathrm{gr}$ algenic acid, $0.1 \mathrm{gr}$ aluminum hydroxide, $0.025 \mathrm{gr}$ magnesium trisilicate and $0.17 \mathrm{gr}$ sodium bicarbonate) in children with endoscopy-confirmed esophagitis.(201) Cucchiara, et al, investigated infants and children with a diagnosis of GERD based upon radiology, $\mathrm{pH}$-metry and/or endoscopy results, comparing cimetidine with a liquid magnesium hydroxide and 
aluminum hydroxide mixture to determine the primary outcome of symptom resolution. (202) No statistically significant differences were found in erosive esophagitis or histology between infants and children receiving a H2RA and those receiving an antacid/alginate. The quality of evidence was very low.

In conclusion, it is uncertain whether the use of an H2RA improves histology/ macroscopy in infants and children with GERD compared with antacids/alginates.

\section{PPIs vs feeding intervention}

The search yielded one study on the use of lansoprazole (comparing two doses, $15 \mathrm{mg}$ once a day vs $7.5 \mathrm{mg}$ twice a day) vs hydrolyzed formula in infants with GERD defined by an IGERQ-R score > 16.(217) Both of the lansoprazole groups experienced significantly greater improvement in symptoms, defined as an improvement in I-GERQ-R scores, over the course of the 2 week trial compared with the hydrolysate formula, but no differences were found in the degree of symptom response between the two lansoprazole doses. The quality of evidence was very low. Although not predefined as an outcome measure, no adverse events of treatment were reported during the study period.

In conclusion, it is uncertain whether the use of lansoprazole improves signs and symptoms based on the I-GERQ-R questionnaire in infants with GERD compared with hydrolyzed formula. It is uncertain whether the use of lansoprazole leads to more sideeffects in infants with GERD compared with hydrolyzed formula.

\section{H2RAs vs sucralfate}

The search identified one study comparing cimetidine with sucralfate in children with endoscopy-based diagnosis of erosive esophagitis in an eight-week trial.(218) The study reported no significant differences in endoscopic healing between the groups treated with cimetidine versus sucralfate. Quality of the evidence was very low. Although not included as predefined outcome measure, no adverse events were reported by any of the study subjects.

In conclusion, it is uncertain whether the use of cimetidine improves histology/ macroscopy in infants and children with GERD when compared to sucralfate. It is uncertain whether the use of cimetidine leads to more side-effects in infants and children with GERD compared with sucralfate.

\section{Other considerations for treatment}

- PPIs vs H2RAs-Although their pharmacological mechanisms differ, both PPIs and H2RAs are acid-suppressing agents and thus similar outcomes can be expected. Although the studies are imperfect, symptom control between H2RA and PPIs is comparable. Rates of healing of erosive or histologic esophagitis are higher after 12 weeks of therapy with a PPI in contrast to H2RA.(1) Although evidence in children is very low, evidence in adults with erosive esophagitis shows that PPIs are superior to any other pharmacological treatments. (51, 219-221) Limited data are available on rates of esophagitis relapse seen after discontinuation of therapy. A single pediatric study by Boccia et al. showed a low microscopic esophagitis recurrence rate and GERD symptom recurrence long term after 
healing with omeprazole, irrespective of the maintenance therapy.(222) Therefore, based upon evidence from adult literature and expert opinion, the working group recommends PPIs as first-line treatment.(223) However, the working group also concluded that the decision of which to use should be based on practical considerations, such as ease of administration and medication cost and suggests H2RAs as a second line therapy in the treatment of esophagitis caused by acid reflux when PPIs are not available. Choice of PPIs or H2RA depends entirely on availability and cost, as no evidence supports superiority of any one PPI or H2RA over another.

From a dosing perspective, the pediatric trials for the healing of erosive and microscopic esophagitis have shown consistently high rates of healing at PPI doses of $1-1.7 \mathrm{mg} / \mathrm{kg} / \mathrm{day}$ (see Table 4) $(83,224,225)$

- Safety-Despite the fact that none of the GRADE approved studies reported any serious adverse events in children taking H2RA or PPIs, case control studies show increased risk of infection in infants and children taking these medications compared to non-users. These infections include necrotizing enterocolitis, pneumonia, upper respiratory tract infections, sepsis, urinary tract infections, and Clostridium difficile infections.(51, 226, 227) Acid has a protective effect against bacterial gastrointestinal infections, and it is therefore important that widespread unnecessary usage of acid suppressive medications be avoided, and that when these drugs are used, unnecessarily long-term usage be avoided whenever possible. Thus, it is important to be able to identify those children and young people with reflux esophagitis and symptoms responsive to acid suppression therapy so that treatment is used appropriately. Additionally, the working group also recommends the importance of regular assessment of the ongoing need for long-term acid suppression therapy in infants and children with GERD.

While increased risk of fractures, dementia, myocardial infarction, and renal disease have been reported in PPI users, no pediatric evidence convincingly documents these risks, and these studies are often confounded by comorbidities found in patients taking PPIs. However, given the mounting data in adults questioning the safety of these medications in multiple organ systems, these medications should be prescribed only when there is a clear diagnosis of GERD and, whenever possible, the lowest doses should be prescribed for the shortest length of time possible. There is a critical need for PPI safety studies in pediatrics, particularly because of the high rates of prescribing in this vulnerable population.

\section{Recommendations}

5.2 Based on expert opinion, the working group recommends the use of PPIs as first-line treatment of reflux-related erosive esophagitis in infants and children with GERD (Algorithm 2).

\section{VOTING: 7, 7, 8, 9, 9, 9, 9, 9, 9, 9. (strong recommendation)}

5.3 Based on expert opinion, the working group suggests to use H2RAs in the treatment of reflux related erosive esophagitis in infants and children if PPIs are not available or contra-indicated (Algorithm 2). 
VOTING: $7,8,8,8,9,9,9,9,9,9$. (weak recommendation)

\section{Recommendations}

5.4 The working group recommends not to use H2RA or PPI for the treatment of crying/ distress in otherwise healthy infants.

VOTING: 5, 7, 7, 8, 9, 9, 9, 9, 9, 9. (strong recommendation)

5.5 The working group recommends that H2RA or PPI should not be used for the treatment of visible regurgitation in otherwise healthy infants.

VOTING: $7,8,8,8,9,9,9,9,9,9$. (strong recommendation)

5.6 Based on expert opinion, the working group recommends a 4-8 week course of H2RAs or PPIs for treatment of typical symptoms (i.e. heartburn, retrosternal or epigastric pain) in children with GERD (Algorithm 2).

VOTING: $7,7,8,8,8,8,9,9,9,9$. (strong recommendation)

5.7 Based on expert opinion, the working group suggests not to use H2RAs or PPIs in patients with extraesophageal symptoms (i.e. cough, wheezing, asthma), except in the presence of typical GERD symptoms and/or diagnostic testing suggestive of GERD. VOTING: $6,6,6,6,8,8,8,8,8,9$. (weak recommendation)

5.8 Based on expert opinion, the working group recommends evaluation of treatment efficacy and exclusion of alternative causes of symptoms in infants and children not responding to $4-8$ weeks of optimal medical therapy for GERD (Algorithm 2).

VOTING: $6,7,7,8,8,8,8,9,9,9$. (strong recommendation)

5.9 Based on expert opinion, the working group recommends the regular assessment of the ongoing need of long-term acid suppression therapy in infants and children with GERD (Algorithm 2).

VOTING: $6,7,7,9,9,9,9,9,9,9$. (strong recommendation)

\section{Prokinetics}

Baclofen vs placebo-The search identified one double-blinded placebo RCT of baclofen versus placebo in 30 children with intractable GERD symptoms, applying manometry, pH-metry and gastric emptying results as outcome measures. Each patient was blinded to receive drug or placebo, and manometry and $\mathrm{pH}$ recording were performed for 2 hours after each drug was administered. Baclofen significantly reduced the rates of acid reflux and TLESRs and improved gastric emptying measured by breath testing. Although this study did not assess symptom response, it did report on the total number of adverse events and was therefore included for review. Based upon this study, no significant difference in the number of adverse events was found between study groups. The quality of evidence was very low.(228) 
Other considerations for baclofen use: Baclofen reduces the frequency of TLESRs, reduces acid reflux and accelerates gastric emptying, but it has not been evaluated in controlled trials for treatment of GERD in children.(225) Based on adult literature review, baclofen may be useful for treatment of GERD patients, but should not be regarded as firstchoice therapy largely because of the potential side effects seen in adult studies.(229)

- Safety of baclofen: Side effects such as dyspeptic symptoms, drowsiness, dizziness, fatigue, and lowered threshold for seizures have been reported in adults, but not in children possibly due to the limited number of treated children. Such side-effects preclude its routine use.

In conclusion, it is uncertain if the use of baclofen for the reduction of signs and symptoms in infants and children with GERD leads to side-effects compared with placebo.

\section{Recommendation}

5.10 Based on expert opinion, the working group suggests that baclofen can be considered prior to surgery in children in whom other pharmacological treatments have failed.

VOTING: $6,6,6,6,7,7,7,8,8,8$. (weak recommendation)

\section{Domperidone and metoclopramide}

Domperidone vs placebo: The search identified two studies comparing domperidone and placebo. $(230,231)$ De Loore et al. investigated infants and children with a clinical diagnosis of GER, defined by the presence of vomiting after a meal (230), while Carroccio et al. evaluated symptomatic infants and children with GERD confirmed by pH-metry.(231) Based upon the results of De Loore et al. in which 47 infants and children were randomized to a two-week double-blind trial comparing domperidone, metoclopramide or placebo, domperidone led to significant improvement in the percentage of patients vomiting at the end of the treatment period compared with placebo $(\mathrm{p}<0.001)$. Carroccio et al., randomized patients to domperidone alone, domperidone with 2 different antacids or placebo and found that domperidone, when paired with antacids, reduced GERD symptoms (though not assessed as required to be included for analysis as an outcome measure in the current guideline) as well as pH-metry variables compared with placebo.(230) Both studies reported no side-effects. Quality of evidence was very low. $(230,231)$

In conclusion, it is uncertain whether the use of domperidone reduces visible regurgitation/vomiting as signs and symptoms in infants and children with GER compared with placebo. It is uncertain whether the use of domperidone for the reduction of signs and symptoms in infants and children with GER(D) leads to more side-effects compared with placebo.

Metoclopramide vs placebo-The search identified three studies on the use of metoclopramide versus placebo. Two were conducted in infants with $\mathrm{pH}$-metry-confirmed 
GERD $(232,233)$, and one was done in both infants and children with a clinical diagnosis of GERD.(230) One of these studies was conducted in a cross-over design, and two were randomized controlled trials. $(230,232,233)$ De Loore et al., reported a two-week doubleblind trial comparing domperidone, metoclopramide and placebo, and found significant improvement in the percentage of patients vomiting in those receiving metoclopramide compared with placebo $(\mathrm{p}<0.001)$, however no raw data were provided. The quality of evidence was very low.(230) Though not included as a predefined outcome measure in the present guideline, neither the study by Tolia et al. nor the study by De Loore et al. found significant improvement based on $\mathrm{pH}$-metry parameters $(230,232)$ No significant adverse events were reported during the study period. $(230,232)$

In conclusion, it is uncertain whether the use of metoclopramide improves visible regurgitation/vomiting as signs and symptoms in infants and children with GER. It is uncertain whether the use of metoclopramide for the reduction of signs and symptoms in infants and children with GER(D) leads to more side-effects compared with placebo.

Domperidone vs metoclopramide-The search yielded one study comparing domperidone and metoclopramide in infants and children with a clinical diagnosis of GER defined by pronounced vomiting after meals.(230) De Loore, et al, found significant improvement in the percentage of patients vomiting at the end of treatment in the group treated with domperidone compared with metoclopramide $(\mathrm{p}<0.05)$, however no raw data were provided. Quality of evidence was very low. No side effects were reported during the study period.(230)

In conclusion, it is uncertain whether the use of domperidone reduces visible regurgitation/vomiting as signs and symptoms in infants and children with GER compared with metoclopramide. It is uncertain whether the use of domperidone for the reduction of signs and symptoms in infants and children with GER leads to more sideeffects compared with metoclopramide.

- Safety of domperidone and metoclopramide: Domperidone and metoclopramide are antidopaminergic agents that facilitate gastric emptying. Over the last 5 years, one metaanalysis has been completed on the safety of metoclopramide that reviewed 108 (57 prospective) studies.(234) The most common adverse effects were extrapyramidal symptoms (9\%; 95\% CI 5-17\%), diarrhea (6\%; 95\% CI 4-9\%), and sedation (multiple-dose studies: 6\%; 95\% CI 3-12). Dysrhythmia, respiratory distress/arrest, neuroleptic malignant syndrome, and tardive dyskinesia were rarely associated with metoclopramide use. Its therapeutic dosage is very close to the toxic dosage resulting in a very narrow safe dosing range. In some countries, regulatory agencies have removed it from the market because of its side effects and in 2013, the European Medicines Agency released a statement that the risk of neurological adverse for metoclopramide outweighed the benefit when taken for a prolonged amount of time at a high dose. A similar warning was made by the Food and Drug Administration in 2009, and Health Canada issued a statement in 2015 declaring that metoclopramide is contraindicated in infants $<1$ year of age due to its side-effects. As with metoclopramide, the side effect concerns relative to medication efficacy with domperidone are significant. The most concerning and significant adverse event related to its use is 
prolongation of the QTc interval, an event that has been reported in 1 out of 5 pediatric studies although there are conflicting results among studies and heterogeneity among study populations.(235) Domperidone also has been associated with extrapyramidal central nervous system side effects, which preclude its routine use.(212, 236-239) In 2014, the Medicine and Healthcare products Regulatory Authority (MHRA) released a statement that there was a small risk of adverse cardiac events (specifically serious ventricular arrhythmia and sudden cardiac death) with the use of domperidone. Domperidone is not available in the United States and Health Canada has issued a warning related to its use in 2012 because of the risk of sudden death. The working group was therefore concerned that these agents should only be considered for use following specialist advice and as a last-line therapy. Insufficient evidence of clinical efficacy exists to justify routine use of either metoclopramide or domperidone for GERD, and these agents should thus not be regarded as an initial treatment for GERD in infants and children.

\section{Recommendation}

5.11 The working group suggests not to use domperidone in the treatment of GERD in infants and children.

\section{VOTING: 6, 7, 8, 8, 8, 9, 9, 9,9,9. (weak recommendation)}

5.12 The working group suggests not to use metoclopramide in the treatment of GERD in infants and children.

VOTING: 8, 8, 9, 9, 9, 9, 9, 9, 9, 9. (weak recommendation)

\section{Other prokinetics (i.e. erythromycin, cisapride and bethanechol)}

Cisapride-Cisapride is a mixed serotonergic agent that facilitates the release of acetylcholine at synapses in the myenteric plexus, thereby increasing gastric emptying and improving esophageal and intestinal peristalsis. It was withdrawn from the market of most countries more than 10 years ago, after it was found to produce prolongation of the QTc interval, increasing the risk of sudden death.(1) Thereafter, its use has been restricted to heavily regulated, limited-access programs supervised by a pediatric gastroenterologist and to patients in clinical trials, safety studies, or registries.(1) The treatment principles for GERD are not different, and it was for these reasons that the working group decided (though several RCTs on the efficacy of cisapride in pediatrics exist to remove cisapride from the available treatment options for GERD.(240-245)

Erythromycin or bethanechol-The search did not identify any studies fulfilling our inclusion criteria. However, one randomized controlled trial of erythromycin $(5 \mathrm{mg} / \mathrm{kg}$ every 8 hours) versus placebo met inclusion criteria for the treatment of feeding intolerance, using improvement in reflux burden measured by $\mathrm{pH}$-metry and improvement of GERD symptoms as secondary outcomes. In this study, erythromycin and placebo both improved pH-metry parameters, time to full enteral feeds and GERD symptoms equally.(246) Subsequent placebo controlled randomized trials in infants using higher dose erythromycin (4-12.5 $\mathrm{mg} / \mathrm{kg} / \mathrm{dose}$ TID-QID) showed improvement in time to full enteral feedings and/or weight 
gain, although reflux endpoints were not assessed.(247-249) While good evidence shows that erythromycin may improve feeding tolerance in infants, no evidence supports the benefit of erythromycin for treatment of GERD.

- Other considerations: Bethanechol, a direct cholinergic agonist, is not approved by the FDA for use in children, has been studied in a few trials in pediatric GERD, has uncertain efficacy, and carries a high potential of side effects. $(250,251)$ Erythromycin and azithromycin, motilin agonists not approved by the FDA for treatment of GERD, are sometimes used in patients with gastroparesis to accelerate gastric emptying. Patients with aerodigestive disorders may derive some benefit due to its anti-inflammatory properties for the lung, although bethanechol is not approved by the FDA for use in children.(1) In a single randomized controlled crossover study of azithromycin in adults undergoing pH-MII testing, no reduction was reported in the total number of reflux events measured by pH-MII, but reduction was observed in the percentage of time $\mathrm{pH}$ was <4.(252) Although its role in the therapy of GER and GERD has not been investigated, erythromycin is in widespread use in the NHS and in the United States as a prokinetic.(3)

In conclusion, there is no evidence to support the use of bethanechol or erythromycin for the treatment of GERD in infants and children.

\section{Recommendation}

5.13 Based on expert opinion, the working group suggests not to use any other prokinetics (i.e. erythromycin, betanechol) as first line treatment in infants and children with GERD.

VOTING: 8, 8, 8, 8, 9, 9, 9, 9, 9, 9 (weak recommendation)

\section{Question 6: Which infants and children would benefit from surgical treatment (i.e. fundoplication) after (non)-pharmacological treatment and what are the efficacies of these surgical therapies?}

\section{Fundoplication}

The search did not identify any RCTs meeting our inclusion criteria concerning surgical treatment of infants and children with GERD refractory to non-pharmacological and pharmacological treatment. (See Appendix A for summary of search strategy, results and study selection). Only comparative studies (2 RCTs $(253,254)$ and one observational study(255)) were identified. This question is thus answered based on expert opinion and earlier published guidelines and literature relevant to the research question with a recognition of the publication bias often found in the surgical literature. $(1,3)$

- Other considerations when considering fundoplication-Antireflux surgery is usually undertaken after other options have failed or as an option to manage GERD-related complications.(1) Fundoplication decreases reflux by increasing the LES baseline pressure, decreasing the number of TLESRs and the nadir pressure during swallow induced 
relaxation, increasing the length of the intra-abdominal esophagus, accentuating the angle of His and reducing a hiatal hernia if present. Different antireflux surgical approaches exist. Laparoscopic Nissen fundoplication is considered the gold standard for surgical treatment of severe GERD and has largely replaced open Nissen fundoplication as the preferred antireflux surgery due to its decreased morbidity, shorter hospital stay, and fewer perioperative problems.(256) Robot-assisted Nissen fundoplication represents a safe alternative to conventional laparoscopic surgery in children, but does not provide any substantial clinical advantage.(257)

Most of the literature on surgical therapy in children with GERD consists of retrospective case series in which documentation of the diagnosis of GERD and details of previous medical therapy are lacking. This makes it difficult to assess the indications for and responses to surgery. Moreover, children with underlying conditions predisposing to the most severe forms of GERD comprise a large percentage of many surgical series. In general, outcomes of antireflux surgery have been more carefully evaluated in adults than in children. In adults, laparoscopic fundoplication is associated with approximately $95 \%$ patient satisfaction and improved quality of life in patients with chronic GERD. According to the guidelines written by the Society of American Gastrointestinal and Endoscopic Surgeons (SAGES), surgical procedures for GERD are curative in $85 \%-93 \%$ of cases. $(258,259)$ A systematic review of adult literature found that antireflux surgery may be superior in preventing esophageal adenocarcinoma compared with medical therapy in patients with Barrett's esophagus.(260) Failure rates of fundoplication in adults range from $3-16 \%$, however between $37 \%$ and $62 \%$ of patients are taking PPI a few years after the intervention. $(256,261,262)$ Postoperative dysphagia, though often resolving over time, is the most commonly reported complication reported in adult and pediatric literature.(263-265) In a large cohort analysis from the National Surgical Quality Improvement Program (NSQIP) database, surgical mortality was less than $0.05 \%$ in patients younger than 70 years of age. (266)

Based on a systematic review of pediatric literature, antireflux surgery in children shows a good overall success rate (median 86\%) in terms of complete relief of typical GERD symptoms.(267) In a recent survival analysis, 5-year survival post-fundoplication ranged from $59 \%$ up to almost $100 \%$, with the lowest survival in the children with neurologic compromise.(268) Based upon a prospective, multicenter study in 25 children (age 2-18 years) with therapy-resistant GERD, laparoscopic antireflux surgery reduced reflux symptoms, total acid exposure time and number of (weakly) acidic reflux episodes. However, persisting/recurrent reflux symptoms were reported in 3/25 patients and new-onset dysphagia also developed in 3 patients.(269) Outcome of surgery does not seem to be influenced by surgical technique, although postoperative dysphagia seems to occur less frequently after partial fundoplication.(267) In a retrospective review of 823 children (age < 18 years) who underwent Nissen fundoplication, the incidence of redo fundoplication was $12.2 \%$. This risk increased with hiatal dissection, retching, and younger age at initial surgery.(270) Another series of 2008 fundoplications in children (age range $5-19$ years) reported wrap failure rates of $4.6 \%$ after initial surgery and $6.8 \%$ after redo surgery.(256) Antireflux surgery has the poorest success rate in the treatment of extraesophageal symptoms including aspiration pneumonia. In the population of children with 
extraesophageal symptoms, multiple studies have failed to show consistent benefit, including no reduction of mechanical ventilation, pneumonias or asthma.(271-274) Furthermore, pediatric data report no significant reduction in the use of acid suppression medication after fundoplication, with more than $75 \%$ of patients taking medication 1 year after surgery.(274)

Antireflux surgery may be of benefit in children with confirmed GERD who have failed or are significantly non-adherent to optimal medical therapy or who have life-threatening complications of proven GERD. Before surgery, it is essential to rule out non-GERD causes of symptoms and ensure that the diagnosis of chronic-relapsing GERD is firmly established. It is important to provide families with appropriate education and a realistic understanding of the potential complications of surgery, including symptom recurrence (Question 4).(1) In all cases, the risks of surgery need to be weighed against the potential benefit and patient selection is critical; only patients with clearly proven GERD should be considered for surgery. Risks from fundoplication including gas-bloat, early satiety/pain, dysphagia, retching, dumping syndrome, worsening aspiration risk from esophageal stasis, and wrap slipping/unwrapping resulting in the need for reoperation. In all cases, the risks and benefits of surgical intervention should be weighed against those of medications and/or post-pyloric feeds.

\section{Recommendations}

6.1 Based on expert opinion, the working group suggests antireflux surgery, including fundoplication, can be considered in infants and children with GERD and:

- $\quad$ life threatening complications (e.g. cardiorespiratory failure) of GERD after failure of optimal medical treatment

- $\quad$ symptoms refractory to optimal therapy (question 4, 5, 6), after appropriate evaluation to exclude other underlying diseases

- $\quad$ chronic conditions (i.e. neurologically impaired, cystic fibrosis) with a significant risk of GERD-related complications

- the need for chronic pharmacotherapy for control of signs and/or symptoms of GERD.

VOTING: 5, 7, 7, 7, 8, 9, 9, 9, 9, 9. (weak recommendation)

\section{Other surgical interventions for the treatment of refractory GERD}

The search did not identify any RCTs meeting our inclusion criteria concerning infants and children with GERD, refractory to non-pharmacological and pharmacological treatment, investigating the efficacy of new treatment options not already discussed elsewhere in the guidelines compared with no treatment or any other pharmacological treatment (See Appendix A for summary of search strategy, results and study selection). This question is thus answered based on expert opinions and earlier published guidelines and literature relevant to the research question. $(1,3)$ 
Total esophagogastric disconnection-Total esophagogastric disconnection (TED, Bianchi procedure) is an alternative surgical procedure in resistant GERD. It was first described in 1997 by Bianchi as a new surgical procedure to treat severe GERD in children with neurological impairment, but has also been proposed in other conditions, such as esophageal atresia, tracheoesophageal fistula, or caustic esophageal lesions.

This procedure permanently eliminates GERD by transecting the esophagus from the stomach and creating an esophagojejunal anastomosis. The biliopancreatic limb is then anastomosed to the jejunal loop approximately $30 \mathrm{~cm}$ distal to the esophagojejunal anastomosis to drain the gastric contents. Gastric feedings may still be utilized via a gastrostomy tube in the remnant stomach without the risk of reflux.

In a non-randomized prospective comparative study, Gatti, et al, reported on 12 neurologically impaired children who underwent fundoplication with gastrostomy and 14 who underwent TED. The latter group showed a significant benefit for growth, respiratory infections, hospital stay, feeding time, and quality of life.(275) In another retrospective study of 20 neurologically impaired children, TED was as beneficial as Nissen fundoplication for controlling GERD, but with a lower failure rate.(276) As esophagogastric disconnection was considered a safe definitive solution for GERD, because it eliminates the risk of recurrent reflux, some authors have recommended its use as a primary treatment of choice for severely neurologically impaired patients who are experiencing GERD and are completely dependent on tube feeds.(277) A recent systematic review of 181 cases of TED (117 primary operations and 64 rescue procedures) reported $16.0 \%$ early complications and $15.5 \%$ late complications including 3.3\% deaths related to the procedure and $11.6 \%$ requiring re-operation.(278) In a recent retrospective long term study comparing TED and fundoplication in neurologically impaired children, Lansdale, et al, showed that TED was effective in controlling GERD. However, TED was more likely to require intensive care, and operative time, length of stay and time to full feeds were all longer.(279) In addition, long term complications have been recently reported, including stenosis of the esophagojejunal anastomosis up to 9 years after TED, requiring repeated dilations, and Barrett esophagus 8 to 9 years after TED.(280) Nutritional and metabolic complications including dumping syndrome and chronic digestive malabsorption (i.e. Vitamin B12) are frequent after TED, requiring prolonged enteral nutrition.(281)

In conclusion, no evidence supports total esophagogastric disconnection in infants and children with GERD refractory to pharmacological treatment.

\section{Recommendations}

6.2 Based on expert opinion, the working group recommends not to use total esophagogastric disconnection as a first line surgical treatment in infants and children with GERD refractory to optimal treatment.

VOTING: 8, 8, 9, 9, 9, 9, 9, 9, 9, 9. (strong recommendation)

6.3 Based on expert opinion, the working group suggests the use of total esophagogastric disconnection can be considered as a rescue procedure for neurologically impaired children with a failed fundoplication. 
Transpyloric/jejunal feeding-Transpyloric/jejunal feeding outcomes have been studied in two groups: patients with extraesophageal reflux complications (aspiration pneumonia, apnea and bradycardia) and infants with growth concerns. For treatment of extraesophageal reflux, large database studies in children suggest that rates of GERD complications (aspiration pneumonia) in children with neurologic disability are comparable between patients who received fundoplication and those receiving transpyloric feedings.(271, 282) Interestingly, in these studies, the patients with transpyloric feeding actually had higher rates of comorbidities despite similar outcomes suggesting that transpyloric feeding has equivalent efficacy to fundoplication even in children with significant comorbidities. The strength of these studies lies in their large numbers and their well-defined outcomes. One of the limitations to these studies (and studies of fundoplication as well) is patient comorbidities that may bias the outcomes. For example, children with neurologic compromise frequently have oropharyngeal dysphagia with resultant aspiration. Because transpyloric feeding (or fundoplication) has no impact on swallowing function, aspiration pneumonias may persist because of the contribution of swallowing dysfunction independently of reflux burden. Therefore, the impact of transpyloric feeding alone is impossible to assess and any beneficial effects may be negated by the severity of swallowing dysfunction.

Transpyloric feedings are also used in the neonatal population. Studies of neonates with apnea and bradycardia suggest that transpyloric feeding may have some benefit in the reduction of the rates of both apnea and bradycardia in the post-transpyloric feeding compared with pre-transpyloric feeding period within a given infant.(283, 284) Several older RCTs of gastric versus transpyloric feeds in infants failed to show any benefit in growth or pneumonia. $(285,286)$

No studies compare reflux burden within patients when they are fed into the stomach compared with when they are then fed into the small intestine to determine the reflux benefit of transpyloric feeds within individual patients. However, in studies using pH-MII in children receiving transpyloric feeding, rates of reflux (mean $22.6 \pm 21.5$ per 24 hours) are comparable or lower than previously reported numbers of reflux in children who underwent fundoplication (median 66 (18-87) per 24 hours). $(78,287)$

The enthusiasm with transpyloric feeding is tempered by the high complication rates related to tube placement and malfunction. Studies report high rates of complication including clogging (29\%), dislodgement (66\%), intussusception (20\%), and perforation (2-3\%).(288, 289)

In conclusion, no evidence supports transpyloric/jejunal feeding in infants and children with GERD refractory to pharmacological treatment. 


\section{Recommendation}

6.4 Based on expert opinion, the working group suggests that the use of transpyloric/ jejunal feedings can be considered in the treatment of infants and children with GERD refractory to optimal treatment as an alternative of fundoplication.

VOTING: 5, 6, 7, 8, 8, 8, 8, 9, 9, 9. (weak recommendation)

Radiofrequency ablation-Despite the efficacy of fundoplication for the treatment of GERD refractory to medical treatment, there has been an interest in trying to develop less invasive and equally effective, endoscopic treatments for GERD. Stretta, a form of radiofrequency ablation of the lower esophageal sphincter (LES) represents one of the options available for this purpose. Stretta has returned to the market in 2010 after a four-year hiatus when its original company filed for bankruptcy.

The Stretta procedure was initially considered by the Society of American Gastrointestinal and Endoscopic Surgeons (SAGES) an effective procedure for the management of GERD and an acceptable modality in patients who had declined a fundoplication.(290) A more recent meta-analysis concluded that compared with sham therapy the use of Stretta in adults with GERD does not produce significant changes in physiologic parameters, including reflux events, quality of life and reflux medication discontinuation.(51) Much like a previous report from the American College of Gastroenterology, it concluded that "The usage of current endoscopy therapy or transoral incisionless fundoplication cannot be recommended as an alternative to medical or traditional surgical therapy.(291) No RCTs have been reported in children on the use of Stretta for GERD. Two published case series from the same group of investigators were completed in children.(291,292) A small group of children ( 6 and 8 respectively) received the procedure, and most children seemed to benefit symptomatically from the Stretta after a follow-up ranging between 6 and 15 months. The group of patients was very heterogeneous, with several of them having already having undergone fundoplication; some post-operative complications (aspiration, gastric dilation) were reported. No pH-metric or endoscopic follow-up was performed.

In conclusion, no evidence supports radiofrequency ablation in infants and children with GERD refractory to pharmacological treatment.

\section{Recommendation}

6.5 Based on expert opinion, the working group recommends not to use radiofrequency ablation in infants and children with GERD refractory to optimal treatment.

VOTING: 8, 8, 8, 8, 8, 9, 9, 9, 9, 9. (strong recommendation)

\section{Endoscopic full thickness plication}

Endoluminal endoscopic gastroplication has been described in children as an alternative to surgical fundoplication. Currently, use of this treatment is precluded in infants and toddlers by size of the equipment. A recent review of the adult literature shows an overall patient 
satisfaction of $72 \%$ with an overall PPI discontinuation rate of $67 \%$ across all studies, with a mean follow-up of 8.3 months. $\mathrm{pH}$-metry parameters were not consistently normalized. The major complication rate was $3.2 \%$, and the failure rate was $7.2 \%$ across all studies.(293) No RCTs using this technique were found in the pediatric literature. Two published case series describe the use of this technique in children with GERD. Both reports were from the same group of investigators and described the same group of 17 patients (age range 6 to 15 years) with GERD refractory to or dependent on medical therapy. After endoluminal gastroplication, all patients except one had been able to discontinue medications for reflux but three had recurrent symptoms requiring a repeat procedure 2 to 24 months postoperatively.(294)Three years after surgery, 9 patients (56\%) were still off antireflux medication.(295)

In conclusion, no evidence supports endoscopic full thickness plication in infants and children with GERD refractory to pharmacological treatment

\section{Recommendation}

6.6 Based on expert opinion, the working group suggests not to use endoscopic full thickness plication in children with GERD refractory to optimal treatment.

VOTING: $8,8,8,8,8,9,9,9,9,9$. (weak recommendation)

\section{Question 7: What is the prognosis of GERD in infants and children and what are prognostic factors?}

Four original studies were eligible for inclusion.(296-299) No additional studies were identified through bibliographic review of included studies or after checking reference lists of the ESPGHAN/NASPGHAN 2009 and NICE 2015 guidelines (See Appendix A for summary of search strategy, results and study selection). Characteristics of included studies can be found in Appendix B4. Two studies were conducted in a general pediatric department $(299,300)$, one study in a pediatric gastroenterology department (297) and one study in the primary care setting (298). Appendix C2 summarizes the risk of bias assessment (QUIPS tool) for the included studies. All studies scored high or moderate risk of bias in at least two of the six domains.

\section{The prognosis of GERD in infants and children}

Results of reported outcome measures of GERD related symptoms and complications are summarized in Appendix E. Three studies used a definition of esophagitis as an outcome measure.(296-298) In these three studies, none of the evaluated patients developed Barrett's esophagus at follow-up (12 months to > 5 years). In one UK database study by Ruigomez et al., 1242 children with newly diagnosed GERD based on the presence of symptoms were followed (mean follow up: $4 \pm 1.9$ years) and only 40 ultimately underwent endoscopy and had evidence of esophagitis.(298) Orenstein et al. prospectively followed 19 children who had histologic evidence of esophagitis to determine the natural history of untreated esophagitis. While 9 patients withdrew from the study or required medication intervention, 
10 infants followed for one year had persistent microscopic esophagitis despite complete symptom resolution (I-GERQ-R score < 7).(296) El-Serag el al. performed a study of adults (median age 20 years, SD: 4) who had GERD symptoms for over 15 years and found that, of the patients who underwent endoscopy, 21\% (3/14) had erosive esophagitis.(297) Of the studies reporting on long-term medication use in patients with esophagitis, 46-69\% of patients were taking long term acid suppression.(296, 297)

\section{Prognostic factors in infants and children with GERD}

Two studies analyzed a total of seven prognostic determinants in 18 associations with the occurrence of GERD symptoms and/or complications at follow-up. $(297,298)$ Results on prognostic factors are summarized in Appendix E. Age of onset of GERD symptoms < 5 years and the use of acid-suppression at time of initial diagnosis may result in less favorable outcome. Firm conclusions, however, are limited by the poor quality of the studies. No evidence exists showing an association between gender, ethnicity, and/or family history of GERD or number of visits to the primary care physician.

\section{Question 8: What is the appropriate evaluation of infants and children 0-18 years with GERD refractory to non-pharmacological and pharmacological treatment?}

As mentioned previously in questions 3 and 5, the working group recommends a 4-8 week empiric course of H2RAs or PPIs for the treatment of typical symptoms (i.e. heartburn, retrosternal or epigastric pain) in children with GERD (Algorithm 2). Treatment efficacy should be evaluated after $4-8$ weeks of therapy. When symptoms persist despite adequate medical treatment, providers should (re-)evaluate treatment compliance and differential diagnoses. Most frequently, failure of treatment will be due to one of these two causes. If compliance with optimal medical therapy for GERD (See Questions 4 and 5) is confirmed, careful attention should be given to the presence of alarm signs or symptoms that may suggest unrecognized differential diagnoses that mimic GERD.

Regardless of response, after $4-8$ weeks of optimal GERD therapy, it is recommended to try to wean the patient from therapy. If symptoms do not improve or recur, additional testing should be considered to determine etiology of symptoms. In certain situations, such as lack of access to pediatric gastroenterologist, PPI may be restarted and the patient referred for additional evaluation.

In this context, the evaluation may include investigations to confirm the persistence of GERD and/or evaluate its nature (e.g. NERD) and/or assess for the presence of differential diagnoses to explain the persisting symptom profile. An esophagogastroduodenoscopy with biopsies (if not performed within 6 months prior) and upper GI series (if not performed within 12 months before) should be performed to (re-)confirm anatomy and exclude other causes by histology of the biopsies. Other investigations such as esophageal manometry or gastric emptying, should be performed based on individual patient history (See Question 3 and Algorithms 1 (infants) and 2 (children)). 


\section{Recommendations}

8.1 Based on expert opinion, the working group recommends evaluation of treatment efficacy and exclusion of alternative causes of symptoms in infants and children not responding to $4-8$ weeks of optimal therapy for GERD.

\section{VOTING: 6, 7, 7, 8, 8, 8, 8, 9, 9, 9. (strong recommendation)}

8.2 Based on expert opinion, the working group recommends to refer infants and children with GERD to the pediatric gastroenterologist if:

- $\quad$ There are alarm signs or symptoms suggesting an underlying gastrointestinal disease (Table 3)

- $\quad$ Patients are refractory to optimal treatment (Question 1)

- $\quad$ Patients cannot be permanently weaned from pharmacological treatment within 6-12 months (additional evaluation should be considered after $4-8$ weeks of optimal GERD therapy if clinically indicated)

VOTING: $7,8,8,8,8,8,8,8,8,9,9$. (strong recommendation)

\section{SUMMARY OF THE DEFINITIONS}

\begin{tabular}{|c|c|}
\hline GER: & $\begin{array}{l}\text { the passage of gastric contents into the esophagus with or without regurgitation and } \\
\text { vomiting. }\end{array}$ \\
\hline GERD: & when GER leads to troublesome symptoms and/or complications. \\
\hline Refractory GERD: & GERD not responding to optimal treatment after eight weeks. \\
\hline Optimal Therapy: & $\begin{array}{l}\text { Maximum pharmacologic and/or non-pharmacologic therapy based on the region of } \\
\text { practice of the subspecialist }\end{array}$ \\
\hline Infants: & under 12 months \\
\hline Children: & 12 months to 18 years \\
\hline Regurgitation: & $\begin{array}{l}\text { the passage of refluxed contents into the pharynx, mouth or from The mouth. Other } \\
\text { terms such as 'spitting-up', 'posseting', and 'spilling' are considered equivalent to } \\
\text { regurgitation. }\end{array}$ \\
\hline Vomiting: & $\begin{array}{l}\text { a coordinated autonomic and voluntary motor response, causing forceful expulsion of } \\
\text { gastric contents through the mouth. }\end{array}$ \\
\hline Rumination: & $\begin{array}{l}\text { effortless regurgitation of recently ingested food into the mouth With subsequent } \\
\text { mastication and re-swallowing. }\end{array}$ \\
\hline Rumination syndrome: & $\begin{array}{l}\text { distinct clinical entity in which rumination follows in minutes after ingestion of a } \\
\text { meal, does not occur during sleep and does not respond to standard treatment for } \\
\text { gastro-esophageal reflux. In infant rumination syndrome, this involves repetitive } \\
\text { contractions of the abdominal wall muscles, diaphragm and tongue. }(301,302)\end{array}$ \\
\hline Reflux hypersensitivity: & $\begin{array}{l}\text { patients with esophageal symptoms (heartburn or chest pain) who lack evidence of } \\
\text { reflux on endoscopy or abnormal acid burden on reflux monitoring, but do have } \\
\text { evidence that reflux events trigger symptoms. }\end{array}$ \\
\hline Functional Heartburn: & $\begin{array}{l}\text { patients with esophageal symptoms (heartburn or chest pain) who lack evidence of } \\
\text { reflux on endoscopy or abnormal acid burden on reflux monitoring, and do not have } \\
\text { evidence that symptoms are triggered by reflux events. }\end{array}$ \\
\hline $\begin{array}{l}\text { Non-erosive reflux disease } \\
\text { (NERD): }\end{array}$ & $\begin{array}{l}\text { patients with esophageal symptoms who lack evidence of reflux on endoscopy but do } \\
\text { have and abnormal acid burden that may or may not trigger symptoms. }\end{array}$ \\
\hline
\end{tabular}




\section{SUMMARY OF THE RECOMMENDATIONS}

1. Definitions

1.1 We recommend using the following definitions for GER/GERD for all infants and children.

\begin{tabular}{ll}
\hline GER: & the passage of gastric contents into the esophagus with or without regurgitation and vomiting. \\
GERD: & when GER leads to troublesome symptoms and/or complications. \\
Refractory GERD: & GERD not responding to optimal treatment after eight weeks. \\
\hline
\end{tabular}

\section{Red flags}

2.1 We recommend to use Tables $1-3$ for symptoms and signs that may be associated with gastroesophageal reflux disease (GERD), for alarm symptoms and diagnostic clues to identify an alternative underlying disease which are responsible for the symptoms.

\section{Diagnostic interventions for GERD}

3.1 We suggest not to use barium contrast studies for the diagnosis of GERD in infants and children.

3.2 We suggest to use barium contrast studies to exclude anatomical abnormalities.

3.3 We suggest not to use ultrasonography for the diagnosis of GERD in infants and children.

3.4 We suggest to use ultrasonography to exclude anatomical abnormalities.

3.5 We suggest not to use esophago-gastro-duodenoscopy to diagnose GERD in infants and children.

3.6 We suggest to use esophago-gastro-duodenoscopy with biopsies to assess complications of GERD, in case an underlying mucosal disease is suspected and prior to escalation of therapy.

3.7 We suggest that salivary pepsin should not be used for the diagnosis of GERD in infants and children.

3.8 We suggest not to use currently available extraesophageal biomarkers for the diagnosis of GERD in infants and children.

3.9 We suggest not to use manometry for the diagnosis of GERD in infants and children.

3.10 We suggest to consider to use manometry when a motility disorder is suspected.

3.11 We suggest scintigraphy should not be used for the diagnosis of GERD in infants and children.

3.12 We suggest not to use transpyloric/jejunal feeding trials for the diagnosis of GERD in infants and children. 
3.13 We suggest not to use a trial of PPIs as a diagnostic test for GERD in infants.

3.14 We suggest a 4-8 week trial of PPIs for typical symptoms (heartburn, retrosternal or epigastric pain) in children as a diagnostic test for GERD (See Questions 5 and 8 for further therapeutic recommendations).

3.15 We suggest not to use a trial of PPIs as a diagnostic test for GERD in patients presenting with extraesophageal symptoms.

3.16 We suggest, when pH-MII is not available, to consider to use $\mathrm{pH}$-metry only to

1. Correlate persistent troublesome symptoms with acid gastroesophageal reflux events (See also under $\mathrm{pH}-\mathrm{MII}$ )

2. Clarify the role of acid reflux in the etiology of esophagitis and other signs and symptoms suggestive for GERD.

3. Determine the efficacy of acid suppression therapy.

3.17 We suggest to consider to use pH-MII testing only to

1. Correlate persistent troublesome symptoms with acid and non-acid gastroesophageal reflux events

2. Clarify the role of acid and non-acid reflux in the etiology of esophagitis and other signs and symptoms suggestive for GERD.

3. Determine the efficacy of acid suppression therapy.

4. Differentiate NERD, hypersensitive esophagus and functional heartburn in patients with normal endoscopy.

\section{Non-pharmacological treatment}

4.1 We suggest use thickened feedings for treating visible regurgitation/vomiting in infants with GERD (Algorithm 1).

4.2 We suggest to modify feeding volumes and frequency according to age and weight to avoid overfeeding in infants with GERD (Algorithm 1).

4.3 We suggest a 2-4 week trial of extensively hydrolyzed protein-based (or amino-acid based) formula in infants suspected of GERD after optimal nonpharmacological treatment has failed (Algorithm 1, or see ESPGHAN 2012 CMPA guidelines).(178)

4.4 We recommend not to use positional therapy (i.e. head elevation, lateral and prone positioning) to treat symptoms of GERD in sleeping infants.

4.5 We suggest to consider to use of head elevation or left lateral positioning to treat symptoms of GERD in children.

4.6 We suggest not to use massage therapy to treat infant GERD.

4.7 We suggest not to use currently available lifestyle interventions or complementary treatments such as prebiotics, probiotics, or herbal medications to treat GERD. 
4.8 We suggest to inform caregivers and children that excessive body weight is associated with an increased prevalence of GERD.

4.9 We recommend to provide patient/parental education and support as part of the treatment of GERD (Algorithm 1).

\section{Pharmacological treatment}

5.1 We suggest not to use antacids/alginates for chronic treatment of infants and children with GERD.

5.2 We recommend the use of PPIs as first-line treatment of reflux-related erosive esophagitis in infants and children with GERD (Algorithm 2).

5.3 We suggest to use H2RAs in the treatment of reflux related erosive esophagitis in infants and children if PPIs are not available or contra-indicated.

5.4 We recommend not to use H2RA or PPI for the treatment of crying/distress in otherwise healthy infants.

5.5 We recommend not to use H2RA or PPI for the treatment of visible regurgitation in otherwise healthy infants.

5.6 We recommend a $4-8$ week course of H2RAs or PPIs for treatment of typical symptoms (i.e. heartburn, retrosternal or epigastric pain) in children with GERD (Algorithm 2).

5.7 We suggest not to use H2RAs or PPIs in patients with extraesophageal symptoms (i.e. cough, wheezing, asthma), except in the presence of typical GERD symptoms and/or diagnostic testing suggestive of GERD.

5.8 We recommend evaluation of treatment efficacy and exclusion of alternative causes of symptoms in infants and children not responding to $4-8$ weeks of optimal medical therapy for GERD (Algorithm 2).

5.9 We recommend the regular assessment of the ongoing need of long-term acid suppression therapy in infants and children with GERD (Algorithm 2)

5.10 We suggest to consider the use of baclofen prior to surgery in children in whom other pharmacological treatments have failed.

5.11 We suggest not to use domperidone in the treatment of GERD in infants and children.

5.12 We suggest not to use metoclopramide in the treatment of GERD in infants and children.

5.13 We suggest not to use any other prokinetics (i.e. erythromycin, bethanechol) as a first line treatment in infants and children with GERD.

\section{Surgical treatment and new treatment options}

6.1 We suggest to consider antireflux surgery, including fundoplication, in infants and children with GERD and: 
- $\quad$ life threatening complications such as apneas or BRUE after failure of optimal medical treatment

- $\quad$ symptoms refractory to optimal therapy (Question 4, 5, 6), after appropriate evaluation to exclude other underlying diseases

- $\quad$ chronic conditions (i.e. neurologically impaired, cystic fibrosis) with a significant risk of GERD related complications

- the need for chronic pharmacotherapy for control of signs and/or symptoms of GERD.

6.2 We recommend not to use total esophagogastric disconnection as a first line surgical treatment in infants and children with GERD refractory to optimal treatment.

6.3 We suggest to consider to use total esophagogastric disconnection as a rescue procedure for neurologically impaired children with a failed fundoplication.

6.4 We suggest to consider the use of transpyloric/jejunal feedings in the treatment of infants and children with GERD refractory to optimal treatment as an alternative of fundoplication.

6.5 We recommend not to use radiofrequency ablation in infants and children with GERD refractory to optimal treatment.

6.6 We suggest not to use endoscopic full thickness plication in children with GERD refractory to optimal treatment.

\section{Evaluation of refractory GERD}

8.1 We recommend evaluation of treatment efficacy and exclusion of alternative causes of symptoms in infants and children not responding to $4-8$ weeks of optimal therapy for GERD.

8.2 We recommend referral of infants and children with GERD to the pediatric gastroenterologist if:

- $\quad$ There are alarm signs or symptoms suggesting an underlying gastrointestinal disease (Table 3)

- $\quad$ Patients are refractory to optimal treatment (Question 1)

- $\quad$ Patients cannot be permanently weaned from pharmacological treatment within 6 - 12 months (see 8: additional evaluation should be considered after $4-8$ weeks of optimal GERD therapy if clinically indicated)

\section{Supplementary Material}

Refer to Web version on PubMed Central for supplementary material. 


\section{Acknowledgments}

Funding Disclosure: Guideline development was financially supported by NASPGHAN and ESPGHAN. RR received funding though the NIH. This work was not through the Wellcome Trust; Howard Hughes Medical Institute (HHMI)

\section{References}

1. Vandenplas Y, Rudolph CD, Di Lorenzo C, et al. Pediatric gastroesophageal reflux clinical practice guidelines: joint recommendations of the North American Society for Pediatric Gastroenterology, Hepatology, and Nutrition (NASPGHAN) and the European Society for Pediatric Gastroenterology, Hepatology, and Nutrition (ESPGHAN). J Pediatr Gastroenterol Nutr. 2009; 49(4):498-547. [PubMed: 19745761]

2. Shekelle P, Woolf S, Grimshaw JM, et al. Developing clinical practice guidelines: reviewing, reporting, and publishing guidelines; updating guidelines; the emerging issues of enhancing guideline implementability and accounting for comorbid conditions in guideline development. Implement Sci. 2012; 7:62. [PubMed: 22762242]

3. Davies I, Burman-Roy S, Murphy MS. Gastro-oesophageal reflux disease in children: NICE guidance. Bmj. 2015; 350:g7703. [PubMed: 25591811]

4. Brouwers MC, Kho ME, Browman GP, et al. AGREE II: advancing guideline development, reporting, and evaluation in health care. Prev Med. 2010; 51(5):421-4. [PubMed: 20728466]

5. Guyatt GH, Oxman AD, Vist GE, et al. GRADE: an emerging consensus on rating quality of evidence and strength of recommendations. BMJ. 2008; 336(7650):924-6. [PubMed: 18436948]

6. Orenstein SR. Symptoms and reflux in infants: Infant Gastroesophageal Reflux Questionnaire Revised (I-GERQ-R)--utility for symptom tracking and diagnosis. Curr Gastroenterol Rep. 2010; 12(6):431-6. [PubMed: 20857238]

7. Whiting P, Rutjes AW, Reitsma JB, et al. The development of QUADAS: a tool for the quality assessment of studies of diagnostic accuracy included in systematic reviews. BMC Med Res Methodol. 2003; 3:25. [PubMed: 14606960]

8. Davis P, Hayden J, Springer J, et al. Prognostic factors for morbidity and mortality in elderly patients undergoing acute gastrointestinal surgery: a systematic review. Can J Surg. 2014; 57(2):E44-52. [PubMed: 24666459]

9. Hayden JA, Cote P, Bombardier C. Evaluation of the quality of prognosis studies in systematic reviews. Ann Intern Med. 2006; 144(6):427-37. [PubMed: 16549855]

10. Sherman PM, Hassall E, Fagundes-Neto U, et al. A global, evidence-based consensus on the definition of gastroesophageal reflux disease in the pediatric population. Arch Pediatr. 2010; 17(11):1586-93. [PubMed: 20943357]

11. Vakil N, van Zanten SV, Kahrilas P, et al. The Montreal definition and classification of gastroesophageal reflux disease: a global evidence-based consensus. Am J Gastroenterol. 2006; 101(8):1900-20. quiz 43. [PubMed: 16928254]

12. Martigne L, Delaage PH, Thomas-Delecourt F, et al. Prevalence and management of gastroesophageal reflux disease in children and adolescents: a nationwide cross-sectional observational study. Eur J Pediatr. 2012; 171(12):1767-73. [PubMed: 22903328]

13. Gupta SK, Hassall E, Chiu YL, et al. Presenting symptoms of nonerosive and erosive esophagitis in pediatric patients. Dig Dis Sci. 2006; 51(5):858-63. [PubMed: 16718535]

14. Gunasekaran TS, Dahlberg M, Ramesh P, et al. Prevalence and associated features of gastroesophageal reflux symptoms in a Caucasian-predominant adolescent school population. Dig Dis Sci. 2008; 53(9):2373-9. [PubMed: 18204971]

15. Stanford EA, Chambers CT, Craig KD. The role of developmental factors in predicting young children's use of a self-report scale for pain. Pain. 2006; 120(1-2):16-23. [PubMed: 16359800]

16. von Baeyer CL, Spagrud LJ. Systematic review of observational (behavioral) measures of pain for children and adolescents aged 3 to 18 years. Pain. 2007; 127(1-2):140-50. [PubMed: 16996689]

17. Krishnan U, Mousa H, Dall'Oglio L, et al. ESPGHAN-NASPGHAN Guidelines for the Evaluation and Treatment of Gastrointestinal and Nutritional Complications in Children With Esophageal 
Atresia-Tracheoesophageal Fistula. J Pediatr Gastroenterol Nutr. 2016; 63(5):550-70. [PubMed: 27579697]

18. Turck D, Braegger CP, Colombo C, et al. ESPEN-ESPGHAN-ECFS guidelines on nutrition care for infants, children, and adults with cystic fibrosis. Clin Nutr. 2016; 35(3):557-77. [PubMed: 27068495]

19. Romano C, van Wynckel M, Hulst J, et al. European Society for Paediatric Gastroenterology, Hepatology and Nutrition Guidelines for the Evaluation and Treatment of Gastrointestinal and Nutritional Complications in Children With Neurological Impairment. J Pediatr Gastroenterol Nutr. 2017; 65(2):242-64. [PubMed: 28737572]

20. Tolia V, Vandenplas Y. Systematic review: the extra-oesophageal symptoms of gastro-oesophageal reflux disease in children. Aliment Pharmacol Ther. 2009; 29(3):258-72. [PubMed: 19143046]

21. Sherman PM, Hassall E, Fagundes-Neto U, et al. A global, evidence-based consensus on the definition of gastroesophageal reflux disease in the pediatric population. Am J Gastroenterol. 2009; 104(5):1278-95. quiz 96. [PubMed: 19352345]

22. Gaffney KF. Infant exposure to environmental tobacco smoke. J Nurs Scholarsh. 2001; 33(4):3437. [PubMed: 11775304]

23. Orenstein SR, McGowan JD. Efficacy of conservative therapy as taught in the primary care setting for symptoms suggesting infant gastroesophageal reflux. J Pediatr. 2008; 152(3):310-4. [PubMed: 18280832]

24. Hegar B, Dewanti NR, Kadim M, et al. Natural evolution of regurgitation in healthy infants. Acta Paediatr. 2009; 98(7):1189-93. [PubMed: 19397533]

25. van der Pol RJ, Smits MJ, Venmans L, et al. Diagnostic accuracy of tests in pediatric gastroesophageal reflux disease. J Pediatr. 2013; 162(5):983-7. e1-4. [PubMed: 23219449]

26. Farhath S, He Z, Saslow J, et al. Detection of pepsin in mouth swab: correlation with clinical gastroesophageal reflux in preterm infants. J Matern Fetal Neonatal Med. 2013; 26(8):819-24. [PubMed: 23311720]

27. Patra S, Singh V, Chandra J, et al. Diagnostic modalities for gastro-esophageal reflux in infantile wheezers. J Trop Pediatr. 2011; 57(2):99-103. [PubMed: 20595328]

28. Arasu TS, Wyllie R, Fitzgerald JF, et al. Gastroesophageal reflux in infants and children comparative accuracy of diagnostic methods. J Pediatr. 1980; 96(5):798-803. [PubMed: 7365577]

29. Boix-Ochoa J, Lafuenta JM, Gil-Vernet JM. Twenty-four hour exophageal pH monitoring in gastroesophageal reflux. J Pediatr Surg. 1980; 15(1):74-8. [PubMed: 7365661]

30. Cucchiara S, Minella R, Iervolino C, et al. Omeprazole and high dose ranitidine in the treatment of refractory reflux oesophagitis. Arch Dis Child. 1993; 69(6):655-9. [PubMed: 8285777]

31. Cucchiara S, Staiano A, Gobio Casali L, et al. Value of the 24 hour intraoesophageal $\mathrm{pH}$ monitoring in children. Gut. 1990; 31(2):129-33. [PubMed: 2311969]

32. Da Dalt L, Mazzoleni S, Montini G, et al. Diagnostic accuracy of $\mathrm{pH}$ monitoring in gastrooesophageal reflux. Arch Dis Child. 1989; 64(10):1421-6. [PubMed: 2684030]

33. Ravelli AM, Villanacci V, Ruzzenenti N, et al. Dilated intercellular spaces: a major morphological feature of esophagitis. J Pediatr Gastroenterol Nutr. 2006; 42(5):510-5. [PubMed: 16707972]

34. Kahn A, Rebuffat E, Sottiaux M, et al. Sleep apneas and acid esophageal reflux in control infants and in infants with an apparent life-threatening event. Biol Neonate. 1990; 57(3-4):144-9. [PubMed: 2322598]

35. Dalla Vecchia LK, Grosfeld JL, West KW, et al. Reoperation after Nissen fundoplication in children with gastroesophageal reflux: experience with 130 patients. Ann Surg. 1997; 226(3):31521. discussion 21-3. [PubMed: 9339938]

36. Schneider A, Gottrand F, Sfeir R, et al. Postoperative lower esophageal dilation in children following the performance of Nissen fundoplication. Eur J Pediatr Surg. 2012; 22(5):399-403. [PubMed: 22773348]

37. Duncan DR, Amirault J, Mitchell P, et al. Oropharyngeal Dysphagia is Strongly Correlated With Apparent Life-Threatening Events. J Pediatr Gastroenterol Nutr. 2016

38. Weir KA, McMahon S, Taylor S, et al. Oropharyngeal aspiration and silent aspiration in children. Chest. 2011; 140(3):589-97. [PubMed: 21436244] 
39. Weir K, McMahon S, Barry L, et al. Clinical signs and symptoms of oropharyngeal aspiration and dysphagia in children. Eur Respir J. 2009; 33(3):604-11. [PubMed: 19010985]

40. Westra SJ, Wolf BH, Staalman CR. Ultrasound diagnosis of gastroesophageal reflux and hiatal hernia in infants and young children. J Clin Ultrasound. 1990; 18(6):477-85. [PubMed: 2162855]

41. Jang HS, Lee JS, Lim GY, et al. Correlation of color Doppler sonographic findings with $\mathrm{pH}$ measurements in gastroesophageal reflux in children. J Clin Ultrasound. 2001; 29(4):212-7. [PubMed: 11323775]

42. Cucchiara S, Minella R, D'Armiento F, et al. Histologic grading of reflux oesophagitis and its relationship with intra-oesophageal and intragastric $\mathrm{pH}$ variables. European Journal of Gastroenterology \& Hepatology. 1993; 5(8):621-26.

43. Winter HS, Madara JL, Stafford RJ, et al. Intraepithelial eosinophils: a new diagnostic criterion for reflux esophagitis. Gastroenterology. 1982; 83(4):818-23. [PubMed: 7106512]

44. Thakkar K, El-Serag HB, Mattek N, et al. Complications of pediatric EGD: a 4-year experience in PEDS-CORI. Gastrointest Endosc. 2007; 65(2):213-21. [PubMed: 17258979]

45. Samer Ammar M, Pfefferkorn MD, Croffie JM, et al. Complications after outpatient upper GI endoscopy in children: 30-day follow-up. Am J Gastroenterol. 2003; 98(7):1508-11. [PubMed: 12873571]

46. Friedt M, Welsch S. An update on pediatric endoscopy. Eur J Med Res. 2013; 18:24. [PubMed: 23885793]

47. Hill CA, Ramakrishna J, Fracchia MS, et al. Prevalence of eosinophilic esophagitis in children with refractory aerodigestive symptoms. JAMA Otolaryngol Head Neck Surg. 2013; 139(9):9036. [PubMed: 24051745]

48. Rosen R, Amirault J, Johnston N, et al. The utility of endoscopy and multichannel intraluminal impedance testing in children with cough and wheezing. Pediatr Pulmonol. 2014; 49(11):1090-6. [PubMed: 24178927]

49. Kubik M, Thottam P, Shaffer A, et al. The role of the otolaryngologist in the evaluation and diagnosis of eosinophilic esophagitis. Laryngoscope. 2017; 127(6):1459-64. [PubMed: 27900765]

50. Pouw RE, Bredenoord AJ. Mistakes in the use of PPIs and how to avoid them. UEG Education. 2017; 17:15-17.

51. Katz PO, Gerson LB, Vela MF. Guidelines for the diagnosis and management of gastroesophageal reflux disease. Am J Gastroenterol. 2013; 108(3):308-28. quiz 29. [PubMed: 23419381]

52. Dy F, Amirault J, Mitchell PD, et al. Salivary Pepsin Lacks Sensitivity as a Diagnostic Tool to Evaluate Extraesophageal Reflux Disease. J Pediatr. 2016; 177:53-8. [PubMed: 27453366]

53. Fortunato JE, D'Agostino RB Jr, Lively MO. Pepsin in saliva as a biomarker for oropharyngeal reflux compared with 24-hour esophageal impedance/pH monitoring in pediatric patients. Neurogastroenterol Motil. 2016

54. Rosen R, Johnston N, Hart K, et al. The presence of pepsin in the lung and its relationship to pathologic gastro-esophageal reflux. Neurogastroenterol Motil. 2012; 24(2):129-33. e84-5. [PubMed: 22141343]

55. Farrell S, McMaster C, Gibson D, et al. Pepsin in bronchoalveolar lavage fluid: a specific and sensitive method of diagnosing gastro-oesophageal reflux-related pulmonary aspiration. J Pediatr Surg. 2006; 41(2):289-93. [PubMed: 16481237]

56. Krishnan U, Mitchell JD, Messina I, et al. Assay of tracheal pepsin as a marker of reflux aspiration. J Pediatr Gastroenterol Nutr. 2002; 35(3):303-8. [PubMed: 12352517]

57. O'Reilly RC, He Z, Bloedon E, et al. The role of extraesophageal reflux in otitis media in infants and children. Laryngoscope. 2008; 118(7 Part 2 Suppl 116):1-9. [PubMed: 18594333]

58. Abdel-aziz MM, El-Fattah AM, Abdalla AF. Clinical evaluation of pepsin for laryngopharyngeal reflux in children with otitis media with effusion. Int J Pediatr Otorhinolaryngol. 2013; 77(10): 1765-70. [PubMed: 24011938]

59. Crapko M, Kerschner JE, Syring M, et al. Role of extra-esophageal reflux in chronic otitis media with effusion. Laryngoscope. 2007; 117(8):1419-23. [PubMed: 17585281]

60. Abd El-Fattah AM, Abdul Maksoud GA, Ramadan AS, et al. Pepsin assay: a marker for reflux in pediatric glue ear. Otolaryngol Head Neck Surg. 2007; 136(3):464-70. [PubMed: 17321879] 
61. Rosen R, Fritz J, Nurko A, et al. Lipid-laden macrophage index is not an indicator of gastroesophageal reflux-related respiratory disease in children. Pediatrics. 2008; 121(4):e879-84. [PubMed: 18362101]

62. Barrett MW, Myers JC, Watson DI, et al. Detection of bile reflux: in vivo validation of the Bilitec fibreoptic system. Dis Esophagus. 2000; 13(1):44-50. [PubMed: 11005331]

63. Vaezi MF, Lacamera RG, Richter JE. Validation studies of Bilitec 2000: an ambulatory duodenogastric reflux monitoring system. Am J Physiol. 1994; 267(6 Pt 1):G1050-7. [PubMed: 7810652]

64. Mattioli G, Sacco O, Repetto P, et al. Necessity for surgery in children with gastrooesophageal reflux and supraoesophageal symptoms. Eur J Pediatr Surg. 2004; 14(1):7-13. [PubMed: 15024672]

65. Loots C, van Herwaarden MY, Benninga MA, et al. Gastroesophageal reflux, esophageal function, gastric emptying, and the relationship to dysphagia before and after antireflux surgery in children. J Pediatr. 2013; 162(3):566-73.e2. [PubMed: 23102795]

66. Smits MJ, Loots CM, Benninga MA, et al. New insights in gastroesophageal reflux, esophageal function and gastric emptying in relation to dysphagia before and after anti-reflux surgery in children. Curr Gastroenterol Rep. 2013; 15(10):351. [PubMed: 24014120]

67. Tucker E, Knowles K, Wright J, et al. Rumination variations: aetiology and classification of abnormal behavioural responses to digestive symptoms based on high-resolution manometry studies. Aliment Pharmacol Ther. 2013; 37(2):263-74. [PubMed: 23173868]

68. Kessing BF, Bredenoord AJ, Smout AJ. Objective manometric criteria for the rumination syndrome. Am J Gastroenterol. 2014; 109(1):52-9. [PubMed: 24366235]

69. Rosen R, Rodriguez L, Nurko S. Pediatric rumination subtypes: A study using high-resolution esophageal manometry with impedance. Neurogastroenterol Motil. 2017; 29(5)

70. Singendonk MMJ, Oors JM, Bredenoord AJ, et al. Objectively diagnosing rumination syndrome in children using esophageal pH-impedance and manometry. Neurogastroenterol Motil. 2017; 29(5)

71. Grunder FR, Aspirot A, Faure C. High Resolution Esophageal Manometry Patterns in Children and Adolescents with Rumination Syndrome. J Pediatr Gastroenterol Nutr. 2017

72. Rosen R, Amirault J, Giligan E, et al. Intraesophageal pressure recording improves the detection of cough during multichannel intraluminal impedance testing in children. J Pediatr Gastroenterol Nutr. 2014; 58(1):22-6. [PubMed: 23942006]

73. Heyman S. Gastric emptying in children. J Nucl Med. 1998; 39(5):865-9. [PubMed: 9591590]

74. Rudd TG, Christie DL. Demonstration of gastroesophageal reflux in children by radionuclide gastroesophagography. Radiology. 1979; 131(2):483-6. [PubMed: 441340]

75. Vandenplas Y, Derde MP, Piepsz A. Evaluation of reflux episodes during simultaneous esophageal $\mathrm{pH}$ monitoring and gastroesophageal reflux scintigraphy in children. J Pediatr Gastroenterol Nutr. 1992; 14(3):256-60. [PubMed: 1619528]

76. Abell TL, Camilleri M, Donohoe K, et al. Consensus recommendations for gastric emptying scintigraphy: a joint report of the American Neurogastroenterology and Motility Society and the Society of Nuclear Medicine. J Nucl Med Technol. 2008; 36(1):44-54. [PubMed: 18287197]

77. Ravelli AM, Panarotto MB, Verdoni L, et al. Pulmonary aspiration shown by scintigraphy in gastroesophageal reflux-related respiratory disease. Chest. 2006; 130(5):1520-6. [PubMed: 17099032]

78. Rosen R, Hart K, Warlaumont M. Incidence of gastroesophageal reflux during transpyloric feeds. J Pediatr Gastroenterol Nutr. 2011; 52(5):532-5. [PubMed: 21464758]

79. Stone B, Hester G, Jackson D, et al. Effectiveness of Fundoplication or Gastrojejunal Feeding in Children With Neurologic Impairment. Hosp Pediatr. 2017; 7(3):140-48. [PubMed: 28159744]

80. van der Pol RJ, Smits MJ, van Wijk MP, et al. Efficacy of proton-pump inhibitors in children with gastroesophageal reflux disease: a systematic review. Pediatrics. 2011; 127(5):925-35. [PubMed: 21464183]

81. Haddad I, Kierkus J, Tron E, et al. Efficacy and safety of rabeprazole in children (1-11 years) with gastroesophageal reflux disease. J Pediatr Gastroenterol Nutr. 2013; 57(6):798-807. [PubMed: 23863328] 
82. Fiedorek S, Tolia V, Gold BD, et al. Efficacy and safety of lansoprazole in adolescents with symptomatic erosive and non-erosive gastroesophageal reflux disease. J Pediatr Gastroenterol Nutr. 2005; 40(3):319-27. [PubMed: 15735486]

83. Baker R, Tsou VM, Tung J, et al. Clinical results from a randomized, double-blind, dose-ranging study of pantoprazole in children aged 1 through 5 years with symptomatic histologic or erosive esophagitis. Clin Pediatr (Phila). 2010; 49(9):852-65. [PubMed: 20522615]

84. Tolia V, Ferry G, Gunasekaran T, et al. Efficacy of lansoprazole in the treatment of gastroesophageal reflux disease in children. J Pediatr Gastroenterol Nutr. 2002; 35(Suppl 4):S30818. [PubMed: 12607791]

85. Gilger MA, Tolia V, Vandenplas Y, et al. Safety and Tolerability of Esomeprazole in Children With Gastroesophageal Reflux Disease. J Pediatr Gastroenterol Nutr. 2015; 60(Suppl 1):S16-23.

86. Bautista J, Fullerton H, Briseno M, et al. The effect of an empirical trial of high-dose lansoprazole on symptom response of patients with non-cardiac chest pain--a randomized, double-blind, placebo-controlled, crossover trial. Aliment Pharmacol Ther. 2004; 19(10):1123-30. [PubMed: 15142202]

87. Fass R, Fennerty MB, Ofman JJ, et al. The clinical and economic value of a short course of omeprazole in patients with noncardiac chest pain. Gastroenterology. 1998; 115(1):42-9. [PubMed: 9649457]

88. Fass R, Murthy U, Hayden CW, et al. Omeprazole $40 \mathrm{mg}$ once a day is equally effective as lansoprazole $30 \mathrm{mg}$ twice a day in symptom control of patients with gastro-oesophageal reflux disease (GERD) who are resistant to conventional-dose lansoprazole therapy-a prospective, randomized, multi-centre study. Aliment Pharmacol Ther. 2000; 14(12):1595-603. [PubMed: 11121907]

89. Talley NJ, Armstrong D, Junghard O, et al. Predictors of treatment response in patients with nonerosive reflux disease. Aliment Pharmacol Ther. 2006; 24(2):371-6. [PubMed: 16842464]

90. Savarino E, Zentilin P, Savarino V. NERD: an umbrella term including heterogeneous subpopulations. Nat Rev Gastroenterol Hepatol. 2013; 10(6):371-80. [PubMed: 23528345]

91. Cheng FK, Albert DM, Maydonovitch CL, et al. Categorization of patients with reflux symptoms referred for $\mathrm{pH}$ and impedance testing while off therapy. Clin Gastroenterol Hepatol. 2015; 13(5): 867-73. [PubMed: 25445765]

92. Lang JE, Holbrook JT, Mougey EB, et al. Lansoprazole Is Associated with Worsening Asthma Control in Children with the CYP2C19 Poor Metabolizer Phenotype. Ann Am Thorac Soc. 2015; 12(6):878-85. [PubMed: 25844821]

93. Holbrook JT, Wise RA, Gold BD, et al. Lansoprazole for children with poorly controlled asthma: a randomized controlled trial. Jama. 2012; 307(4):373-81. [PubMed: 22274684]

94. Chang AB, Lasserson TJ, Gaffney J, et al. Gastro-oesophageal reflux treatment for prolonged nonspecific cough in children and adults. Cochrane Database Syst Rev. 2011; (1) Cd004823.

95. Patwari AK, Bajaj P, Kashyp R, et al. Diagnostic modalities for gastroesophageal reflux. Indian J Pediatr. 2002; 69(2):133-6. [PubMed: 11929028]

96. Vandenplas Y, Salvatore S, Devreker T, et al. Gastro-oesophageal reflux disease: oesophageal impedance versus pH monitoring. Acta Paediatr. 2007; 96(7):956-62. [PubMed: 17498193]

97. Chiou E, Rosen R, Jiang H, et al. Diagnosis of supra-esophageal gastric reflux: correlation of oropharyngeal $\mathrm{pH}$ with esophageal impedance monitoring for gastro-esophageal reflux. Neurogastroenterol Motil. 2011; 23(8):717-e326. [PubMed: 21592256]

98. Chiou E, Rosen R, Nurko S. Effect of different pH criteria on dual-sensor pH monitoring in the evaluation of supraesophageal gastric reflux in children. J Pediatr Gastroenterol Nutr. 2011; 52(4): 399-403. [PubMed: 21206381]

99. Salvatore S, Arrigo S, Luini C, et al. Esophageal impedance in children: symptom-based results. J Pediatr. 2010; 157(6):949-54.e1-2. [PubMed: 20828711]

100. Omari TI, Schwarzer A, vanWijk MP, et al. Optimisation of the reflux-symptom association statistics for use in infants being investigated by 24-hour $\mathrm{pH}$ impedance. J Pediatr Gastroenterol Nutr. 2011; 52(4):408-13. [PubMed: 21240018] 
101. Farahmand F, Sabbaghian M, Ghodousi S, et al. Gastroesophageal reflux disease and tooth erosion: a cross-sectional observational study. Gut Liver. 2013; 7(3):278-81. [PubMed: 23710307]

102. Ganesh M, Hertzberg A, Nurko S, et al. Acid Rather Than Nonacid Reflux Burden Is a Predictor of Tooth Erosion. J Pediatr Gastroenterol Nutr. 2016; 62(2):309-13. [PubMed: 26230904]

103. Krishnan U, Mousa H, Dall'Oglio L, et al. ESPGHAN-NASPGHAN Guidelines for the Evaluation and Treatment of Gastrointestinal and Nutritional Complications in Children with Esophageal Atresia- Tracheoesophageal Fistula. J Pediatr Gastroenterol Nutr. 2016

104. Papadopoulou A, Koletzko S, Heuschkel R, et al. Management guidelines of eosinophilic esophagitis in childhood. J Pediatr Gastroenterol Nutr. 2014; 58(1):107-18. [PubMed: 24378521]

105. Liacouras CA, Furuta GT, Hirano I, et al. Eosinophilic esophagitis: updated consensus recommendations for children and adults. J Allergy Clin Immunol. 2011; 128(1):3-20.e6. quiz 21-2. [PubMed: 21477849]

106. Palm K, Sawicki G, Rosen R. The impact of reflux burden on Pseudomonas positivity in children with cystic fibrosis. Pediatr Pulmonol. 2012; 47(6):582-7. [PubMed: 22162484]

107. Vandenplas Y, Hauser B. An updated review on gastro-esophageal reflux in pediatrics. Expert Rev Gastroenterol Hepatol. 2015; 9(12):1511-21. [PubMed: 26414355]

108. Croffie JM, Fitzgerald JF, Molleston JP, et al. Accuracy and tolerability of the Bravo catheter-free $\mathrm{pH}$ capsule in patients between the ages of 4 and 18 years. J Pediatr Gastroenterol Nutr. 2007; 45(5):559-63. [PubMed: 18030233]

109. Rao NM, Campbell DI, Rao P. Two years' experience of using the Bravo wireless oesophageal $\mathrm{pH}$ monitoring system at a single UK tertiary centre. Acta Paediatr. 2017; 106(2):312-15. [PubMed: 27862298]

110. Cabrera J, Davis M, Horn D, et al. Esophageal pH monitoring with the BRAVO capsule: experience in a single tertiary medical center. J Pediatr Gastroenterol Nutr. 2011; 53(4):404-8. [PubMed: 21519281]

111. Rodriguez L, Morley-Fletcher A, Souza A, et al. Effect of anesthesia on gastroesophageal reflux in children: a study using BRAVO wireless $\mathrm{pH}$ study measurements. Neurogastroenterol Motil. 2015; 27(11):1553-8. [PubMed: 26264213]

112. Chawla A, Girda E, Walker G, et al. Effect of Propofol on Acid Reflux Measured with the Bravo pH Monitoring System. ISRN Gastroenterol. 2013; 2013:605931. [PubMed: 23691337]

113. Ummarino D, Vandermeulen L, Roosens B, et al. Gastroesophageal reflux evaluation in patients affected by chronic cough: Restech versus multichannel intraluminal impedance/pH metry. Laryngoscope. 2013; 123(4):980-4. [PubMed: 23023943]

114. Mazzoleni G, Vailati C, Lisma DG, et al. Correlation between oropharyngeal pH-monitoring and esophageal $\mathrm{pH}$-impedance monitoring in patients with suspected GERD-related extra-esophageal symptoms. Neurogastroenterol Motil. 2014; 26(11):1557-64. [PubMed: 25208949]

115. Fitzpatrick AM, Holbrook JT, Wei CY, et al. Exhaled breath condensate pH does not discriminate asymptomatic gastroesophageal reflux or the response to lansoprazole treatment in children with poorly controlled asthma. J Allergy Clin Immunol Pract. 2014; 2(5):579-86.e7. [PubMed: 25213052]

116. Rosen R, Mitchell PD, Amirault J, et al. The Edematous and Erythematous Airway Does Not Denote Pathologic Gastroesophageal Reflux. J Pediatr. 2017; 183:127-31. [PubMed: 27979581]

117. Wenzl TG, Silny J, Schenke S, et al. Gastroesophageal reflux and respiratory phenomena in infants: status of the intraluminal impedance technique. J Pediatr Gastroenterol Nutr. 1999; 28(4): 423-8. [PubMed: 10204508]

118. Rosen R, Nurko S. The importance of multichannel intraluminal impedance in the evaluation of children with persistent respiratory symptoms. Am J Gastroenterol. 2004; 99(12):2452-8. [PubMed: 15571595]

119. Omari TI, Barnett CP, Benninga MA, et al. Mechanisms of gastro-oesophageal reflux in preterm and term infants with reflux disease. Gut. 2002; 51(4):475-9. [PubMed: 12235066]

120. Rosen R, Lord C, Nurko S. The sensitivity of multichannel intraluminal impedance and the $\mathrm{pH}$ probe in the evaluation of gastroesophageal reflux in children. Clin Gastroenterol Hepatol. 2006; 4(2):167-72. [PubMed: 16469676] 
121. Imam H, Shay S, Ali A, et al. Bolus transit patterns in healthy subjects: a study using simultaneous impedance monitoring, videoesophagram, and esophageal manometry. Am J Physiol Gastrointest Liver Physiol. 2005; 288(5):G1000-6. [PubMed: 15826930]

122. Peter CS, Wiechers C, Bohnhorst B, et al. Detection of small bolus volumes using multiple intraluminal impedance in preterm infants. J Pediatr Gastroenterol Nutr. 2003; 36(3):381-4. [PubMed: 12604979]

123. Rosen R, Lord C, Nurko S. The sensitivity of multi-channel intraluminal impedance (MII) compared to $\mathrm{pH}$ probe in the detection of gastroesophgeal reflux in children. Clinical Gastroenterology and Hepatology. 2006; 4(2):167-72. [PubMed: 16469676]

124. Francavilla R, Magista AM, Bucci N, et al. Comparison of esophageal pH and multichannel intraluminal impedance testing in pediatric patients with suspected gastroesophageal reflux. $\mathrm{J}$ Pediatr Gastroenterol Nutr. 2010; 50(2):154-60. [PubMed: 19680154]

125. Wenzl TG, Moroder C, Trachterna M, et al. Esophageal $\mathrm{pH}$ monitoring and impedance measurement: a comparison of two diagnostic tests for gastroesophageal reflux. J Pediatr Gastroenterol Nutr. 2002; 34(5):519-23. [PubMed: 12050578]

126. Rosen R, Furuta G, Fritz J, et al. Role of acid and nonacid reflux in children with eosinophilic esophagitis compared with patients with gastroesophageal reflux and control patients. J Pediatr Gastroenterol Nutr. 2008; 46(5):520-3. [PubMed: 18493206]

127. Mousa H, Machado R, Orsi M, et al. Combined multichannel intraluminal impedance-pH (MII$\mathrm{pH})$ : multicenter report of normal values from 117 children. Curr Gastroenterol Rep. 2014; 16(8): 400. [PubMed: 25064319]

128. Heard R, Castell J, Castell DO, et al. Characterization of patients with low baseline impedance on multichannel intraluminal impedance-pH reflux testing. J Clin Gastroenterol. 2012; 46(7):e55-7. [PubMed: 22476039]

129. Smits MJ, Loots CM, van Wijk MP, et al. An expert panel-based study on recognition of gastroesophageal reflux in difficult esophageal $\mathrm{pH}$-impedance tracings. Neurogastroenterol Motil. 2015; 27(5):637-45. [PubMed: 25756933]

130. Wenzl TG, Benninga MA, Loots CM, et al. Indications, methodology, and interpretation of combined esophageal impedance-pH monitoring in children: ESPGHAN EURO-PIG standard protocol. J Pediatr Gastroenterol Nutr. 2012; 55(2):230-4. [PubMed: 22711055]

131. Loots CM, van Wijk MP, Blondeau $\mathrm{K}$, et al. Interobserver and intraobserver variability in pHimpedance analysis between 10 experts and automated analysis. J Pediatr. 2012; 160(3):44146.e1. [PubMed: 21924738]

132. Pilic D, Höfs C, Weitmann S. Inter- and intraobserver agreement in 24-hour combined multiple intraluminal impedance and $\mathrm{pH}$ measurement in children - a quality assessment from the German Pediatric Impedance Group (G-PIG). J Pediatr Gastroenterol Nutr. 2011; 53:255-9. [PubMed: 21865970]

133. Ravi K, DeVault KR, Murray JA, et al. Inter-observer agreement for multichannel intraluminal impedance-pH testing. Dis Esophagus. 2010; 23(7):540-4. [PubMed: 20459441]

134. Rosen R, Levine P, Lewis J, et al. Reflux events detected by pH-MII do not determine fundoplication outcome. J Pediatr Gastroenterol Nutr. 2010; 50(3):251-5. [PubMed: 20118804]

135. Duncan DR, Amirault J, Johnston N, et al. Gastroesophageal Reflux Burden, Even in Children That Aspirate, Does Not Increase Pediatric Hospitalization. J Pediatr Gastroenterol Nutr. 2015

136. Giacchino M, Savarino V, Savarino E. Distinction between patients with non-erosive reflux disease and functional heartburn. Ann Gastroenterol. 2013; 26(4):283-89. [PubMed: 24714313]

137. Mahoney LB, Rosen R. The Prevalence of Rome IV Non-Erosive Esophageal Phenotypes in Children. Gastroenterology. 2017; 152(5):S708.

138. Savarino E, Zentilin P, Tutuian R, et al. The role of nonacid reflux in NERD: lessons learned from impedance-pH monitoring in 150 patients off therapy. Am J Gastroenterol. 2008; 103(11):268593. [PubMed: 18775017]

139. Viazis N, Keyoglou A, Kanellopoulos AK, et al. Selective serotonin reuptake inhibitors for the treatment of hypersensitive esophagus: a randomized, double-blind, placebo-controlled study. Am J Gastroenterol. 2012; 107(11):1662-7. [PubMed: 21625270] 
140. Limsrivilai J, Charatcharoenwitthaya P, Pausawasdi N, et al. Imipramine for Treatment of Esophageal Hypersensitivity and Functional Heartburn: A Randomized Placebo-Controlled Trial. Am J Gastroenterol. 2016; 111(2):217-24. [PubMed: 26753892]

141. Lopez-Alonso M, Moya MJ, Cabo JA, et al. Twenty-four-hour esophageal impedance-pH monitoring in healthy preterm neonates: rate and characteristics of acid, weakly acidic, and weakly alkaline gastroesophageal reflux. Pediatrics. 2006; 118(2):e299-308. [PubMed: 16831894]

142. Corvaglia L, Rotatori R, Ferlini M, et al. The effect of body positioning on gastroesophageal reflux in premature infants: evaluation by combined impedance and $\mathrm{pH}$ monitoring. J Pediatr. 2007; 151(6):591-6. 96.e1. [PubMed: 18035136]

143. Jadcherla SR, Chan CY, Moore R, et al. Impact of feeding strategies on the frequency and clearance of acid and nonacid gastroesophageal reflux events in dysphagic neonates. JPEN J Parenter Enteral Nutr. 2012; 36(4):449-55. [PubMed: 22038208]

144. Ghezzi M, Silvestri M, Guida E, et al. Acid and weakly acid gastroesophageal refluxes and type of respiratory symptoms in children. Respir Med. 2011; 105(7):972-8. [PubMed: 21334184]

145. Mattioli G, Pini-Prato A, Gentilino V, et al. Esophageal impedance/pH monitoring in pediatric patients: preliminary experience with 50 cases. Dig Dis Sci. 2006; 51(12):2341-7. [PubMed: 17120147]

146. Condino AA, Sondheimer J, Pan Z, et al. Evaluation of gastroesophageal reflux in pediatric patients with asthma using impedance-pH monitoring. J Pediatr. 2006; 149(2):216-9. [PubMed: 16887437]

147. Mousa H, Woodley FW, Metheney M, et al. Testing the association between gastroesophageal reflux and apnea in infants. Journal of Pediatric Gastroenterology and Nutrition. 2005; 41(2): 169-77. [PubMed: 16056095]

148. Salvatore S, Hauser B, Devreker T, et al. Esophageal impedance and esophagitis in children: any correlation? J Pediatr Gastroenterol Nutr. 2009; 49(5):566-70. [PubMed: 19820412]

149. Hojsak I, Ivkovic L, Trbojevic T, et al. The role of combined 24-h multichannel intraluminal impedance-pH monitoring in the evaluation of children with gastrointestinal symptoms suggesting gastro-esophageal reflux disease. Neurogastroenterol Motil. 2016; 28(10):1488-93. [PubMed: 27137138]

150. Hemmink GJ, Bredenoord AJ, Weusten BL, et al. Esophageal pH-impedance monitoring in patients with therapy-resistant reflux symptoms: 'on' or 'off' proton pump inhibitor? Am J Gastroenterol. 2008; 103(10):2446-53. [PubMed: 18684197]

151. Zerbib F, des Varannes SB, Roman S, et al. Normal values and day-to-day variability of 24-h ambulatory oesophageal impedance-pH monitoring in a Belgian-French cohort of healthy subjects. Aliment Pharmacol Ther. 2005; 22(10):1011-21. [PubMed: 16268977]

152. Breumelhof $\mathrm{R}$, Smout AJ. The symptom sensitivity index: a valuable additional parameter in 24hour esophageal pH recording. Am J Gastroenterol. 1991; 86(2):160-4. [PubMed: 1992627]

153. Weusten BL, Roelofs JM, Akkermans LM, et al. The symptom-association probability: an improved method for symptom analysis of 24-hour esophageal $\mathrm{pH}$ data. Gastroenterology. 1994; 107(6):1741-5. [PubMed: 7958686]

154. Wiener GJ, Richter JE, Copper JB, et al. The symptom index: a clinically important parameter of ambulatory 24-hour esophageal pH monitoring. Am J Gastroenterol. 1988; 83(4):358-61. [PubMed: 3348191]

155. Neu M, Pan Z, Workman R, et al. Benefits of massage therapy for infants with symptoms of gastroesophageal reflux disease. Biol Res Nurs. 2014; 16(4):387-97. [PubMed: 24379449]

156. Loots C, Kritas S, van Wijk M, et al. Body positioning and medical therapy for infantile gastroesophageal reflux symptoms. J Pediatr Gastroenterol Nutr. 2014; 59(2):237-43. [PubMed: 24732026]

157. Vandenplas Y, Hachimi-Idrissi S, Casteels A, et al. A clinical trial with an "anti-regurgitation" formula. Eur J Pediatr. 1994; 153(6):419-23. [PubMed: 8088297]

158. Iacono G, Vetrano S, Cataldo F, et al. Clinical trial with thickened feeding for treatment of regurgitation in infants. Dig Liver Dis. 2002; 34(7):532-3. 
159. Chao HC, Vandenplas Y. Comparison of the effect of a cornstarch thickened formula and strengthened regular formula on regurgitation, gastric emptying and weight gain in infantile regurgitation. Dis Esophagus. 2007; 20(2):155-60. [PubMed: 17439600]

160. Xinias I, Mouane N, Le Luyer B, et al. Cornstarch thickened formula reduces oesophageal acid exposure time in infants. Dig Liver Dis. 2005; 37(1):23-7. [PubMed: 15702855]

161. Ostrom KM, Jacobs JR, Merritt RJ, et al. Decreased regurgitation with a soy formula containing added soy fiber. Clin Pediatr (Phila). 2006; 45(1):29-36. [PubMed: 16429213]

162. Chao HC, Vandenplas Y. Effect of cereal-thickened formula and upright positioning on regurgitation, gastric emptying, and weight gain in infants with regurgitation. Nutrition. 2007; 23(1):23-8. [PubMed: 17189087]

163. Miyazawa R, Tomomasa T, Kaneko H, et al. Effect of formula thickened with locust bean gum on gastric emptying in infants. J Paediatr Child Health. 2006; 42(12):808-12. [PubMed: 17096718]

164. Miyazawa R, Tomomasa T, Kaneko H, et al. Effect of formula thickened with reduced concentration of locust bean gum on gastroesophageal reflux. Acta Paediatr. 2007; 96(6):910-4. [PubMed: 17537023]

165. Miyazawa R, Tomomasa T, Kaneko H, et al. Effect of locust bean gum in anti-regurgitant milk on the regurgitation in uncomplicated gastroesophageal reflux. J Pediatr Gastroenterol Nutr. 2004; 38(5):479-83. [PubMed: 15097434]

166. Moukarzel AA, Abdelnour H, Akatcherian C. Effects of a prethickened formula on esophageal $\mathrm{pH}$ and gastric emptying of infants with GER. J Clin Gastroenterol. 2007; 41(9):823-9. [PubMed: 17881928]

167. Vanderhoof JA, Moran JR, Harris CL, et al. Efficacy of a pre-thickened infant formula: a multicenter, double-blind, randomized, placebo-controlled parallel group trial in 104 infants with symptomatic gastroesophageal reflux. Clin Pediatr (Phila). 2003; 42(6):483-95. [PubMed: 12921449]

168. Hegar B, Rantos R, Firmansyah A, et al. Natural evolution of infantile regurgitation versus the efficacy of thickened formula. J Pediatr Gastroenterol Nutr. 2008; 47(1):26-30. [PubMed: 18607265]

169. Orenstein SR, Magill HL, Brooks P. Thickening of infant feedings for therapy of gastroesophageal reflux. J Pediatr. 1987; 110(2):181-6. [PubMed: 3806287]

170. Ummarino D, Miele E, Martinelli M, et al. Effect of magnesium alginate plus simethicone on gastroesophageal reflux in infants. J Pediatr Gastroenterol Nutr. 2015; 60(2):230-5. [PubMed: 25079477]

171. Horvath A, Dziechciarz P, Szajewska H. The effect of thickened-feed interventions on gastroesophageal reflux in infants: systematic review and meta-analysis of randomized, controlled trials. Pediatrics. 2008; 122(6):e1268-77. [PubMed: 19001038]

172. Wenzl TG, Schneider S, Scheele F, et al. Effects of thickened feeding on gastroesophageal reflux in infants: a placebo-controlled crossover study using intraluminal impedance. Pediatrics. 2003; 111(4 Pt 1):e355-9. [PubMed: 12671151]

173. Corvaglia L, Ferlini M, Rotatori R, et al. Starch thickening of human milk is ineffective in reducing the gastroesophageal reflux in preterm infants: a crossover study using intraluminal impedance. J Pediatr. 2006; 148(2):265-8. [PubMed: 16492440]

174. Beal J, Silverman B, Bellant J, et al. Late onset necrotizing enterocolitis in infants following use of a xanthan gum-containing thickening agent. J Pediatr. 2012; 161(2):354-6. [PubMed: 22575248]

175. Woods CW, Oliver T, Lewis K, et al. Development of necrotizing enterocolitis in premature infants receiving thickened feeds using SimplyThick(R). J Perinatol. 2012; 32(2):150-2. [PubMed: 22289705]

176. Vandenplas Y, Benninga M, Broekaert I, et al. Functional gastro-intestinal disorder algorithms focus on early recognition, parental reassurance and nutritional strategies. Acta Paediatr. 2016; 105(3):244-52. [PubMed: 26584953]

177. Winter H, Kum-Nji P, Mahomedy SH, et al. Efficacy and safety of pantoprazole delayed-release granules for oral suspension in a placebo-controlled treatment-withdrawal study in infants 1-11 
months old with symptomatic GERD. J Pediatr Gastroenterol Nutr. 2010; 50(6):609-18. [PubMed: 20400912]

178. Koletzko S, Niggemann B, Arato A, et al. Diagnostic approach and management of cow's-milk protein allergy in infants and children: ESPGHAN GI Committee practical guidelines. J Pediatr Gastroenterol Nutr. 2012; 55(2):221-9. [PubMed: 22569527]

179. Borrelli O, Mancini V, Thapar N, et al. Cow's milk challenge increases weakly acidic reflux in children with cow's milk allergy and gastroesophageal reflux disease. J Pediatr. 2012; 161(3): 476-81.e1. [PubMed: 22513270]

180. Corvaglia L, Mariani E, Aceti A, et al. Extensively hydrolyzed protein formula reduces acid gastro-esophageal reflux in symptomatic preterm infants. Early Hum Dev. 2013; 89(7):453-5. [PubMed: 23642476]

181. Agostoni C, Axelsson I, Goulet O, et al. Soy protein infant formulae and follow-on formulae: a commentary by the ESPGHAN Committee on Nutrition. J Pediatr Gastroenterol Nutr. 2006; 42(4):352-61. [PubMed: 16641572]

182. Bhatia J, Greer F. Use of soy protein-based formulas in infant feeding. Pediatrics. 2008; 121(5): 1062-8. [PubMed: 18450914]

183. Katz Y, Gutierrez-Castrellon P, Gonzalez MG, et al. A comprehensive review of sensitization and allergy to soy-based products. Clin Rev Allergy Immunol. 2014; 46(3):272-81. [PubMed: 24425446]

184. Alsalamah M, Makhajia M, Somers G, et al. Anaphylaxis to Milk After Elimination Diet for Eosinophilic Gastrointestinal Disease. Am J Gastroenterol. 2016; 111(5):752-3. [PubMed: 27151130]

185. Maslin K, Grundy J, Glasbey G, et al. Cows' milk exclusion diet during infancy: Is there a longterm effect on children's eating behaviour and food preferences? Pediatr Allergy Immunol. 2016; 27(2):141-6. [PubMed: 26592369]

186. Omari TI, Rommel N, Staunton E, et al. Paradoxical impact of body positioning on gastroesophageal reflux and gastric emptying in the premature neonate. J Pediatr. 2004; 145(2): 194-200. [PubMed: 15289766]

187. van Wijk MP, Benninga MA, Dent J, et al. Effect of body position changes on postprandial gastroesophageal reflux and gastric emptying in the healthy premature neonate. J Pediatr. 2007; 151(6):585-90. 90.e1-2. [PubMed: 18035135]

188. Vandenplas Y, De Schepper J, Verheyden S, et al. A preliminary report on the efficacy of the Multicare AR-Bed in 3-week-3-month-old infants on regurgitation, associated symptoms and acid reflux. Arch Dis Child. 2010; 95(1):26-30. [PubMed: 19700421]

189. Moon RY. SIDS and other sleep-related infant deaths: expansion of recommendations for a safe infant sleeping environment. Pediatrics. 2011; 128(5):1030-9. [PubMed: 22007004]

190. Ness-Jensen E, Hveem K, El-Serag H, et al. Lifestyle Intervention in Gastroesophageal Reflux Disease. Clin Gastroenterol Hepatol. 2016; 14(2):175-82.e3. [PubMed: 25956834]

191. Loots C, Smits M, Omari T, et al. Effect of lateral positioning on gastroesophageal reflux (GER) and underlying mechanisms in GER disease (GERD) patients and healthy controls. Neurogastroenterol Motil. 2013; 25(3):222-9. e161-2. [PubMed: 23190417]

192. Indrio F, Di Mauro A, Riezzo G, et al. Prophylactic use of a probiotic in the prevention of colic, regurgitation, and functional constipation: a randomized clinical trial. JAMA Pediatr. 2014; 168(3):228-33. [PubMed: 24424513]

193. Koebnick C, Getahun D, Smith N, et al. Extreme childhood obesity is associated with increased risk for gastroesophageal reflux disease in a large population-based study. Int J Pediatr Obes. 2011; 6(2-2):e257-63. [PubMed: 20615162]

194. Pashankar DS, Corbin Z, Shah SK, et al. Increased prevalence of gastroesophageal reflux symptoms in obese children evaluated in an academic medical center. J Clin Gastroenterol. 2009; 43(5):410-3. [PubMed: 19098686]

195. Malaty HM, Fraley JK, Abudayyeh S, et al. Obesity and gastroesophageal reflux disease and gastroesophageal reflux symptoms in children. Clin Exp Gastroenterol. 2009; 2:31-6. [PubMed: 21694824] 
196. Elitsur Y, Dementieva Y, Elitsur R, et al. Obesity is not a risk factor in children with reflux esophagitis: a retrospective analysis of 738 children. Metab Syndr Relat Disord. 2009; 7(3):2114. [PubMed: 19284313]

197. Kaltenbach T, Crockett S, Gerson LB. Are lifestyle measures effective in patients with gastroesophageal reflux disease? An evidence-based approach. Arch Intern Med. 2006; 166(9): 965-71. [PubMed: 16682569]

198. Clark NM, Gong M. Management of chronic disease by practitioners and patients: are we teaching the wrong things? Bmj. 2000; 320(7234):572-5. [PubMed: 10688569]

199. Cabana MD, Slish KK, Evans D, et al. Impact of physician asthma care education on patient outcomes. Pediatrics. 2006; 117(6):2149-57. [PubMed: 16740859]

200. Miller S. Comparison of the efficacy and safety of a new aluminium-free paediatric alginate preparation and placebo in infants with recurrent gastro-oesophageal reflux. Curr Med Res Opin. 1999; 15(3):160-8. [PubMed: 10621922]

201. Oderda G, Dell'Olio D, Forni M, et al. Treatment of childhood peptic oesophagitis with famotidine or alginate-antacid. Ital J Gastroenterol. 1990; 22(6):346-9. [PubMed: 2131953]

202. Cucchiara S, Staiano A, Romaniello G, et al. Antacids and cimetidine treatment for gastrooesophageal reflux and peptic oesophagitis. Arch Dis Child. 1984; 59(9):842-7. [PubMed: 6385868]

203. Tighe M, Afzal NA, Bevan A, et al. Pharmacological treatment of children with gastrooesophageal reflux. Cochrane Database Syst Rev. 2014; (11) Cd008550.

204. Del Buono R, Wenzl TG, Ball G, et al. Effect of Gaviscon Infant on gastro-oesophageal reflux in infants assessed by combined intraluminal impedance/pH. Arch Dis Child. 2005; 90(5):460-3. [PubMed: 15851425]

205. Woodard-Knight L, Fudge A, Teubner J, et al. Aluminium absorption and antacid therapy in infancy. J Paediatr Child Health. 1992; 28(3):257-9. [PubMed: 1605980]

206. Tsou VM, Young RM, Hart MH, et al. Elevated plasma aluminum levels in normal infants receiving antacids containing aluminum. Pediatrics. 1991; 87(2):148-51. [PubMed: 1987526]

207. Orenstein SR, Hassall E, Furmaga-Jablonska W, et al. Multicenter, double-blind, randomized, placebo-controlled trial assessing the efficacy and safety of proton pump inhibitor lansoprazole in infants with symptoms of gastroesophageal reflux disease. J Pediatr. 2009; 154(4):514-20.e4. [PubMed: 19054529]

208. Davidson G, Wenzl TG, Thomson M, et al. Efficacy and safety of once-daily esomeprazole for the treatment of gastroesophageal reflux disease in neonatal patients. J Pediatr. 2013; 163(3): 692-8.e1-2. [PubMed: 23800403]

209. Winter H, Gunasekaran T, Tolia V, et al. Esomeprazole for the treatment of GERD in infants ages 1-11 months. J Pediatr Gastroenterol Nutr. 2012; 55(1):14-20. [PubMed: 22241513]

210. Hussain S, Kierkus J, Hu P, et al. Safety and efficacy of delayed release rabeprazole in 1- to 11month-old infants with symptomatic GERD. J Pediatr Gastroenterol Nutr. 2014; 58(2):226-36. [PubMed: 24121146]

211. Moore DJ, Tao BS, Lines DR, et al. Double-blind placebo-controlled trial of omeprazole in irritable infants with gastroesophageal reflux. J Pediatr. 2003; 143(2):219-23. [PubMed: 12970637]

212. Cohen S, Bueno de Mesquita M, Mimouni FB. Adverse effects reported in the use of gastroesophageal reflux disease treatments in children: a 10 years literature review. Br J Clin Pharmacol. 2015; 80(2):200-8. [PubMed: 25752807]

213. Cucchiara S, Gobio-Casali L, Balli F, et al. Cimetidine treatment of reflux esophagitis in children: an Italian multicentric study. J Pediatr Gastroenterol Nutr. 1989; 8(2):150-6. [PubMed: 2651632]

214. Orenstein SR, Blumer JL, Faessel HM, et al. Ranitidine, 75 mg, over-the-counter dose: pharmacokinetic and pharmacodynamic effects in children with symptoms of gastro-oesophageal reflux. Aliment Pharmacol Ther. 2002; 16(5):899-907. [PubMed: 11966498]

215. Simeone D, Caria MC, Miele E, et al. Treatment of childhood peptic esophagitis: a double-blind placebo-controlled trial of nizatidine. J Pediatr Gastroenterol Nutr. 1997; 25(1):51-5. [PubMed: 9226527] 
216. Ummarino D, Miele E, Masi P, et al. Impact of antisecretory treatment on respiratory symptoms of gastroesophageal reflux disease in children. Dis Esophagus. 2012; 25(8):671-7. [PubMed: 22236501]

217. Khoshoo V, Dhume P. Clinical response to 2 dosing regimens of lansoprazole in infants with gastroesophageal reflux. J Pediatr Gastroenterol Nutr. 2008; 46(3):352-4. [PubMed: 18376260]

218. Arguelles-Martin F, Gonzalez-Fernandez F, Gentles MG. Sucralfate versus cimetidine in the treatment of reflux esophagitis in children. Am J Med. 1989; 86(6a):73-6. [PubMed: 2735338]

219. Cremonini F, Ziogas DC, Chang HY, et al. Meta-analysis: the effects of placebo treatment on gastro-oesophageal reflux disease. Aliment Pharmacol Ther. 2010; 32(1):29-42. [PubMed: 20353496]

220. Chiba N, De Gara CJ, Wilkinson JM, et al. Speed of healing and symptom relief in grade II to IV gastroesophageal reflux disease: a meta-analysis. Gastroenterology. 1997; 112(6):1798-810. [PubMed: 9178669]

221. Labenz J, Malfertheiner P. Treatment of uncomplicated reflux disease. World J Gastroenterol. 2005; 11(28):4291-9. [PubMed: 16038023]

222. Boccia G, Manguso F, Miele E, et al. Maintenance therapy for erosive esophagitis in children after healing by omeprazole: is it advisable? Am J Gastroenterol. 2007; 102(6):1291-7. [PubMed: 17319927]

223. Sigterman KE, van Pinxteren B, Bonis PA, et al. Short-term treatment with proton pump inhibitors, H2-receptor antagonists and prokinetics for gastro-oesophageal reflux disease-like symptoms and endoscopy negative reflux disease. Cochrane Database Syst Rev. 2013; 5 Cd002095.

224. Faure C, Michaud L, Shaghaghi EK, et al. Lansoprazole in children: pharmacokinetics and efficacy in reflux oesophagitis. Aliment Pharmacol Ther. 2001; 15(9):1397-402. [PubMed: 11552911]

225. Tolia V, Gilger MA, Barker PN, et al. Healing of erosive esophagitis and improvement of symptoms of gastroesophageal reflux disease after esomeprazole treatment in children 12 to 36 months old. J Pediatr Gastroenterol Nutr. 2010; 51(5):593-8. [PubMed: 20706150]

226. Rosen R, Amirault J, Liu H, et al. Changes in gastric and lung microflora with acid suppression: acid suppression and bacterial growth. JAMA Pediatr. 2014; 168(10):932-7. [PubMed: 25133779]

227. Trikha A, Baillargeon JG, Kuo YF, et al. Development of food allergies in patients with gastroesophageal reflux disease treated with gastric acid suppressive medications. Pediatr Allergy Immunol. 2013; 24(6):582-8. [PubMed: 23905907]

228. Omari TI, Benninga MA, Sansom L, et al. Effect of baclofen on esophagogastric motility and gastroesophageal reflux in children with gastroesophageal reflux disease: a randomized controlled trial. J Pediatr. 2006; 149(4):468-74. [PubMed: 17011315]

229. Li S, Shi S, Chen F, et al. The effects of baclofen for the treatment of gastroesophageal reflux disease: a meta-analysis of randomized controlled trials. Gastroenterol Res Pract. 2014; 2014:307805. [PubMed: 25389436]

230. De Loore I, Van Ravensteyn H, Ameryckx L. Domperidone drops in the symptomatic treatment of chronic paediatric vomiting and regurgitation. A comparison with metoclopramide. Postgrad Med J. 1979; 55(Suppl 1):40-2.

231. Carroccio A, Iacono G, Montalto G, et al. Domperidone plus magnesium hydroxide and aluminum hydroxide: a valid therapy in children with gastroesophageal reflux. A double-blind randomized study versus placebo. Scand J Gastroenterol. 1994; 29(4):300-4. [PubMed: 8047802]

232. Tolia V, Calhoun J, Kuhns L, et al. Randomized, prospective double-blind trial of metoclopramide and placebo for gastroesophageal reflux in infants. J Pediatr. 1989; 115(1):141-5. [PubMed: 2661788]

233. Bellissant E, Duhamel JF, Guillot M, et al. The triangular test to assess the efficacy of metoclopramide in gastroesophageal reflux. Clin Pharmacol Ther. 1997; 61(3):377-84. [PubMed: 9084462] 
234. Lau Moon Lin M, Robinson PD, Flank J, et al. The Safety of Metoclopramide in Children: A Systematic Review and Meta-Analysis. Drug Saf. 2016; 39(7):675-87. [PubMed: 27003816]

235. Morris AD, Chen J, Lau E, et al. Domperidone-Associated QT Interval Prolongation in Nononcologic Pediatric Patients: A Review of the Literature. Can J Hosp Pharm. 2016; 69(3):224-30. [PubMed: 27403002]

236. Gunlemez A, Babaoglu A, Arisoy AE, et al. Effect of domperidone on the QTc interval in premature infants. J Perinatol. 2010; 30(1):50-3. [PubMed: 19626027]

237. Vieira MC, Miyague NI, Van Steen K, et al. Effects of domperidone on QTc interval in infants. Acta Paediatr. 2012; 101(5):494-6. [PubMed: 22226330]

238. Rocha CM, Barbosa MM. QT interval prolongation associated with the oral use of domperidone in an infant. Pediatr Cardiol. 2005; 26(5):720-3. [PubMed: 15690231]

239. Ngoenmak T, Treepongkaruna S, Buddharaksa Y, et al. Effects of Domperidone on QT Interval in Children with Gastroesophageal Reflux Disease. Pediatr Neonatol. 2016; 57(1):60-4. [PubMed: 26141480]

240. Cohen RC, O'Loughlin EV, Davidson GP, et al. Cisapride in the control of symptoms in infants with gastroesophageal reflux: A randomized, double-blind, placebo-controlled trial. J Pediatr. 1999; 134(3):287-92. [PubMed: 10064663]

241. Vandenplas Y, de Roy C, Sacre L. Cisapride decreases prolonged episodes of reflux in infants. J Pediatr Gastroenterol Nutr. 1991; 12(1):44-7. [PubMed: 2061776]

242. Van Eygen M, Van Ravensteyn H. Effect of cisapride on excessive regurgitation in infants. Clin Ther. 1989; 11(5):669-77. [PubMed: 2805024]

243. Levy J, Hayes C, Kern J, et al. Does cisapride influence cardiac rhythm? Results of a United States multicenter, double-blind, placebo-controlled pediatric study. J Pediatr Gastroenterol Nutr. 2001; 32(4):458-63. [PubMed: 11396814]

244. Scott RB, Ferreira C, Smith L, et al. Cisapride in pediatric gastroesophageal reflux. J Pediatr Gastroenterol Nutr. 1997; 25(5):499-506. [PubMed: 9360203]

245. HBFG; EC, L; SC, C; CS. Efficacy of cisapride in the treatment of gastroesophageal reflux (GER) in children. An Esp Pediatr. 1994; 40(1):5-8.

246. Ng SC, Gomez JM, Rajadurai VS, et al. Establishing enteral feeding in preterm infants with feeding intolerance: a randomized controlled study of low-dose erythromycin. J Pediatr Gastroenterol Nutr. 2003; 37(5):554-8. [PubMed: 14581796]

247. Aly H, Abdel-Hady H, Khashaba M, et al. Erythromycin and feeding intolerance in premature infants: a randomized trial. J Perinatol. 2007; 27(1):39-43. [PubMed: 17036029]

248. Ng PC, Lee CH, Wong SP, et al. High-dose oral erythromycin decreased the incidence of parenteral nutrition-associated cholestasis in preterm infants. Gastroenterology. 2007; 132(5): 1726-39. [PubMed: 17484870]

249. Nuntnarumit P, Kiatchoosakun P, Tantiprapa W, et al. Efficacy of oral erythromycin for treatment of feeding intolerance in preterm infants. J Pediatr. 2006; 148(5):600-5. [PubMed: 16737869]

250. Levi P, Marmo F, Saluzzo C, et al. Bethanechol versus antiacids in the treatment of gastroesophageal reflux. Helv Paediatr Acta. 1985; 40(5):349-59. [PubMed: 2867985]

251. Euler AR. Use of bethanechol for the treatment of gastroesophageal reflux. J Pediatr. 1980; 96(2): 321-4. [PubMed: 7351606]

252. Rohof WO, Bennink RJ, de Ruigh AA, et al. Effect of azithromycin on acid reflux, hiatus hernia and proximal acid pocket in the postprandial period. Gut. 2012; 61(12):1670-7. [PubMed: 22267599]

253. McHoney M, Wade AM, Eaton S, et al. Clinical outcome of a randomized controlled blinded trial of open versus laparoscopic Nissen fundoplication in infants and children. Ann Surg. 2011; 254(2):209-16. [PubMed: 21725231]

254. Knatten CK, Fyhn TJ, Edwin B, et al. Thirty-day outcome in children randomized to open and laparoscopic Nissen fundoplication. J Pediatr Surg. 2012; 47(11):1990-6. [PubMed: 23163988]

255. Diaz DM, Gibbons TE, Heiss K, et al. Antireflux surgery outcomes in pediatric gastroesophageal reflux disease. Am J Gastroenterol. 2005; 100(8):1844-52. [PubMed: 16086723] 
256. Rothenberg SS. Two decades of experience with laparoscopic nissen fundoplication in infants and children: a critical evaluation of indications, technique, and results. J Laparoendosc Adv Surg Tech A. 2013; 23(9):791-4. [PubMed: 23941587]

257. Hambraeus M, Arnbjornsson E, Anderberg M. A literature review of the outcomes after robotassisted laparoscopic and conventional laparoscopic Nissen fundoplication for gastro-esophageal reflux disease in children. Int J Med Robot. 2013; 9(4):428-32. [PubMed: 23801656]

258. Stefanidis D, Hope WW, Kohn GP, et al. Guidelines for surgical treatment of gastroesophageal reflux disease. Surg Endosc. 2010; 24(11):2647-69. [PubMed: 20725747]

259. Moore M, Afaneh C, Benhuri D, et al. Gastroesophageal reflux disease: A review of surgical decision making. World J Gastrointest Surg. 2016; 8(1):77-83. [PubMed: 26843915]

260. Maret-Ouda J, Konings P, Lagergren J, et al. Antireflux Surgery and Risk of Esophageal Adenocarcinoma: A Systematic Review and Meta-analysis. Ann Surg. 2016; 263(2):251-7. [PubMed: 26501714]

261. Kubiak R, Andrews J, Grant HW. Long-term outcome of laparoscopic nissen fundoplication compared with laparoscopic thal fundoplication in children: a prospective, randomized study. Ann Surg. 2011; 253(1):44-9. [PubMed: 21233605]

262. Smith CD, McClusky DA, Rajad MA, et al. When fundoplication fails: redo? Ann Surg. 2005; 241(6):861-9. discussion 69-71. [PubMed: 15912035]

263. Kellokumpu I, Voutilainen M, Haglund C, et al. Quality of life following laparoscopic Nissen fundoplication: assessing short-term and long-term outcomes. World J Gastroenterol. 2013; 19(24):3810-8. [PubMed: 23840119]

264. Davis CS, Baldea A, Johns JR, et al. The evolution and long-term results of laparoscopic antireflux surgery for the treatment of gastroesophageal reflux disease. Jsls. 2010; 14(3):332-41. [PubMed: 21333184]

265. Wakeman DS, Wilson NA, Warner BW. Current status of surgical management of gastroesophageal reflux in children. Curr Opin Pediatr. 2016; 28(3):356-62. [PubMed: 27138806]

266. Niebisch S, Fleming FJ, Galey KM, et al. Perioperative risk of laparoscopic fundoplication: safer than previously reported-analysis of the American College of Surgeons National Surgical Quality Improvement Program 2005 to 2009. J Am Coll Surg. 2012; 215(1):61-8. discussion 68-9. [PubMed: 22578304]

267. Mauritz FA, van Herwaarden-Lindeboom MY, Stomp W, et al. The effects and efficacy of antireflux surgery in children with gastroesophageal reflux disease: a systematic review. J Gastrointest Surg. 2011; 15(10):1872-8. [PubMed: 21800225]

268. Wockenforth R, Gillespie CS, Jaffray B. Survival of children following Nissen fundoplication. $\mathrm{Br}$ J Surg. 2011; 98(5):680-5. [PubMed: 21351077]

269. Mauritz FA, Conchillo JM, van Heurn LW, et al. Effects and efficacy of laparoscopic fundoplication in children with GERD: a prospective, multicenter study. Surg Endosc. 2016

270. Baerg J, Thorpe D, Bultron G, et al. A multicenter study of the incidence and factors associated with redo Nissen fundoplication in children. J Pediatr Surg. 2013; 48(6):1306-11. [PubMed: 23845623]

271. Srivastava R, Berry JG, Hall M, et al. Reflux related hospital admissions after fundoplication in children with neurological impairment: retrospective cohort study. Bmj. 2009; 339:b4411. [PubMed: 19923145]

272. Barnhart DC, Hall M, Mahant S, et al. Effectiveness of fundoplication at the time of gastrostomy in infants with neurological impairment. JAMA Pediatr. 2013; 167(10):911-8. [PubMed: 23921627]

273. Goldin AB, Sawin R, Seidel KD, et al. Do antireflux operations decrease the rate of reflux-related hospitalizations in children? Pediatrics. 2006; 118(6):2326-33. [PubMed: 17142515]

274. Lee SL, Sydorak RM, Chiu VY, et al. Long-term antireflux medication use following pediatric Nissen fundoplication. Arch Surg. 2008; 143(9):873-6. discussion 76. [PubMed: 18794425]

275. Gatti C, di Abriola GF, Villa M, et al. Esophagogastric dissociation versus fundoplication: Which is best for severely neurologically impaired children? J Pediatr Surg. 2001; 36(5):677-80. [PubMed: 11329564] 
276. Goyal A, Khalil B, Choo K, et al. Esophagogastric dissociation in the neurologically impaired: an alternative to fundoplication? J Pediatr Surg. 2005; 40(6):915-8. discussion 18-9. [PubMed: 15991170]

277. Morabito A, Lall A, Lo Piccolo R, et al. Total esophagogastric dissociation: 10 years' review. J Pediatr Surg. 2006; 41(5):919-22. [PubMed: 16677883]

278. Peters RT, Goh YL, Veitch JM, et al. Morbidity and mortality in total esophagogastric dissociation: a systematic review. J Pediatr Surg. 2013; 48(4):707-12. [PubMed: 23583122]

279. Lansdale N, McNiff M, Morecroft J, et al. Long-term and 'patient-reported' outcomes of total esophagogastric dissociation versus laparoscopic fundoplication for gastroesophageal reflux disease in the severely neurodisabled child. J Pediatr Surg. 2015; 50(11):1828-32. [PubMed: 26210817]

280. Gottrand M, Michaud L, Guimber D, et al. Barrett esophagus and esophagojejunal anastomotic stenosis as complications of esophagogastric disconnection in children with esophageal atresia. $\mathbf{J}$ Pediatr Gastroenterol Nutr. 2013; 57(1):93-5. [PubMed: 23535759]

281. Madre C, Serhal L, Michaud L, et al. Prolonged enteral feeding is often required to avoid longterm nutritional and metabolic complications after esophagogastric dissociation. J Pediatr Gastroenterol Nutr. 2010; 50(3):280-6. [PubMed: 19668010]

282. Srivastava R, Downey EC, O'Gorman M, et al. Impact of fundoplication versus gastrojejunal feeding tubes on mortality and in preventing aspiration pneumonia in young children with neurologic impairment who have gastroesophageal reflux disease. Pediatrics. 2009; 123(1):33845. [PubMed: 19117901]

283. Malcolm WF, Smith PB, Mears S, et al. Transpyloric tube feeding in very low birthweight infants with suspected gastroesophageal reflux: impact on apnea and bradycardia. J Perinatol. 2009; 29(5):372-5. [PubMed: 19242488]

284. Misra S, Macwan K, Albert V. Transpyloric feeding in gastroesophageal-reflux-associated apnea in premature infants. Acta Paediatr. 2007; 96(10):1426-9. [PubMed: 17850402]

285. Pereira GR, Lemons JA. Controlled study of transpyloric and intermittent gavage feeding in the small preterm infant. Pediatrics. 1981; 67(1):68-72. [PubMed: 6787557]

286. Macdonald PD, Skeoch CH, Carse H, et al. Randomised trial of continuous nasogastric, bolus nasogastric, and transpyloric feeding in infants of birth weight under $1400 \mathrm{~g}$. Arch Dis Child. 1992; 67(4 Spec No):429-31. [PubMed: 1586185]

287. Loots C, van Herwaarden MY, Benninga MA, et al. Gastroesophageal Reflux, Esophageal Function, Gastric Emptying, and the Relationship to Dysphagia before and after Antireflux Surgery in Children. J Pediatr. 2012

288. Wales PW, Diamond IR, Dutta S, et al. Fundoplication and gastrostomy versus image-guided gastrojejunal tube for enteral feeding in neurologically impaired children with gastroesophageal reflux. J Pediatr Surg. 2002; 37(3):407-12. [PubMed: 11877658]

289. Campwala I, Perrone E, Yanni G, et al. Complications of gastrojejunal feeding tubes in children. J Surg Res. 2015; 199(1):67-71. [PubMed: 26227672]

290. Auyang ED, Carter P, Rauth T, et al. SAGES clinical spotlight review: endoluminal treatments for gastroesophageal reflux disease (GERD). Surg Endosc. 2013; 27(8):2658-72. [PubMed: 23801538]

291. Islam S, Geiger JD, Coran AG, et al. Use of radiofrequency ablation of the lower esophageal sphincter to treat recurrent gastroesophageal reflux disease. J Pediatr Surg. 2004; 39(3):282-6. discussion 82-6. [PubMed: 15017538]

292. Liu DC, Somme S, Mavrelis PG, et al. Stretta as the initial antireflux procedure in children. J Pediatr Surg. 2005; 40(1):148-51. discussion 51-2. [PubMed: 15868576]

293. Wendling MR, Melvin WS, Perry KA. Impact of transoral incisionless fundoplication (TIF) on subjective and objective GERD indices: a systematic review of the published literature. Surg Endosc. 2013; 27(10):3754-61. [PubMed: 23644835]

294. Thomson M, Fritscher-Ravens A, Hall S, et al. Endoluminal gastroplication in children with significant gastro-oesophageal reflux disease. Gut. 2004; 53(12):1745-50. [PubMed: 15542508] 
295. Thomson M, Antao B, Hall S, et al. Medium-term outcome of endoluminal gastroplication with the EndoCinch device in children. J Pediatr Gastroenterol Nutr. 2008; 46(2):172-7. [PubMed: 18223376]

296. Orenstein SR, Shalaby TM, Kelsey SF, et al. Natural history of infant reflux esophagitis: symptoms and morphometric histology during one year without pharmacotherapy. Am J Gastroenterol. 2006; 101(3):628-40. [PubMed: 16542296]

297. El-Serag HB, Gilger M, Carter J, et al. Childhood GERD is a risk factor for GERD in adolescents and young adults. Am J Gastroenterol. 2004; 99(5):806-12. [PubMed: 15128341]

298. Ruigomez A, Lundborg P, Johansson S, et al. Follow-up of a cohort of children and adolescents with gastro-esophageal reflux disease who were free of reflux esophagitis at initial diagnosis. Scand J Gastroenterol. 2010; 45(7-8):814-21. [PubMed: 20384527]

299. Shepherd RW, Wren J, Evans S, et al. Gastroesophageal reflux in children. Clinical profile, course and outcome with active therapy in 126 cases. Clin Pediatr (Phila). 1987; 26(2):55-60. [PubMed: 3802692]

300. El-Serag HB, Sweet S, Winchester CC, et al. Update on the epidemiology of gastro-oesophageal reflux disease: a systematic review. Gut. 2014; 63(6):871-80. [PubMed: 23853213]

301. Rasquin A, Di Lorenzo C, Forbes D, et al. Childhood functional gastrointestinal disorders: child/ adolescent. Gastroenterology. 2006; 130(5):1527-37. [PubMed: 16678566]

302. Hyman PE, Milla PJ, Benninga MA, et al. Childhood functional gastrointestinal disorders: neonate/toddler. Gastroenterology. 2006; 130(5):1519-26. [PubMed: 16678565] 

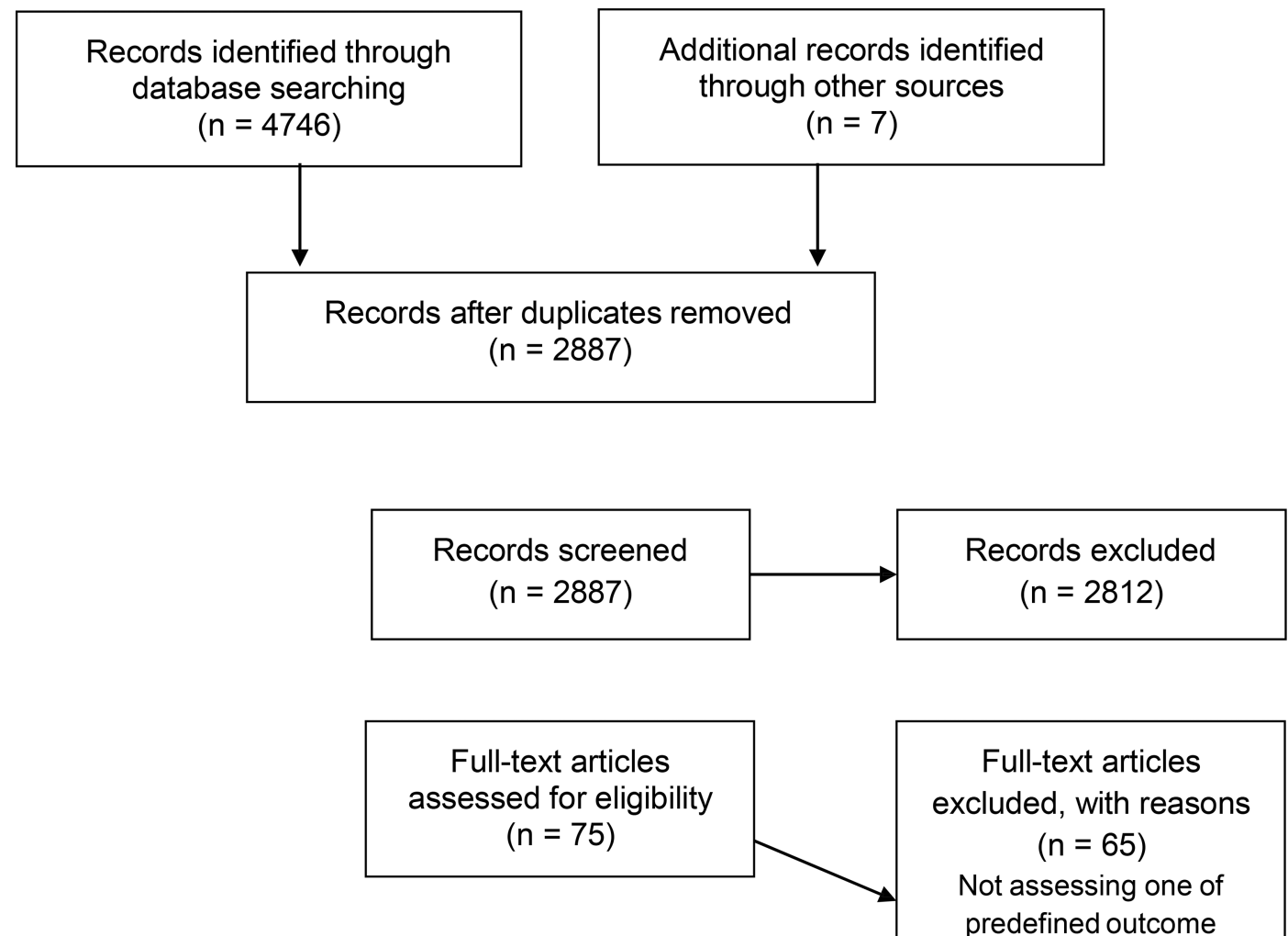

Full-text articles excluded, with reasons $(n=65)$

Not assessing one of predefined outcome

Studies included in measures qualitative synthesis $(n=10)$

\section{Original studies, $\boldsymbol{n}=\mathbf{9}$ \\ - $p H$-metry $(n=8)$ \\ - Endoscopy $(n=3)$ \\ - Biomarkers $(n=1)$ \\ - Gl-scintiscan (n=2) \\ - Upper Gl series $(n=1)$}

\section{Systematic reviews, $n=1$}

Figure 1.

Flow-chart to identify articles related to diagnostic testing 

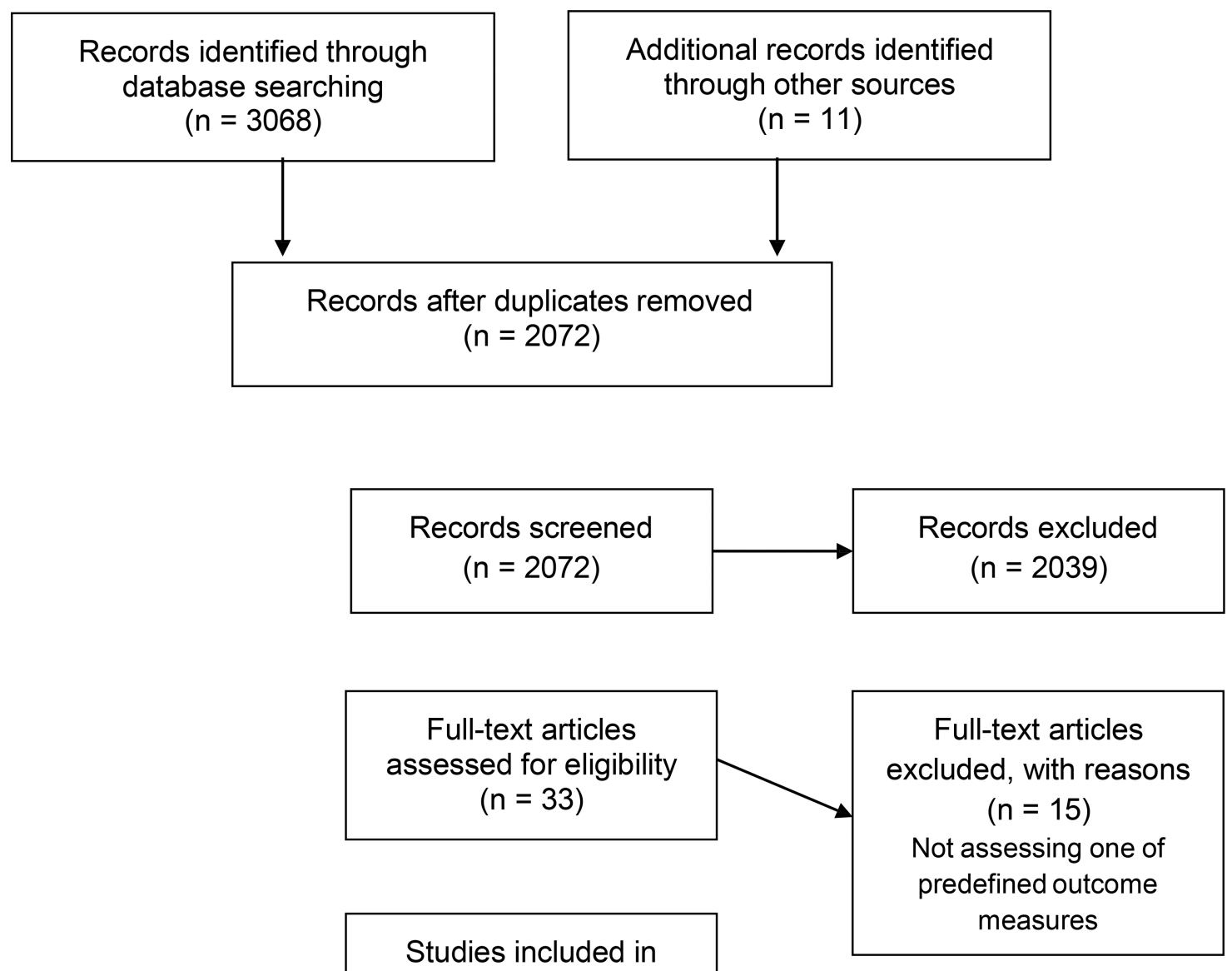

$$
\begin{gathered}
\text { qualitative synthesis } \\
\qquad(n=18)
\end{gathered}
$$

\section{Original studies, $n=16$}

- Massage therapy, $n=1$

- Feeding modifications, $n=14$

- Positioning therapy, $n=1$

\section{Systematic reviews, $n=2$}

Figure 2.

Flow-chart to identify articles related to non-pharmacologic therapies 


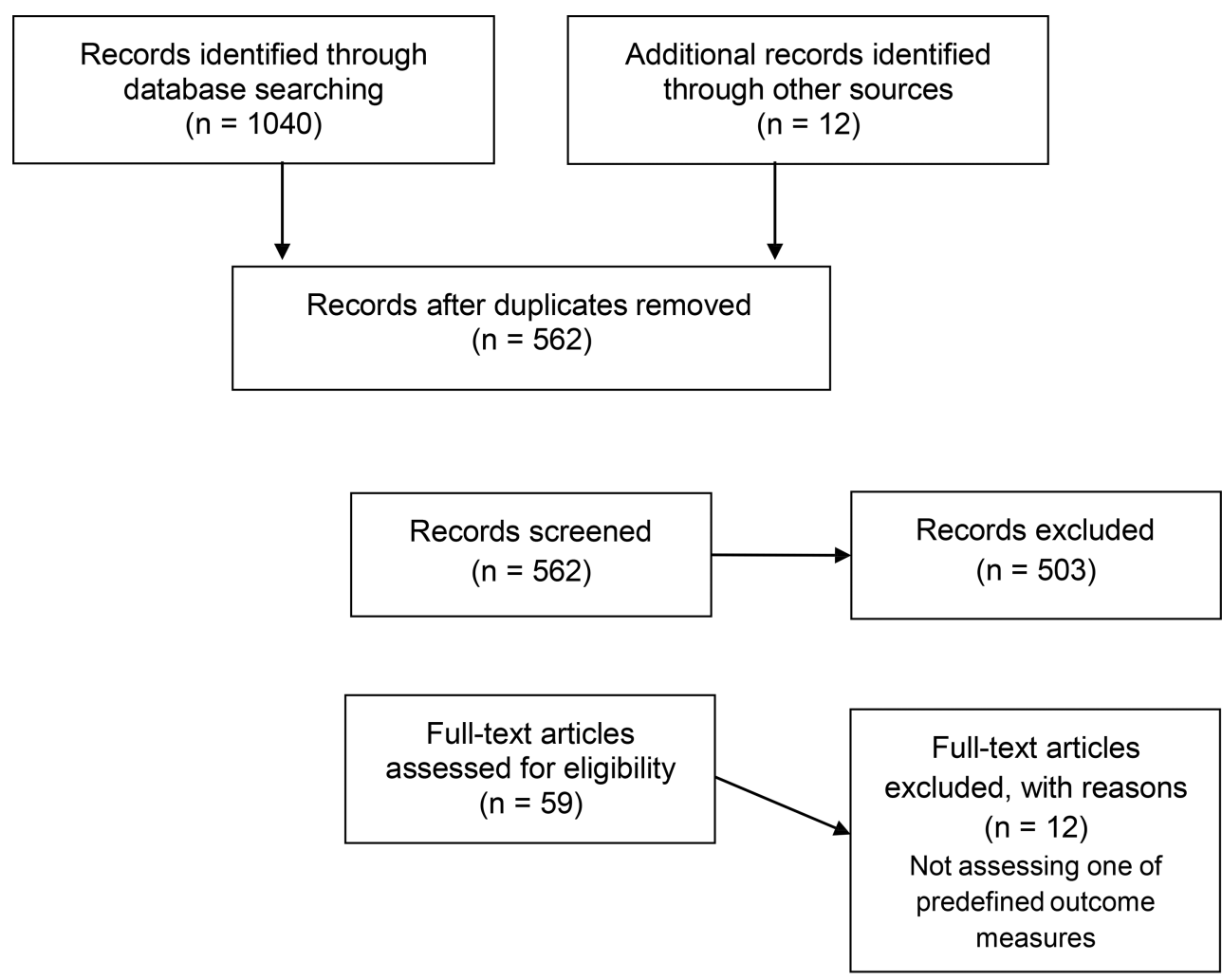

\section{Original studies, $\boldsymbol{n}=\mathbf{2 2}$}

- Alginates/antacids, $n=4$ (antacid vs $H 2 R A, n=2$ )

- H2RAs, $n=8$ ( $n=2$ H2RA vs PPI, $n=2$ H2RA vs antacid, $n=1 \mathrm{H} 2 \mathrm{RA}$ vs sucralfate)

- PPIs, $n=10$ ( $n=2$ PPI vs H2RA)

- Baclofen, $n=1$

- Domperidone, $n=2$

- Metoclopramide, $n=2$ ( $n=1$ metocplopramide vs domperidone)

Systematic Reviews, $n=25$

Figure 3.

Flow-chart to identify articles related to pharmacologic therapies 
Records identified through database searching $(n=828)$
Additional records identified through other sources

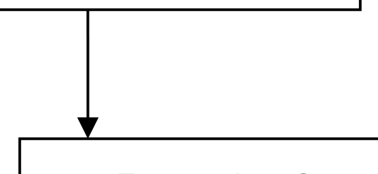

Records after duplicates removed $(n=543)$

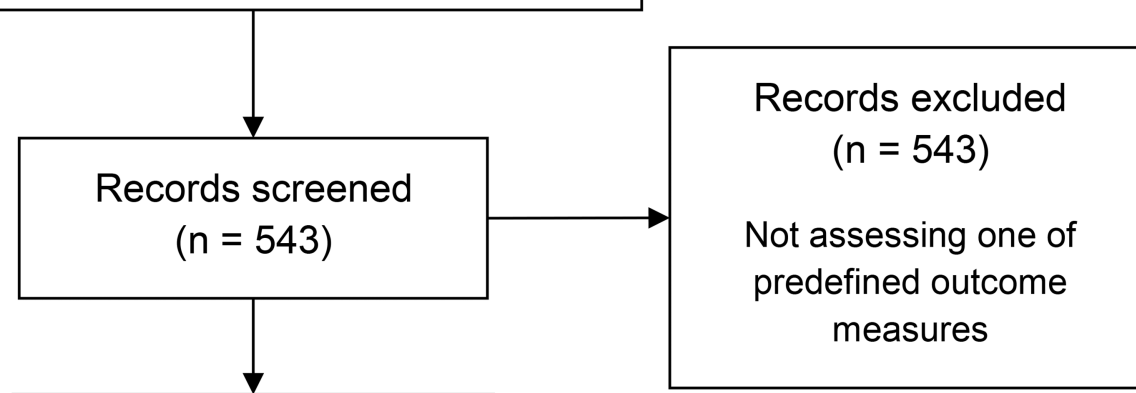

Full-text articles assessed for eligibility $(n=0)$

Studies included in qualitative synthesis $(n=0)$

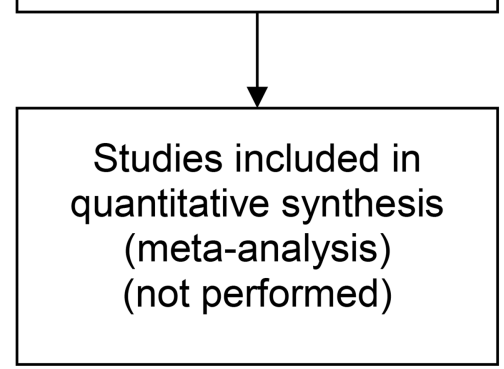

Figure 4.

Flow-chart to identify articles related to surgical therapies 
Records identified through database searching $(n=5365)$
Additional records identified through other sources

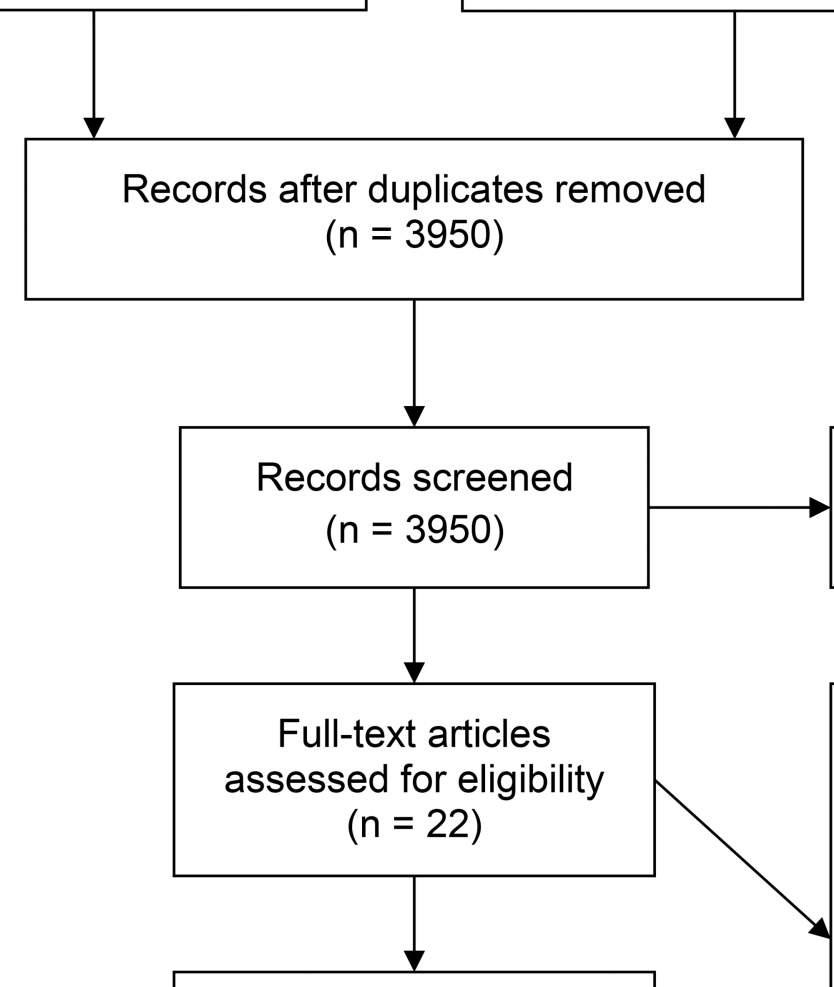

Studies included in qualitative synthesis $(n=4)$

Records excluded $(n=3928)$

Full-text articles excluded, with reasons $(n=18)$

Conference abstract $\mathrm{n}=1$

Not in children $n=3$ No GERD $n=7$ No prospective study $n=5$

Figure 5.

Flow-chart to identify articles related to GERD prognosis 
Infant with Suspicion of GERD

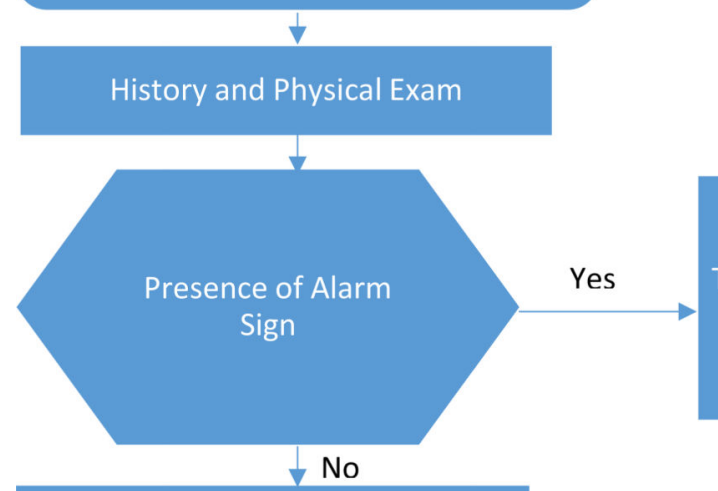

Tailor Testing to Address Alarm Signs and Refer Appropriately

Avoid Overfeeding

Thicken feeds

Continue breastfeeding

\section{Improved}

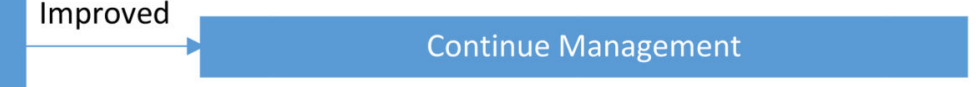

Not Improved

Consider 2-4 weeks of a protein

hydrolysate or amino acid based

formula or in breastfed infants:

elimination of cow's milk in maternal diet

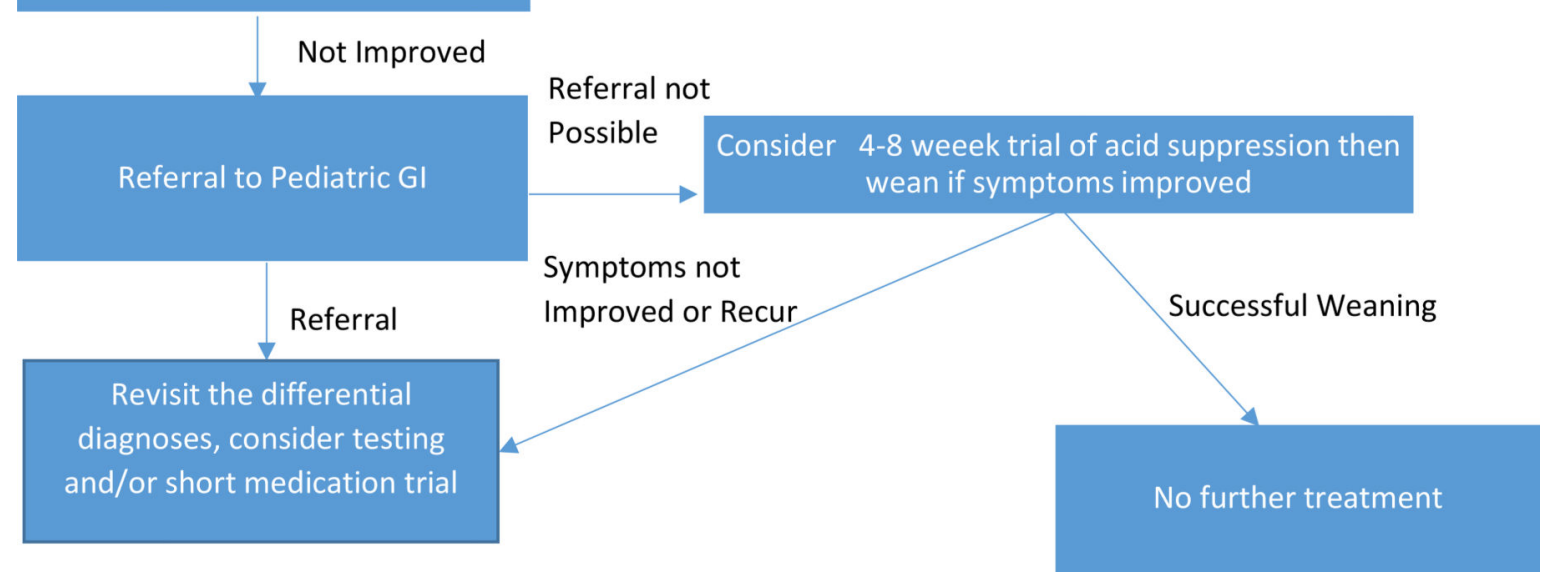

Figure 6.

J Pediatr Gastroenterol Nutr. Author manuscript; available in PMC 2019 March 01. 
Child with Typical Symptoms of GERD

7

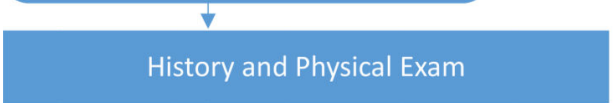

$\nabla$
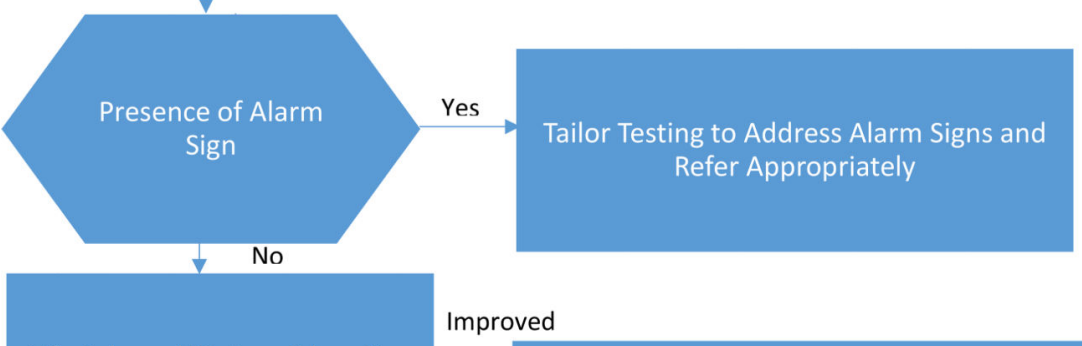

Lifestyle and Dietary Education

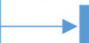

Continue Management
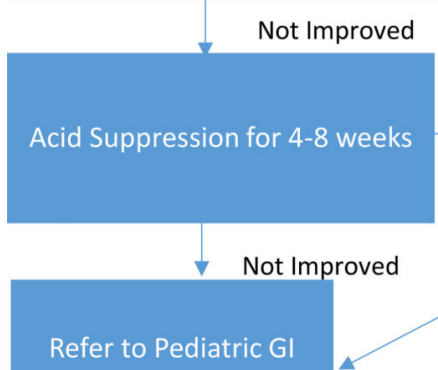

Symptoms Recur with weaning

Persistent symptoms on PPI OR inability Erosions or

to stop PPI after wean attempts Eosinophilic

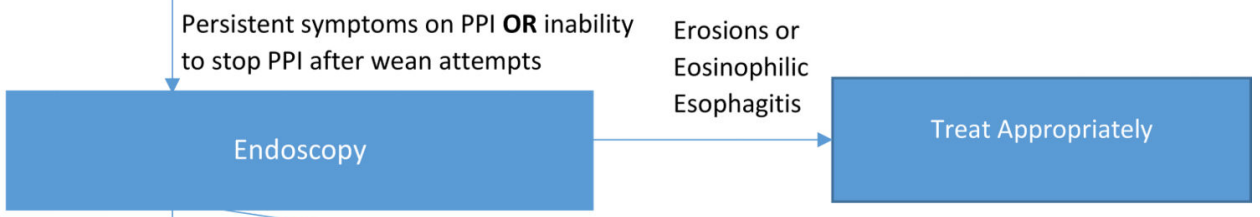

No Erosions, No Erosions, PPI-responsive symptoms

Persistent symptoms despite PPI

Continue PPI for responsive

symptoms with periodic weaning attempts

pH-MII or pH-metry 


\section{pH-MII or pH-metry}

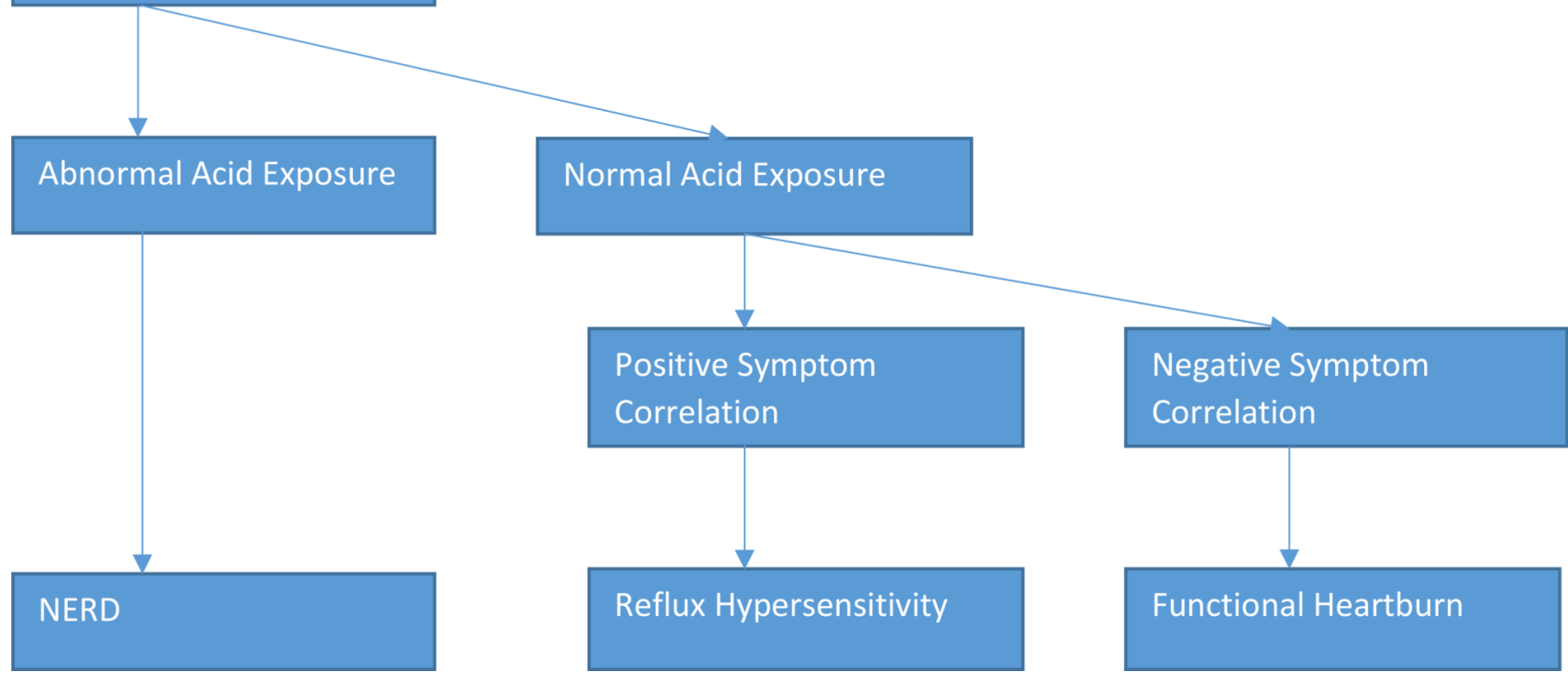

Figure 7. 


\section{Table 1}

Symptoms and signs that may be associated with gastroesophageal reflux disease (GERD) in infants and children $0-18$ years old.

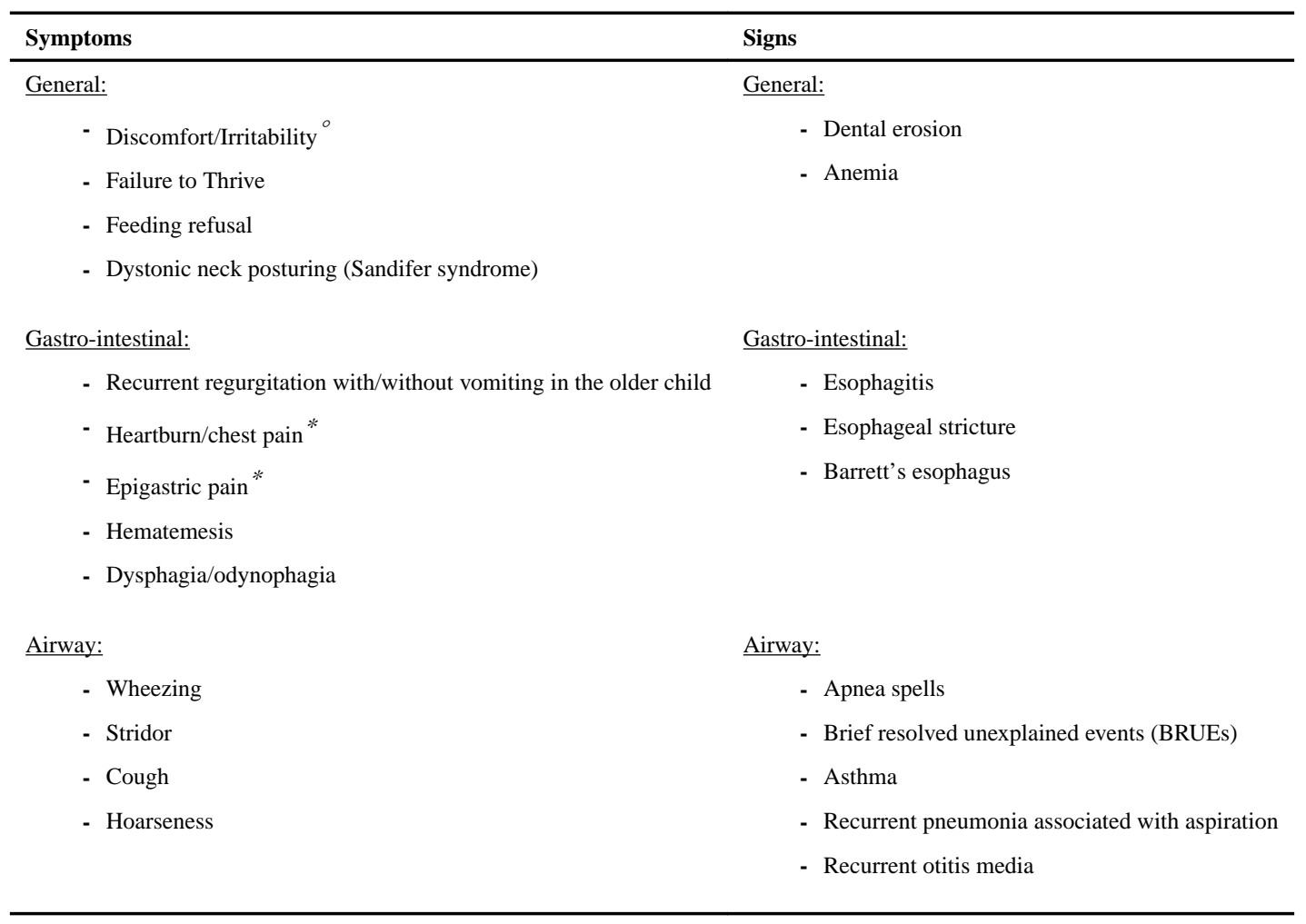

Typical symptoms of GERD in older children

: If excessive irritability and pain is the single manifestation, it is unlikely to be related to GERD 


\section{Table 2}

'Red Flag' symptoms and signs that suggest disorders other than GERD

\begin{tabular}{|c|c|}
\hline Symptoms and signs & Remarks \\
\hline \multicolumn{2}{|l|}{ General: } \\
\hline - Weight loss & \multirow[t]{4}{*}{ Suggesting a variety of conditions, including systemic infections. } \\
\hline - Lethargy & \\
\hline - Fever & \\
\hline - Excessive irritability/pain & \\
\hline - Dysuria & May suggest urinary tract infection, especially in infants and young children. \\
\hline $\begin{array}{l}\text { - Onset of regurgitation/vomiting }>6 \text { months or } \\
\text { increasing/persisting }>12-18 \text { months of age }\end{array}$ & $\begin{array}{l}\text { Late onset as well as symptoms increasing or persisting after infancy, based on } \\
\text { natural course of the disease, may indicate a diagnosis other than GERD. }\end{array}$ \\
\hline \multicolumn{2}{|l|}{ Neurological: } \\
\hline $\begin{array}{l}\text { - Bulging fontanel/rapidly increasing head } \\
\text { circumference }\end{array}$ & $\begin{array}{l}\text { May suggest raised intracranial pressure for example due to meningitis, brain tumor } \\
\text { or hydrocephalus. }\end{array}$ \\
\hline \multicolumn{2}{|l|}{ - Seizures } \\
\hline \multicolumn{2}{|l|}{ - Macro/microcephaly } \\
\hline \multicolumn{2}{|l|}{$\underline{\text { Gastro-intestinal }}$} \\
\hline - Persistent forceful vomiting & Indicative of hypertrophic pyloric stenosis (infants up to 2 months old) \\
\hline - Nocturnal vomiting & May suggest increased intracranial pressure \\
\hline - Bilious vomiting & $\begin{array}{l}\text { Regarded as symptom of intestinal obstruction. Possible causes include } \\
\text { Hirschsprung disease, intestinal atresia or mid-gut volvulus or intussusception. }\end{array}$ \\
\hline - Hematemesis & $\begin{array}{l}\text { Suggests a potentially serious bleed from the esophagus, stomach or upper gut, } \\
\text { possibly GERD-associated, occurring from acid-peptic disease }{ }^{1} \text {, Mallory-Weiss } \\
\text { tear }^{2} \text { or reflux-esophagitis. }\end{array}$ \\
\hline - Chronic diarrhea & May suggest food protein-induced gastroenteropathy ${ }^{3}$. \\
\hline - Rectal bleeding & $\begin{array}{l}\text { Indicative of multiple conditions, including bacterial gastroenteritis, inflammatory } \\
\text { bowel disease, as well as acute surgical conditions and food protein-induced }\end{array}$ \\
\hline & gastroenteropathy rectal bleeding ${ }^{3}$ (bleeding caused by proctocolitis). \\
\hline - Abdominal Distension & Indicative of obstruction, dysmotility, or anatomic abnormalities \\
\hline \multicolumn{2}{|l|}{${ }^{1}$ Especially with NSAID use } \\
\hline \multicolumn{2}{|l|}{2 Associated with vomiting } \\
\hline
\end{tabular}

J Pediatr Gastroenterol Nutr. Author manuscript; available in PMC 2019 March 01. 
Table 3

Differential diagnosis of gastroesophageal reflux disease (GERD) ${ }^{*}$

\author{
Gastrointestinal obstruction \\ - Pyloric stenosis \\ - Malrotation with volvulus \\ - Intussusception \\ - Hirschsprung disease \\ - Antral/duodenal web \\ - Foreign body \\ - Incarcerated hernia \\ - Superior mesenteric artery (SMA) syndrome
}

\section{Neurologic}

- Hydrocephalus

- Subdural hematoma

- Intracranial hemorrhage

- Intracranial mass

Metabolic/endocrine

- Galactosemia

- Hereditary fructose intolerance

- Urea cycle defects

- Amino and organic acidemias

- Fatty acid oxidation disorders

- Metabolic acidosis

- Congenital adrenal hyperplasia/adrenal crisis

Toxic

- Lead poisoning

- Other toxins
Other gastrointestinal disorders

- Achalasia

- Gastroparesis

- Gastroenteritis

- Peptic ulcer

- Eosinophilic esophagitis

- Food allergy/intolerance

- Inflammatory bowel disease

- Pancreatitis

- Appendicitis

\section{Infectious}

- Sepsis/meningitis

- Urinary tract infection

- Upper/lower airway infection

- Otitis media

- Hepatitis

Others

- Pediatric condition falsification (PCF)/factitious disorder by proxy (FDP)

- Child neglect or abuse

- Self-induced vomiting

- Cyclic vomiting syndrome

- Rumination syndrome

Renal

- Obstructive uropathy

- Renal insufficiency

Cardiac

- Heart failure

- Vascular ring

- Autonomic dysfunction

* Adapted from the ESPGHAN/NASPGHAN 2009 GERD guidelines 


\section{Table 4}

Dosages of most frequently used drugs for the treatment of gastroesophageal reflux disease

\begin{tabular}{|c|c|c|}
\hline Drugs & Recommended pediatric dosages & $\begin{array}{l}\text { Maximum dosages } \\
\text { (based upon adult } \\
\text { dosage) }\end{array}$ \\
\hline \multicolumn{3}{|c|}{ Histamine-2 Receptor Antagonists (H2RAs) } \\
\hline - Ranitidine & $5-10 \mathrm{mg} / \mathrm{kg} /$ day & $300 \mathrm{mg}$ \\
\hline - Cimetidine & $30-40 \mathrm{mg} / \mathrm{kg} / \mathrm{day}$ & $800 \mathrm{mg}$ \\
\hline - Nizatidine & $10-20 \mathrm{mg} / \mathrm{kg} / \mathrm{day}$ & $300 \mathrm{mg}$ \\
\hline - Famotidine & $1 \mathrm{mg} / \mathrm{kg} / \mathrm{day}$ & $40 \mathrm{mg}$ \\
\hline \multicolumn{3}{|l|}{ Proton Pump Inhibitors (PPIs) } \\
\hline - Omeprazole & $1-4 \mathrm{mg} / \mathrm{kg} / \mathrm{day}$ & $40 \mathrm{mg}$ \\
\hline - Lansoprazole & $2 \mathrm{mg} / \mathrm{kg} /$ day for infants & $30 \mathrm{mg}$ \\
\hline - Esomeprazole & $10 \mathrm{mg} /$ day (weight $<20 \mathrm{~kg}$ ) or $20 \mathrm{mg} /$ day (weight $>20 \mathrm{~kg}$ ) & $40 \mathrm{mg}$ \\
\hline - Pantoprazole & $1-2 \mathrm{mg} / \mathrm{kg} / \mathrm{day}$ & $40 \mathrm{mg}$ \\
\hline \multicolumn{3}{|l|}{ Prokinetics } \\
\hline - Metoclopramide & $0.4-0.9 \mathrm{mg} / \mathrm{kg} / \mathrm{day}$ & $60 \mathrm{mg}$ \\
\hline - Domperidone & $0.8-0.9 \mathrm{mg} / \mathrm{kg} / \mathrm{day}$ & $30 \mathrm{mg}$ \\
\hline - Baclofen & $0.5 \mathrm{mg} / \mathrm{kg} /$ day & $80 \mathrm{mg}$ \\
\hline \multicolumn{3}{|l|}{ Antacids } \\
\hline - Mg alginate plus simethicone & $2.5 \mathrm{ml} 3 \times /$ day $($ weight $<5 \mathrm{~kg}$ ) or $5 \mathrm{ml} 3 \times /$ day (weight $>5 \mathrm{~kg}$ ) & NA \\
\hline - Sodium alginate & $\begin{array}{l}225 \mathrm{mg} \text { sodium alginate and magnesium alginate } 87.5 \mathrm{mg} \text { ) in a total } 0.65 \mathrm{~g} \text { One } \\
\text { sachet/day (weight }<4.54 \mathrm{~kg} \text { ) or Two sachet/day (weight }>4.54 \mathrm{~kg} \text { ) }\end{array}$ & NA \\
\hline
\end{tabular}

NA; no data available 